\title{
ESCLAVITUD DE POR ACÁ, LA DE ÉBANO Y LA DE LOS OTROS, Y LA HISTORIA PARALELA. PRIMERA PARTE: AÑOS 1000 A. C. - 1824 D. C.
}

\author{
SLAVERY HERE, THE EBONY AND THE OTHER, AND THE \\ PARALLEL STORY. PART I: YEARS 1000 A. C.-1824 D. C.
}

Carlos Gamero Esparza: Universidad Inca Garcilaso de la Vega (Perú) carlos.gamero@ozu.es

\section{CURRÍCULUM VITAE}

Reconocido Periodista peruano del Diario OJO de Lima. Licenciado con Diploma de Honor en la Universidad Inca Garcilaso de la Vega.

\section{RESUMEN}

Durante tres siglos y medio, 10 ó 15 millones de negros africanos fueron trasladados forzosamente a América como esclavos. Más de 12 millones de personas son víctimas del trabajo forzoso en el mundo, según un informe de la Organización Internacional del Trabajo. El término "trata" es un eufemismo conveniente que busca eliminar la dimensión ética del concepto implícito en "la trata de esclavos". Un término mucho más apropiado es el de "comercio negrero", pues la palabra "negrero" ha conservado la carga de infamia que implica rebajar al ser humano a la categoría de mercancía. En cualquier caso, ambos términos se nos presentan en el siglo XXI como lejanos, como desprovistos de verdadero significado. $\mathrm{Y}$ ese es precisamente el objetivo de esta dimensión gráfica: aproximar a nosotros el concepto de la 
esclavitud, procurar, en lo posible a través de la fotografía, que adquiera vida la institución de la esclavitud.

\title{
PALABRAS CLAVE
}

Esclavitud - Negros africanos - Evolución - Mercancía

\begin{abstract}
For three centuries and a half, 10 to 15 million black Africans were forcibly moved to America as slaves. Over 12 million people are victims of forced labor in the world, according to a report by the International Labour Organization. The term "trafficking" is a convenient euphemism that seeks to eliminate the ethical dimension of the concept behind "the slave trade." A more appropriate term is "slave trade" since the word "slave" has kept the load of infamy that involves human beings down to the category of goods. In any case, both terms are presented to us in the XXI century as far as devoid of real meaning. And that is precisely the aim of this size chart: to bring us the concept of slavery, seek, where possible through photography, which come alive the institution of slavery.
\end{abstract}

\section{KEY WORDS}

Slavery - African Black - Evolution - Merchandise

\section{ÍNDICE}

1. Introducción

2. La historia paralela... de una tragedia humana, provocada por homo sapiens... 
2.1. Periodo Precolombino

2.2 Descubrimiento y Siglo XVI

2.3. Siglo XVII

2.4. Siglo XVIII

2.5. Siglo XIX

3. Notas al margen de la primera parte

4. Origen de las ilustraciones

\section{TEXTO:}

\section{Introducción}

"Durante tres siglos y medio, 10 ó 15 millones de negros africanos fueron trasladados forzosamente a América como esclavos (Klein 25)... ¿Cómo pudo resistir la conciencia cristiana un crimen histórico tan horrible? Lo toleró sin perder por eso el sueño. La conciencia renacentista e ilustrada era mucho menos cristiana que la conciencia medieval".

José María Iraburu (Nota_1)

"Nos oprimen en obrajes y cañaverales, cocales, minas y cárceles en nuestros pueblos... nos recogen como brutos y ensartados nos entregan a las haciendas para laborar... a veces sin nada. Los indios rinden la vida con vómitos de sangre." José Gabriel Condorcanqui. Tupac Amaru II (Nota_2)

"...a pesar de esfuerzos aislados, el porcentaje de mortalidad en la travesía era alto (se ha calculado que en algunos años pasó del 50\%) y al llegar los cargamentos 
humanos al Callao, se producía una inspección oficial y a los que no tenían contrato, se les alineaba en la cubierta para ponerlos a disposición de los interesados; en los periódicos solían aparecer, además, avisos ofreciendo chinos". Jorge Basadre (Nota_3)

"Más de 12 millones de personas son víctimas del trabajo forzoso en el mundo, según un informe de la Organización Internacional del Trabajo (OIT)".

BBC Mundo (Nota_4)

Les debemos el acervo cultural y una idiosincrasia única; por ellos resuena la magia de Perú Negro y la melancolía del yaraví; sus manifestaciones plásticas y coreográficas son el reflejo de un folclor que causa asombro en el mundo entero; a ellos les debemos el ingenio y la picardía criolla y un arte culinario sin cuento. Son gentes de acá y del otro lado del charco, son gente de tantas partes y de tantos colores. A ellos, no importa si vinieron de allá o de aquicito nomás, les debemos nuestra identidad como pueblo, un pueblo multirracial y multisecular que es el resumen de todas las risas y todas las lágrimas y todos los sueños y todas las pasiones $\mathrm{y}$ todas las esperanzas y todas las desesperanzas y todos los gritos y todas las canciones y todas las heridas y todos los cielos y todas las tierras y todos los bosques y todas las montañas del Perú profundo. Son gentes de todos los orígenes a los que se sumó la presencia europea, que también dejó su cuota. El establecimiento forzado de unos y el sometimiento del resto de los pobladores de estos reynos del Pirú, tras la Conquista, hizo que estas etnias pasaran a formar parte de un paisaje humano donde ahora no cabe ninguna objeción racista ni consideraciones exclusivistas pues aquí, en el Perú de hoy, si uno no tiene los rasgos de un tipo étnico determinado, tiene el del otro... o ambos o varios a la vez. Por eso se dice no sin razón que el Perú es el país de todas las sangres, pues en este viejo suelo conviven, juntos -y muchas veces revueltos - negros, mulatos, zambos, mestizos, blancos, 
andinos, orientales, selváticos; etc. No en vano ese gran maestro de nuestras letras, que fue don Ricardo Palma, acuñó en una de sus memorables Tradiciones Peruanas aquella frase indeleble que lo explica todo... en el Perú quien no tiene de inga, tiene de mandinga. De hecho, ésta, más que un recuento histórico, es un sacarse el sombrero por aquellos ingas y mandingas que crearon lo que somos ahora; hombres y mujeres que por causa de su origen y/o color de piel fueron arrebatados de sus pueblos para ser explotados o convertidos en mercadería humana, todo a cambio de poco o nada.

Su cruel destino, empero, no fue óbice para que nos dejaran con sus descendientes un legado inmemorial que se escucha en las canciones criollas o se saborea en un sabroso plato típico o se disfruta en el arte pictórico o en un sinfín de manifestaciones culturales; es una herencia que mezcla el aroma de sus tierras lejanas con el misterio de civilizaciones milenarias. Ahora, a los siglos, sus creencias, su filosofía de vida, su amor por la vida, su forma de encarar lo cotidiano, su irresistible creatividad, nos enseñan a ser más humanos. A ellos, pues, sin citar a uno por no omitir a otro, les sobran motivos para el orgullo: su fortaleza espiritual les hizo soportar las pruebas más duras; el negro nunca perdió la sonrisa y el andino jamás dejó de cantarle a sus apus, los señores de sus montañas sagradas. Ellos nos han enseñado una lección de vida que debemos valorar, de una vez por todas: que la humanidad es una sola, no es de ningún color, no es patrimonio de nadie, que ni siquiera la genética puede resistirse al hecho de que el colorinche de mis poros tenga algo que ver con esos ridículos prejuicios y estereotipos tejidos alrededor de unos prójimos cuyos marrones o negros no se los pintaron ellos.

Ésta es, pues, una modesta cronología, diseñada y adaptada en base a datos encontrados en diversas fuentes, que pretende mostrar su rostro humano inmenso y la dimensión histórica y trágica que alcanzó, en nuestro país, la esclavitud y la 
explotación del hombre por sus semejantes. Los angoleños del África y los mitayos andinos y los coolies chinos de Macao -tres pueblos y un destino casi común - nos cuentan ahora el drama que ellos no buscaron. Nos cuentan como llegaron a este país de desconciertos, cómo tuvieron que someterse a unos conquistadores, cómo lloraron y cómo rieron y cómo nacieron y cómo murieron y cómo lucharon... y cómo nos enseñaron a amar la libertad. Ellos están aquí, y nos hablan...

Nota: En la presente hemos considerado oportuno intercalar también algunos datos de acontecimientos paralelos relacionados con lo tratado en este trabajo, ocurridos en otras latitudes, para ubicarlas comparativamente en el tiempo y el espacio, y que, de alguna forma, influyeron en nuestro devenir histórico. De modo que ésta es la historia paralela de la esclavitud en el Perú (y el mundo) desde el siglo XV hasta el XXI, con el fin de ayudar a comprender la coyuntura en la que se desarrolló.

\section{La historia paralela... de una tragedia humana, provocada por homo sapiens...}

\subsection{Periodo Precolombino}

Hacia 1000 a. C.-600 d. C.

¿Negros y chinos precolombinos? Curiosos ceramios de Moche y Salinar, que representan rostros negroides que evocan al África y a personajes con rasgos chinos con barba y sombrero típicos de este país-, se exhiben en varios museos limeños. Este dato es sólo a título referencial, pero los ceramios están aquí. 


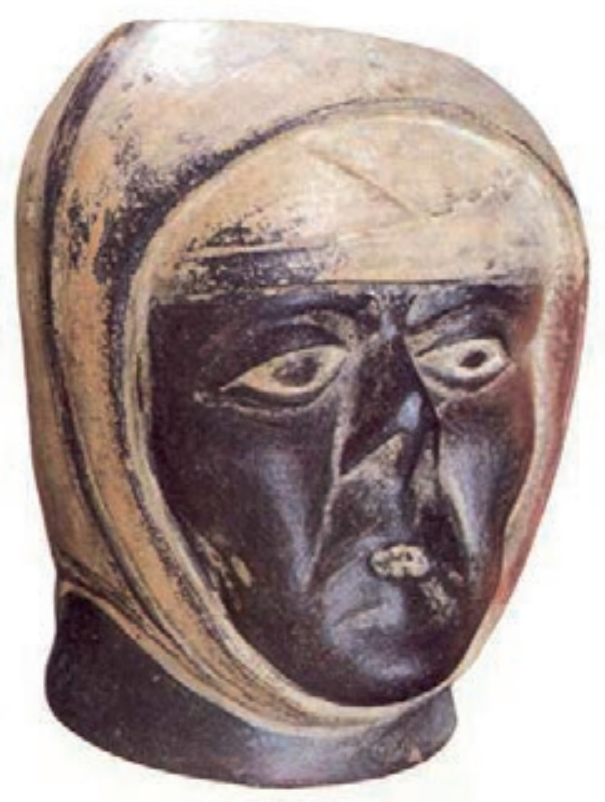

Figura 1. ¿Un negro en el museo? De todas las culturas preincaicas, la mochica retrató los más variados rasgos faciales, de allí que estos ceramios sean también conocidos como huacos- retratos. Es muy probable que este ceramio haya sido pensado para ilustrar las facciones de un hombre de color. Es muy posible que los anónimos artesanos peruanos no se lo hayan imaginado. Museo de Arqueología, Antropología e Historia del Perú. Pueblo Libre, Lima.

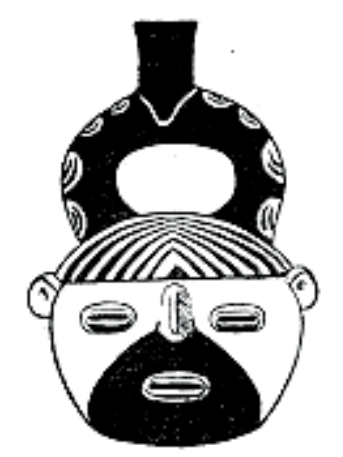

Figura 2. Ceramio mochica que representa a un ¿chino? Fue encontrado en Salinar, valle de Chicama. (aprox. 200 a 600 d. de. C.) Ilustración de Rafael Larco Hoyle.

\section{S. XV}


El investigador canario José Luís Gómez explica que la entrada de los países europeos en la trata de esclavos africanos en el siglo XV inicia una nueva etapa, cenagosa, como señala Castelar, en la devastación de África, en la creación de prejuicios raciales, en la deshumanización y conversión del ser humano en mercancía. (Nota_5)

Los capitanes de Enrique el Navegante (n. 1394 - m. 1460) parten en viaje de exploración al África.

José Luís Gómez relata que en ese año, una expedición portuguesa al mando de Lanzarote de Freitas llega a Portugal con un cargamento de 235 esclavos. Se inicia así la etapa "moderna" de la comercialización (trata) de esclavos negros en la Península Ibérica y pronto en América.

De paso, Gómez señala que tres años antes (1441), Antam Gonçalvez capturó 12 esclavos negros y los trajo a Lisboa como regalo para el príncipe Enrique el Navegante. El comercio de esclavos aumentó con rapidez como método de financiación de las expediciones. En 1441 se funda la Compañía de Lagos y luego la Compañía de Arguim; ambas compañías controlan a partir de 1448 el comercio de esclavos (Peralta). Martínez Montiel nos señala que ya en el siglo XV se embarcaban "anualmente en la costa occidental africana 3.500 esclavos." (Nota_6) 
Las naos portuguesas de Enrique el Navegante llegan a Senegal en busca de metales preciosos.

1450

Lisboa ve arribar a las naos de Enrique el Navegante, que llegan con 200 negros procedente de Arguin.

1460

Diego Gomes descubre Sierra Leona para Portugal.

Unas crónicas recogidas por cronistas españoles señalan que los primeros negros llegados al Perú fueron traídos al Tahuantinsuyu por el inca Tupac Yupanqui (n. ¿? m. 1493) de su expedición a Oceanía. Esta historia ha sido objeto de intensas indagaciones. (Nota_7) 


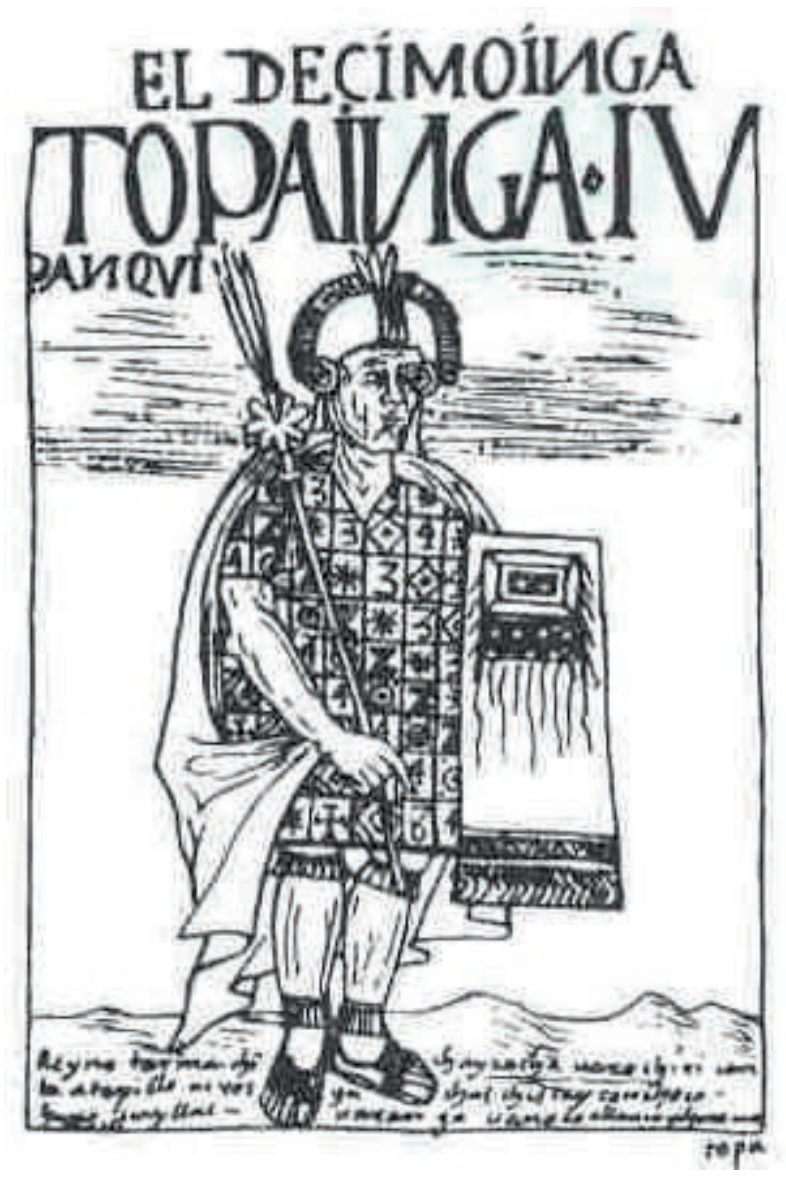

Figura 3. El inca Tupac Yupanqui según un dibujo del cronista indígena Felipe Guamán Poma de Ayala. Ilustración de su obra El Primer Nueva Corónica y Buen Gobierno (1615-16).

1462

El papa Pío II (n. 1405 - m. 1464) declara que los esclavos negros bautizados deberían ser libres (fue una de las primeras voces que abogaron por ellos).

1471-1485

Los barcos lusos siguen descubriendo tierras africanas: Costa de Oro, el delta del Níger, Fernando Poo, Gabón y el río Congo. 
1478

Nace en Trujillo, Cáceres (Extremadura) el conquistador del Perú, Francisco Pizarro. Algunos historiadores suponen que nació dos años antes.

Tratado de Alcaçovas que permite la venta de esclavos en España. Entra en funciones en centro de trata de negros de Sevilla.

\subsection{Descubrimiento y Siglo XVI}

1492

El del timón. Se dice que el primer negro que llegó "oficialmente" a América fue Pietro Alonso, piloto de la Carabela La Niña, una de las tres naves con las que Cristóbal Colón llegó a la isla de Guanahani el 12 de octubre de aquel año.

1494

7 de junio. Debido a las disputas entre España y Portugal sobre los derechos que cada uno de estos reinos se atribuía sobre las tierras y mares descubiertos, se firma el Tratado de Tordesillas, que establece una línea divisoria -que dividió el mundo en dos hemisferios - entre ambos países para sus exploraciones de ultramar, este acuerdo impone también límites que impedirán durante los primeros siglos de la Colonia el comercio directo de esclavos desde las costas de África. 
1498

Vasco de Gama (n. 1469 - m. 1524) llega a Mozambique, dobla el Cabo de Buena Esperanza y descubre Natal, luego arriba a Sofala y Malindi para de allí cruzar el Océano Índico en dirección a Calicut (Calcuta).

\section{Primera mitad del siglo XVI}

Acerca de esta época, el portal católico Corazones.org, explica el fenómeno de la esclavitud de los naturales de las Indias americanas en los siguientes términos: En los primeros años de la conquista de América, «los españoles legitimaban la esclavitud del mismo modo que lo hacían los indígenas. En el caso español se trataba de una institución practicada por todos los europeos y los musulmanes entre sí y con los africanos, y desde luego representaba un derecho de guerra reconocido universalmente y que sólo la Corona interrumpió con los indios americanos cuando dispuso prohibirla» (Esteva Fabregat, La Corona española y el indio americano 175176). (Nota_8)

1502

Se introducen los primeros esclavos negros en las islas del Caribe. Como explica José Luís Gómez, primero se autorizó en La Española (República Dominicana) y en 1530 la trata ya se había institucionalizado en todo el Caribe.

El gobierno español da permiso a Nicolás de Ovando (n. 1451 - m. 1511) para que éste comercie esclavos negros del sur de España a La Española (República Dominicana). 
1505

Aquilón introduce la caña de azúcar en América, planta que sería objeto del trabajo forzado de millones de esclavos negros e indígenas desde Florida hasta el Caribe y Sudamérica.

1510

Fernando el Católico (n. 1474 - m. 1504), siendo regente de Castilla, es el primer monarca en aprobar el envío de esclavos negros a América.

1516

Se inician los ingenios de azúcar en La Española (República Dominicana y Haití) con el empleo de la población indígena.

1517

El padre Bartolomé de las Casas pide a Carlos I sustituir a los indígenas por esclavos negros en el trabajo de las minas en La Española.

1518

Carlos I de España (n. 1500 - m. 1558) da permiso a Lorenzo de Garrevod para que introduzca 4.000 esclavos negros en América. 
$1518-1519$

Una epidemia de viruela, que diezma a la población indígena de la zona del Caribe, acelera el ingreso de esclavos negros a la región. Con el tiempo, esta circunstancia convertiría a Panamá y Cartagena en los más activos puertos de importaciónexportación de mercancía humana hacia el sur (Venezuela, Colombia, Ecuador, Perú, etc.)

1522

La Española. Los esclavos se rebelan y toman el ingenio del gobernador Diego Colón (n. 1476 - m. 1526). La sublevación y represión que continuó fue descrita por el cronista Gonzalo Fernández de Oviedo (n. 1478 - m. 1557), quien relata los ajusticiamientos masivos de esclavos rebeldes capturados. Esta crueldad con la que actuaron los dominadores españoles llamó la atención del padre Bartolomé de las Casas.

1524

Francisco Pizarro se une a Diego de Almagro (n. 1479 - m. 1538) y Hernando de Luque (n. ¿? - m. 1532) para formar la "empresa" de la Conquista del Perú. La historia los conoce como los socios de la conquista. Juntos marcharon al Perú pero cada uno tuvo suerte disímil. 
Según un estudio publicado por Towson University, Maryland, USA, la primera rebelión de esclavos en las Américas se produjo en la isla La Española, hoy República Dominicana y Haití (1522); quince años después se registró otra revuelta en Nueva España, actual México. Ambas, por cierto, fueron sofocadas a sangre y fuego. (Nota_9)

Los 14 del Gallo. Se sabe que los negros de la conquista del Perú sí existieron y eran en su mayor parte nativos de Guinea. Ellos acompañaron a los conquistadores durante todas sus campañas pero no tenían nombre y, aunque participaban en gestas militares, sus glorias y recompensas eran para sus amos. Pero lo más paradójico es que, durante el segundo viaje de Pizarro al Perú, en la Isla del Gallo (fines de septiembre de aquel año), junto a los trece soldados que cruzaron la línea trazada por Pizarro en la arena, estaba un negro, pero generalmente la historia sólo reconoce a los 13 del Gallo. (Nota_10) 

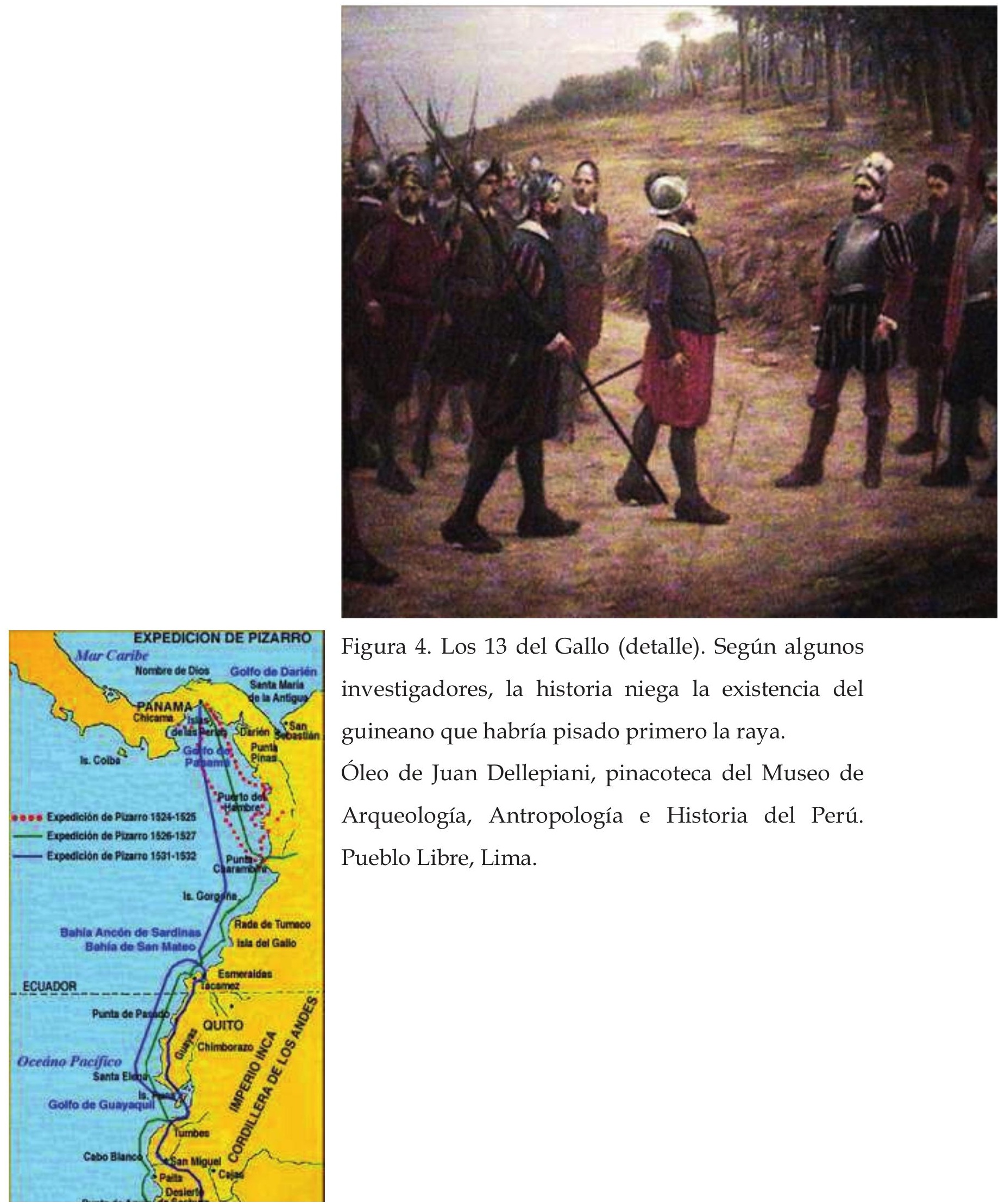

Figura 4. Los 13 del Gallo (detalle). Según algunos investigadores, la historia niega la existencia del guineano que habría pisado primero la raya.

Óleo de Juan Dellepiani, pinacoteca del Museo de Arqueología, Antropología e Historia del Perú. Pueblo Libre, Lima. 
Figura 5. Los tres viajes de Pizarro al Perú. Nótese al norte la isla del Gallo, en la ruta de su segunda expedición al sur. (1526)

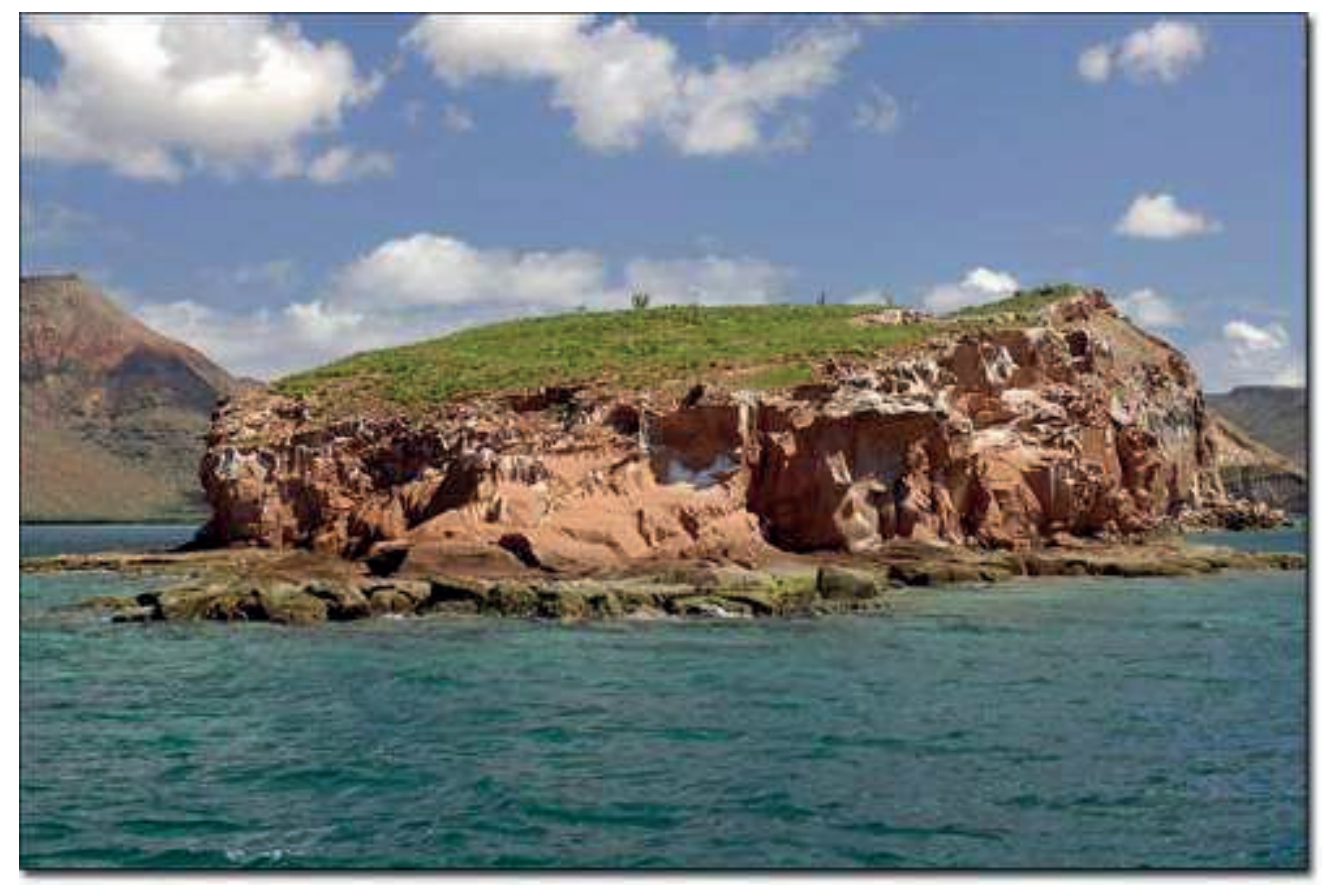

Figura 6. Isola del Gallo. Un navegante norteamericano, que suele viajar en catamarán velero por todo el mundo, fotografió esta legendaria isla situada frente a la costa pacífica de Colombia. Se trata de una tierra sin árboles donde nadie se podría imaginar que aquí se inició la Conquista del Perú. Foto de Pete Fagerlin. 
La presencia de los negros en la Conquista del Perú la demuestra infinidad de documentos de época que hablan de ellos. Por ello que no extrañe la noticia de que entre noviembre y diciembre de este año desembarcó en Tumbes el primer esclavo negro traído al Perú. Probablemente se trate del mismo de la Isla del Gallo, pues Cieza comenta que éste acompañaba a Alonso de Molina, uno de los trece del Gallo.

La Corona española otorga permiso a Enrique Eynger y Gerónimo Sayller para que puedan utilizar la misma licencia de Garrevod.

El primer documento de la Corona española que otorga la potestad de importar esclavos es La capitulación de Toledo, del 26 de julio de este año, otorgado a Francisco Pizarro para traer 50 negros de Guinea, la mitad de ellos mujeres. (Nota_11)

Rebeliones de esclavos negros en La Española (República Dominicana) y Acla, Panamá (1530), las mismas que se repiten en toda la zona del Caribe: en Venezuela (1532), en Cuba y otra vez Panamá (1533); siguieron la rebelión de Sebastián Lemba en La Española (1547), la de Juan Criollo (1550), la de los negros de Portobelo, Panamá (1579), con la cual llegan a firmar un acuerdo con los colonos españoles, que les otorga cierta libertad.

Por aquel año, en Puerto Rico viven 327 blancos y 2.292 esclavos. 
$1531-1532$

Los portugueses comienzan la colonización del actual territorio brasileño.

1531

Volviendo a la historia del negro de la Isla del Gallo, el cronista Pedro Cieza de León (n. circa 1520 - m. 1554) cuenta, en su Crónica del Perú, que durante la tercera expedición de Pizarro al Perú, aquel hombre de color descendió con ellos a tierra en Tumbes y que, con Alonso de Molina, acompañó al curaca de la región hasta su pueblo. Narra también que los naturales se atemorizaron con su presencia y lo miraban curiosos por todas partes, y querían lavarlo para ver si el color de su piel era natural o una pintura que se había puesto encima, y el negro se carcajeaba "echando sus dientes blancos de fuera", señala el cronista. Y parece que no era el único hombre de color que llego con los castellanos, como ya se dijo antes, pues el propio Cieza, al describir el penoso viaje de Diego de Almagro por las cumbres nevadas rumbo a Cajamarca, comenta que en la expedición "heláronse algunos negros y muchos indios e indias." (Nota_12)

16 de noviembre. En una acción temeraria, Francisco Pizarro y su pequeña tropa toman por sorpresa la ciudad de Cajamarca; el embate de las armas y la caballería, desconocidas para los incas, deja miles de muertos entre los indígenas y el inca cae en poder de los conquistadores; es el inicio del fin del Tahuantinsuyu. Atahualpa (n. ¿1502? - m. 1532) era uno de los hijos de Huayna Capac (n. 1493 - m. 1527), y en aquellos momentos acababa de dar muerte a su hermano Huascar, legítimo heredero del trono inca (n. ¿? - m. 1532), tras una cruenta guerra civil por la sucesión. 
Los negros que "nunca existieron". La historia no da muchos detalles acerca de otros africanos que acompañaron a Pizarro en su segundo y tercer viajes al Tahuantinsuyu, tales como el esclavo negro que salvó a Diego de Almagro en Tumbes, cuando los conquistadores fueron atacados por los naturales, al desembarcar en una playa que después se llamó Puerto Pizarro, ni del que murió en la captura de Atahualpa en Cajamarca -la historia, en un principio, dice que sólo hubo un herido entre los españoles aquella mañana del 16 de noviembre de 1532, el propio Francisco Pizarro por evitar que uno de sus hombres matara al Inca, pues quería capturarlo vivo-, ni el negro que se encargó de transportar el oro del rescate del Inca. (Nota_13)

1535

18 de enero. Francisco Pizarro funda, en el valle del Rímac, donde ya existía un gran asentamiento indígena, la Ciudad De los Reyes, después rebautizada como Lima.

1536 a 1548

El despoblamiento de la Sierra. Periodo de luchas intestinas entre almagristas y pizarristas por adueñarse del Perú y, a la vez, entre partidarios y opositores a las Leyes Nuevas de Indias (a partir de 1542, lo cual complicó aún más el panorama), uno de cuyos objetivos era la desaparición del corrupto sistema de encomiendas en las colonias americanas. Durante estos sangrientos enfrentamientos, también conocidos como Las Guerras Civiles de los Conquistadores, se produce una gran curva descendente en la población indígena, no sólo por las matanzas de indios que 
tuvieron lugar en dichas luchas, sino también porque muchos naturales tomaron partido por uno u otro bando, enfrentándose entre ellos mismos.

1536

Varios cronistas describen la desolación de los campos y los pueblos andinos devastados por las enfermedades y las guerras. Esta situación fue tan dramática que se rompió todo equilibrio entre hombres y medio ambiente; asimismo, la infraestructura caminera y el viejo sistema de distribución de alimentos de los incas, que aún funcionaba, quedaron deshechas. Los puentes colgantes ya no eran reconstruidos periódicamente por los ayllus o comunidades, por lo que regiones enteras quedaron aisladas. Muchos pueblos estaban destruidos, quemados o abandonados y los campos se llenaron de menesterosos hambrientos que pedían comida. El caos y la ruina se apoderaron del otrora rico Tahuantinsuyu. Pese a la abundancia de tierras, no había quien las trabajara. Para paliar esta carencia de mano de obra, se fomentó la masiva importación de mano de obra negra en un fallido intento por reemplazar a los indígenas en labores de campo.

El Cusco en guerra. En abril de ese año, Manco Inca o Manco II (n. circa 1500 - m. 1544) es elegido inca por Pizarro y sus hombres, con la idea de que éste iba a ser un rey títere. Pero el nuevo monarca, conocedor de las intenciones de los españoles, no tardaría en rebelarse para iniciar una larga guerra contra los invasores; este conflicto coincidió con el desarrollo de las Guerras Civiles entre Francisco Pizarro y Diego de Almagro.

Entre abril y mayo de aquel año, unos 200.000 guerreros incas, con Manco a la cabeza, inician el asedio del Cusco lanzando flechas incendiarias sobre los tejados de la ciudad donde se habían acuartelado los hombres de Pizarro. 
18 de agosto. Los incas al mando de Kisu Yupanqui, que marchaba con tres ejércitos -unos veinte a treinta mil hombres-, cercan la ciudad de Lima, aunque son derrotados con gran esfuerzo por el marqués Francisco Pizarro con la ayuda de "indios amigos", según el historiador Edmundo Guillén. En la batalla cuerpo a cuerpo dentro de la ciudad, mueren los generales incas que habían dirigido el ataque.

6 de abril. Diego de Almagro, uno de los socios de la conquista, que se había levantado contra Francisco Pizarro, tras su regreso de Chile, por un desacuerdo sobre el repartimiento de unas tierras, es derrotado por Hernando y Gonzalo Pizarro, hermanos del conquistador del Perú, en la batalla de las Salinas. Llevado preso al Cusco, fue estrangulado en la prisión el 8 de julio de aquel año. Su rebelión marcó el inicio de las llamadas Guerras Civiles de los conquistadores. En estas sangrientas luchas, su hijo, Diego de Almagro el mozo, trataría de vengar a su padre.

$1538-1544$

Piezas de ébano. Bajo esta denominación llegaron al Perú los primeros grupos de esclavos negros; fueron traídos por sus amos en las mismas naves que trajeron a los conquistadores. (Nota_14) 
Tras nueve meses, termina el asedio del Cusco ante el ataque de Diego de Almagro, cuyo ejército retornaba de su expedición a Chile. Manco Inca se ve obligado a emprender la retirada a Vilcabamba para iniciar la tenaz resistencia inca contra los conquistadores, la misma que culminaría con la muerte de su hijo menor y sucesor, Tupac Amaru I, ajusticiado en el Cusco en 1572.

1541

26 de junio. Víctima de una conspiración urdida por el hijo de uno de sus socios de la empresa conquistadora, Diego de Almagro el mozo, es asesinado el marqués don Francisco Pizarro, conquistador del Perú, en su palacio de Lima. Lo ultimaron de una estocada en la garganta.

1542

No se oye, padre... En su Brevísima Relación de la Destrucción de las Indias, dirigida al entonces príncipe de las Españas, don Felipe, nuestro señor, el misionero dominico Fray Bartolomé de las Casas (n. Sevilla, 1484 -m. Madrid, 1566), uno de los más grandes humanistas de todos los tiempos, denuncia a los cuatro vientos los abusos y maltratos que vienen sufriendo los indígenas y gente de color en el Nuevo Mundo, por parte de los españoles, y advierte al futuro Felipe II (n. 1556 - m. 1598) que, pese a la existencia de leyes que los protegen, la conquista y la esclavitud estaban acabando con los naturale, y arremete contra la corrupción de un sistema de encomiendas inhumano. De las Casas, quien participó en la redacción de las famosas Leyes Nuevas de Indias, y fue autor de varios libros, entre éstos una monumental Historia General de las Indias, nunca se cansó de denunciar la brutalidad de los hispanos en América, que actuaban a espaldas de la Corona española. (Nota_15) 


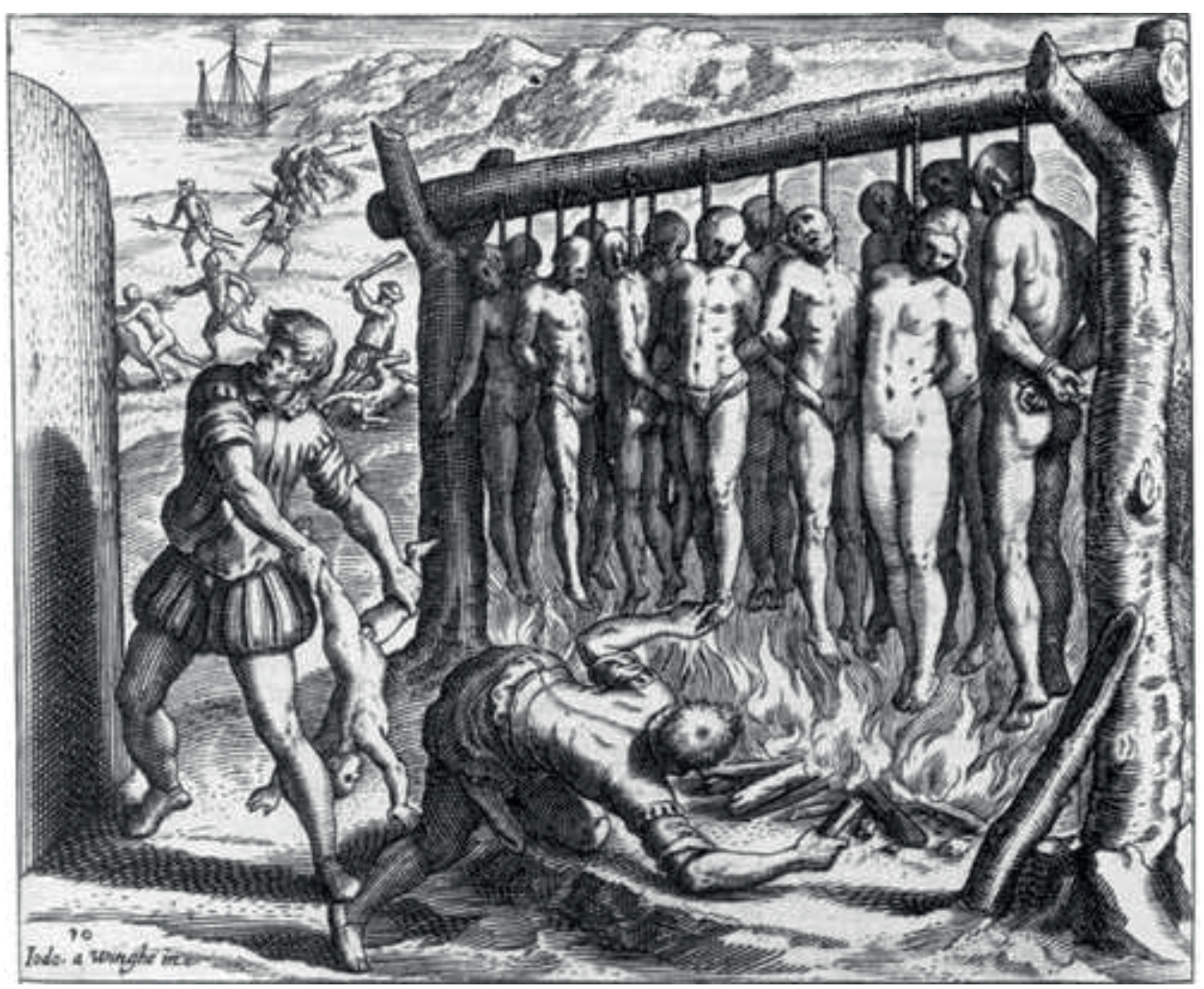

Figura 7. El pintor holandés Theodore de Bry (S. XVI), en su visita a La Española, fue testigo de escenas espantosas que nunca había visto. Este dibujo sirvió para ilustrar el libro Brevísima Relación de la Destrucción de las Indias, monumental obra donde el padre Bartolomé de las Casas denunciaba las atrocidades que se estaban cometiendo en las colonias españolas de América. Introduction to World History. Gallery Images for Lecture. Part III. andrew.cmu.edu. 


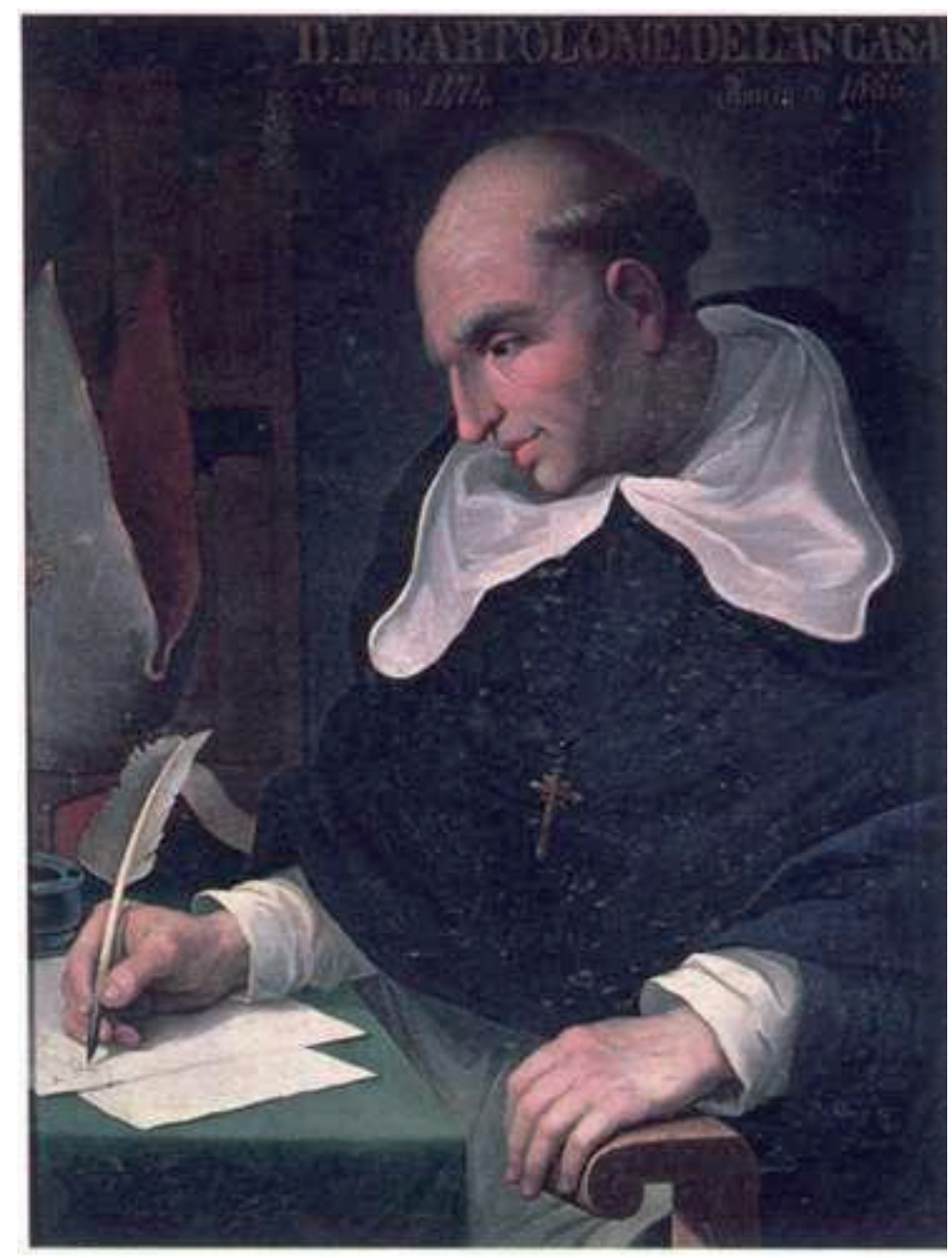

Figura 8. La voz de la conciencia. Bartolomé de las Casas llamó la atención de la monarquía Española sobre las penurias de los indígenas del Nuevo Mundo; su obra influyó para que Carlos I firmara las Leyes Nuevas de Indias, con las que se pretendía reformar el sistema de reparticiones coloniales de los naturales, además de dictar medidas de protección para la población aborigen, que no se cumplieron. Óleo sobre lienzo del siglo XVI. Introduction to World History. Gallery. Images for Lecture. Part III andrew.cmu.edu.

La doble moral de algunos súbditos de la Corona. La protesta del padre de las Casas no estaba demás, pues, si bien los reyes y autoridades de la península ibérica obraron con criterio humanista al editar las Leyes nuevas de Indias, la realidad en las colonias 
escapó al control de la metrópoli pues en tales territorios parecía cundir la ley de la selva. Mientras España quería ejercer sobre las Indias un dominio político y comercial en paz y entendimiento, sus súbditos de ultramar no parecían tener la misma idea, pues su objetivo no era otro que enriquecerse a toda costa y lograr privilegios, beneficios y poder. Las administraciones españolas locales en América, salvo honrosas excepciones, se encargaron de boicotear sistemáticamente todo cuanto venía de Madrid en materia de legislación y reales cédulas, además de otras ordenanzas. Muchos encomenderos corruptos y explotadores, con la complicidad de malos gobernadores, magistrados, clérigos, algunos indígenas de cierta categoría, y hasta virreyes, hicieron de las suyas. En el caso de los naturales fue evidente la doble moral española: mientras por un lado se legislaba para protegerlos, por el otro, tal legislación era letra muerta, pocos o nadie las hacía cumplir. Al parecer, el largo brazo de Madrid nunca pudo o supo frenar los excesos y las ambiciones de muchos castizos que habían convertido a las colonias en algo parecido a su parcela privada.

Negros en los Andes. Se dice que durante la resistencia de los incas de Vilcabamba, Manco II tenía a su servicio a unos cimarrones que conocían las tácticas militares de los españoles. La historia recuerda también a los negros que lucharon junto a los indígenas contra el invasor castellano.

Españoles contra España... Ante el fracaso en América de las leyes dictadas por la Corona Española en 1512 y 1513 a favor de los naturales de las Indias, el rey Carlos I dicta Las Leyes Nuevas de Indias (Barcelona, 20 de noviembre de ese año), que pretenden poner orden en la administración de las colonias y frenar los abusos que vienen sufriendo los pueblos indígenas americanos. La implantación de estas normas, redactadas con tan buen criterio, provocó una gran resistencia por parte de los españoles en las Indias. (Nota_16) 
Tremendo juez. Buscando pacificar el Perú, de una vez por todas, e imponer la autoridad entre las facciones de Gonzalo Pizarro y Diego de Almagro el mozo, en 1541, el rey de España Carlos I envía como juez y oidor a don Cristóbal Vaca de Castro (n. 1492 - m. 1566), un prestigioso magistrado que, finalmente, derrotaría a Almagro en la batalla de Chupas el 16 de septiembre de 1542 y lo haría decapitar en el mismo campo de batalla. Una vez terminada su tarea pacificadora, Vaca de Castro puso la casa en orden, aunque su deseo de difundir las Leyes Nuevas de Indias en tierras andinas le causó problemas con Gonzalo Pizarro. Fue sucedido por Blasco Núñes de Vela, primer virrey del Perú en 1544.

20 de noviembre. Como parte del paquete de la nueva legislación para las Indias, Carlos I firma la real cédula que crea el Virreinato del Perú.

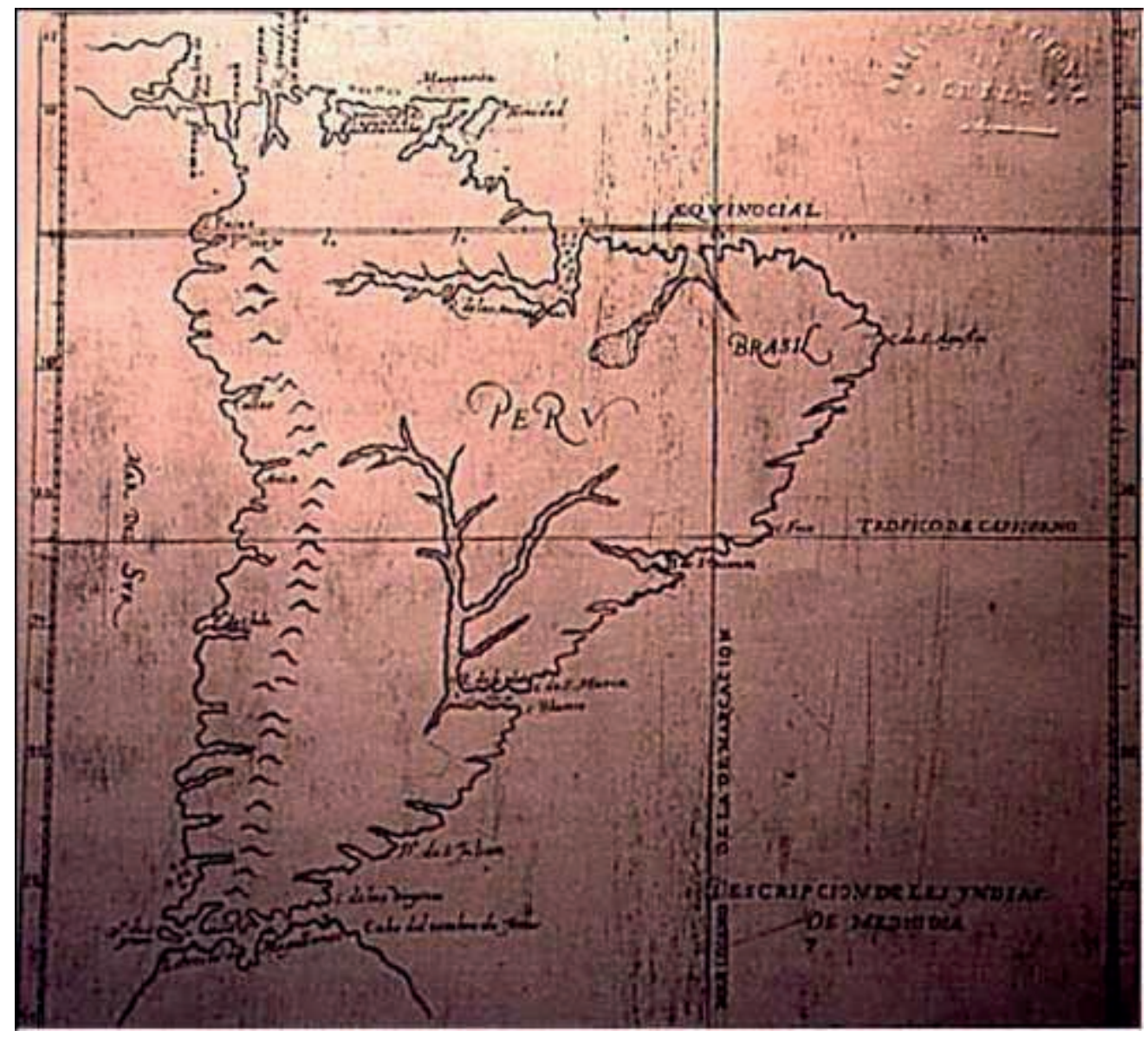


Figura 9. Viejo mapa del Virreinato del Perú en el S. XVI, conservado en la Biblioteca Nacional de Chile. (Colección Medina).

1543

Otra real cédula firmada el primero de marzo nombra al primer virrey del Perú, don Blasco Núñez de Vela (1542-1546).

1544 ó 1545

Un grupo de almagristas, que habían recibido hospitalidad en el palacio real, asesina a Manco II en Vilcabamba.

"La mano de obra constituyó el mayor problema de las Indias", sostiene Manuel Lucena Salmoral. En el transcurso de la era colonial los españoles sometieron a sus súbditos americanos a distintas formas de trabajo. Al mismo tiempo, la esclavitud fue una fuerza laboral muy importante durante este período. (Nota_17a - Nota_17b)

Llegan los corregidores pero... En un nuevo intento por mejorar el gobierno del flamante virreinato del Perú y, de paso, hacer cumplir las Leyes Nuevas de Indias, se instituye la figura del corregidor de indios para intensificar la "acción civilizadora" entre los indígenas, favorecer su evangelización y evitar los abusos que sobre ellos ejercían a menudo los encomenderos. Sin embargo, en esto último, tales autoridades de menor rango poco pudieron hacer. Como ya se adelantó, el mal manejo y la corrupción que se generó en torno a las encomiendas provocó tal caos y desgobierno 
en el Perú, que la Corona española trató de aplicar, con poca fortuna, las Leyes Nuevas de Indias que nadie quería... mediante los corregidores de indios. (Nota_18)

1546

La Cabeza del virrey. Después de su fallido primer intento de aplicar en el Perú las Leyes Nuevas de Indias, y luego de haber sido destituido y enviado de vuelta a España por los almagristas, Blasco Núñez de Vela, primer virrey del Perú (n. 1490 m. 1546), desembarca en Tumbes para volver a Lima, pero es derrotado y decapitado en Añaquito (Ecuador), el 18 de enero. El Perú era un baño de sangre.

Va de trampita. La desaparición del corrupto sistema de encomiendas era uno de los objetivos de las Leyes Nuevas de Indias, sin embargo, en honor a la viveza de los colonizadores, aquellas se volvieron hereditarias, como si de una propiedad privada se tratara, así había pueblos enteros dentro de estos repartimientos territoriales. Y la cosa se complicó aún más cuando surgieron las encomiendas dirigidas por encomenderos indígenas.

El "sheriff" del rey... En tanto seguían las inacabables discordias entre los conquistadores, don Pedro de La Gasca (n. 1485 - m. 1567), que había sido comisionado por Carlos I para enfrentar la rebelión de Gonzalo Pizarro y pacificar el Perú, llega a Lima.

Cumbres borrascosas. A la par de la aparición de los corregidores de indios, y la inaplicabilidad del nuevo marco legal de Carlos I, se introduce en el país la versión hispana de la otrora mita inca -que era un sistema tributario de trabajo personal donde el individuo retribuía de alguna forma por los beneficios que recibía-, es decir, la obligación de los indios -convertidos en mitayos por arte de birlibirloque- 
a trabajar en las minas y obrajes. El objetivo era utilizar el trabajo indígena para proveer de mano de obra y servicios para las encomiendas y reparticiones en el Perú. Así, los naturales eran obligados a extraer los minerales que alimentaban la economía colonial: la plata, el oro, el zinc, el azogue, el cobre, el estaño, el plomo, y otros, y a trabajar en los obrajes, en condiciones infrahumanas. Por este último motivo, con el tiempo, y a la par de la bonanza que este sistema de trabajo forzado procuró al virreinato en los dos siglos siguientes, la mita abusiva en las minas, los obrajes y las chacras provocaron lo que no habían conseguido las sangrientas guerras civiles de los conquistadores y las disputas de los encomenderos: aceleró el despoblamiento de comunidades enteras a lo largo y ancho del antiguo Imperio de los Incas. El decrecimiento demográfico indígena, como ya indicamos, llegó a niveles insospechados y eso se reflejó en las crónicas de la época, que el país de los incas ahora era una tierra desolada. (Nota_19)

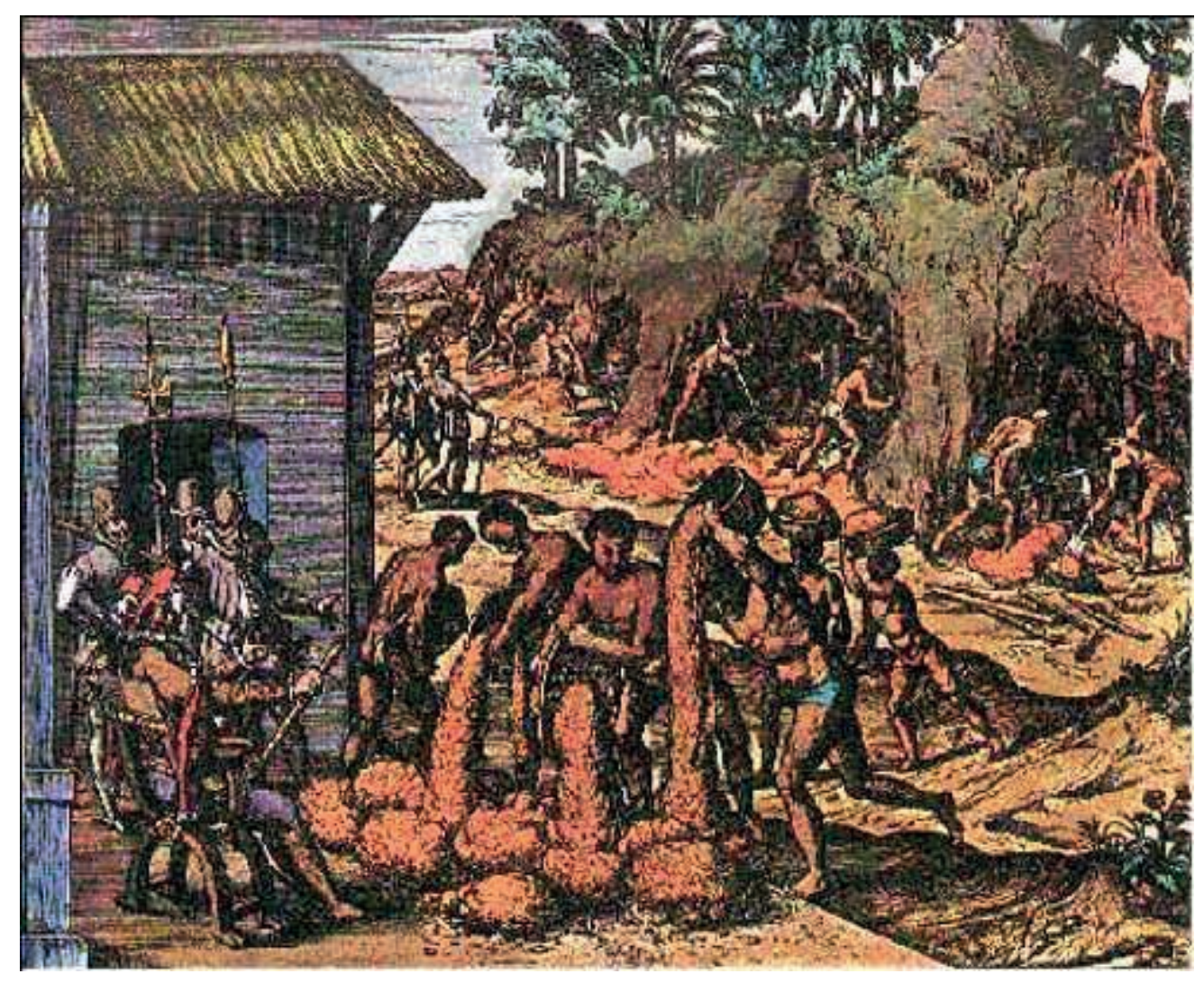


Figura 10a. Escena parecida. Ilustración del siglo XVII del trabajo esclavo indígena y negro en una mina de La Española (República Dominicana). Sólo para graficar las condiciones a las que eran sometidos los trabajadores forzados. Tomado de La América Española Colonial - Siglos XVI, XVII y XVIII. La minería.

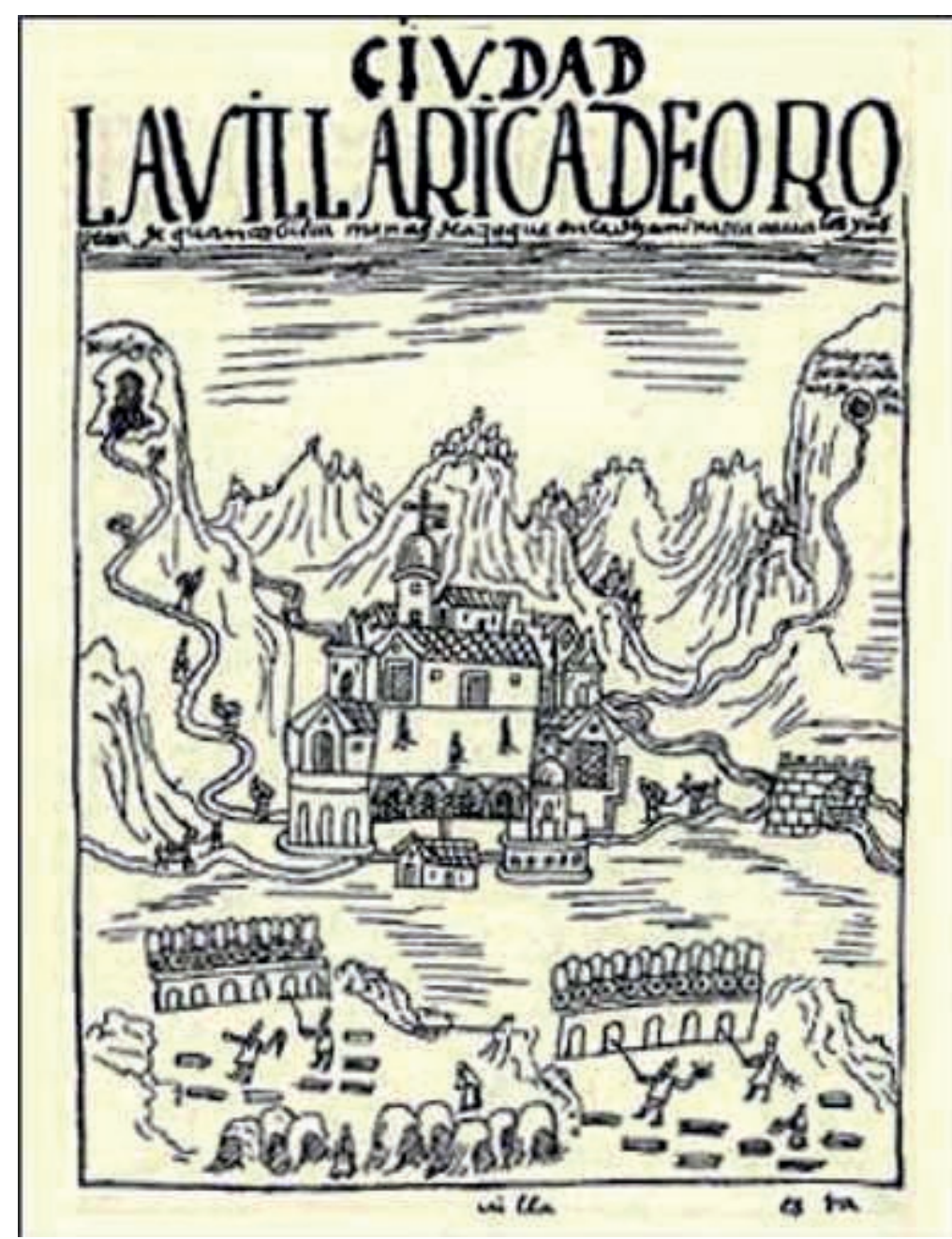

Figura 10b. La mina de Huancavelica, según un grabado del cronista indígena Guamán Poma de Ayala. En la leyenda de este dibujo, el autor se refiere a este lugar bajo estos términos: en dicha mina se acaban los indios. Ilustración de Primer Nueva Corónica y Buen Gobierno (1615-16). 


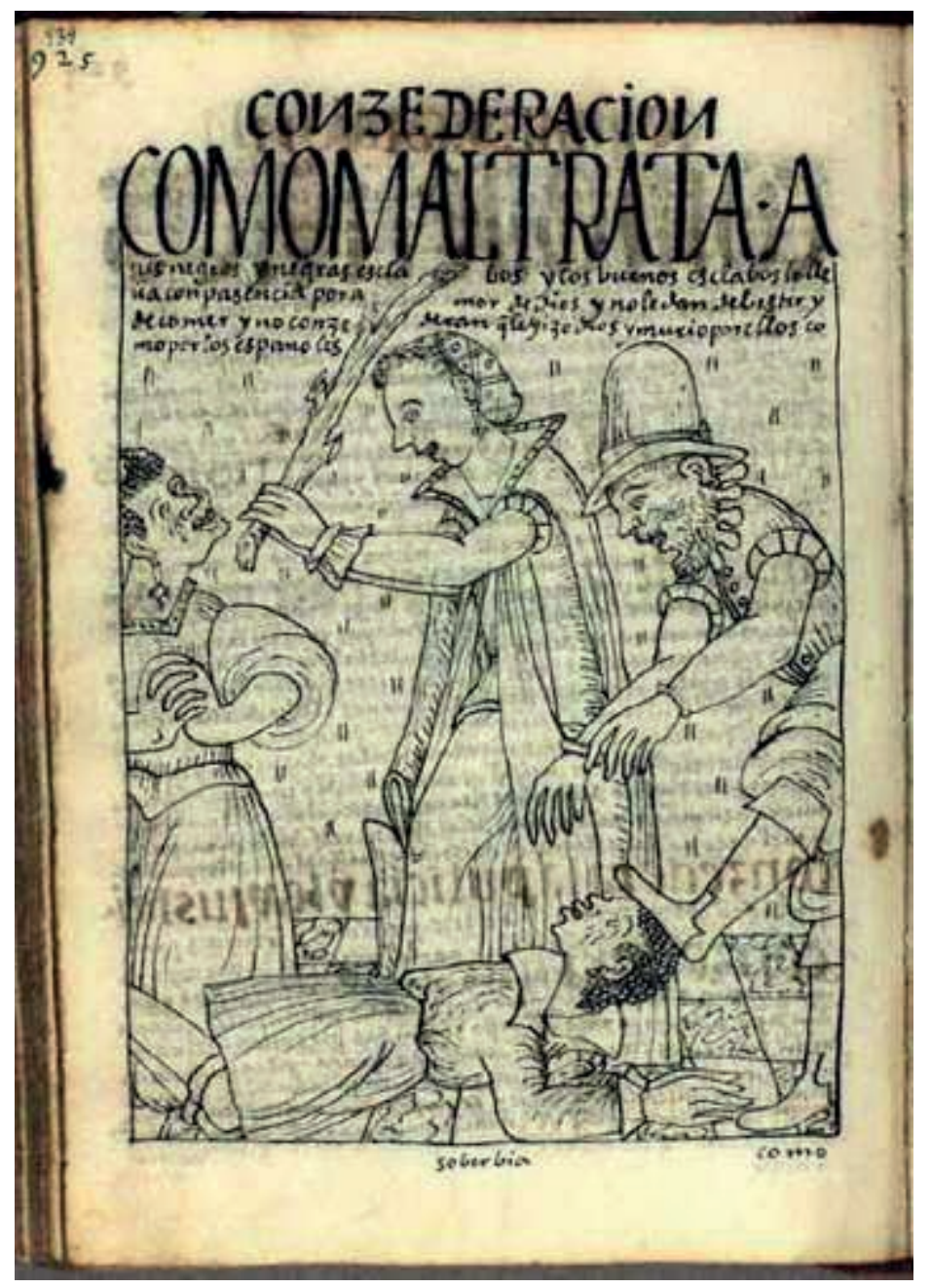

Figura 11. Cómo los españoles maltratan a sus esclavos Africanos, dice la leyenda de esta ilustración, del cronista indígena Felipe Guamán Poma de Ayala. Dibujo tomado de la primera edición de su obra El Primer Nueva Corónica y Buen Gobierno (161516).

Una ley tipificaba a los sirvientes negros como bienes semovientes. (Nota_20)

Por estas fechas ya había unos 3.000 esclavos negros en todo el Perú. 
Aquel 9 de abril, el pacificador Pedro de La Gasca se enfrenta y derrota a Gonzalo Pizarro en la batalla de Jaquijaguana, un lugar emblemático cercano al Cusco. En el mismo campo de batalla, La Gasca hizo decapitar a Pizarro y a sus capitanes. Era el fin de las Guerras Civiles. Una de las primeras acciones que tomó La Gasca, luego de la derrota de Gonzalo Pizarro, fue tratar de abolir las encomiendas bajo el espíritu normativo de las Leyes Nuevas de Indias, a pesar de la gran oposición que esto generó.

$1550-1553$

Negros de batallón. Un caudillo esclavo, de nombre Guadalupe, se convirtió en jefe del primer regimiento de hombres de color (todos en su misma situación) de la historia del Perú. Ocurrió durante la rebelión de Francisco Hernández Girón (1510 1554). (Nota_21)

1553

Zarpan de Londres los primeros barcos negreros rumbo a África.

Según un estudio realizado por el Banco Mundial conjuntamente con el Instituto Riva Agüero, que recopila informaciones acerca de la población negra en el Perú de estos años, Durante la mayor parte del siglo XVI el grueso de los africanos procedía de la Costa Occidental de África, especialmente de la sección situada entre los ríos Níger y Senegal, conocida como ríos de Guinea. Los españoles prefirieron, por mucho tiempo, a los naturales de la zona, por su laboriosidad, alegría y 
adaptabilidad. La Corona española estimuló persistentemente el envío de negros de Guinea a sus posesiones americanas. Otra fuente de reclutamiento de negros eran los pueblos de las caletas de Benin y Biafra y los de la zona del Congo y Angola. (Nota_22)

1556

Por considerarla una amenaza contra el poder español, el virrey Andrés Hurtado de Mendoza, marqués de Cañete (1555-1561), establece el cargo de alcalde de la hermandad, una especie de "sheriff" que, al mando de una tropa, debía operar en las afueras de Lima para controlar a los cimarrones y bandoleros. Entre sus integrantes se encontraban libertos conocidos bajo el sobrenombre de mogollones.

Guineanos de por acá. Durante este periodo, Guinea suministraba ya el 55\% ó 56\% de los esclavos negros exportados hacia el Perú; mientras que otras zonas del África Occidental entre el 11\% y el 12\% y Angola, el resto. Un gran número de ellos eran esclavos domésticos, aunque, por supuesto, no faltaban quienes ejercían otros oficios, como ya se vio. (Nota_23)

1562

John Hawkins realiza el primer transporte de esclavos negros a las Antillas bajo bandera inglesa.

$1564-1567$

John Hawkins lleva esclavos pirateados desde África Occidental a las Antillas. 
Algo más sobre mitas (y mitayos): las reducciones de Toledo. Francisco de Toledo, conde de Oropesa, quinto virrey del Perú (1569-1581), regula las encomiendas y la mita de los indios, estableciendo las reducciones de indios mitayos. Las reducciones funcionaban como centros poblados -apartados de las localidades habitadas por los españoles - donde los indígenas eran reducidos, es decir, reasentados de sus lugares de origen. Se trataba de verdaderos guetos para naturales, donde éstos debían permanecer bajo un régimen represivo. Por otro lado, las reducciones no eran otra cosa que pueblos alimentadores de mitayos para la mita. De aquí los indígenas reducidos eran trasladados como mano de obra a las minas y obrajes. Este sistema, muy exitoso económicamente para la administración colonial, tuvo, empero, efectos devastadores en la demografía, además de que se prestó a la corrupción y a una serie de abusos contra los trabajadores indios, a quienes se daba un trato de esclavos. (Nota_24) 


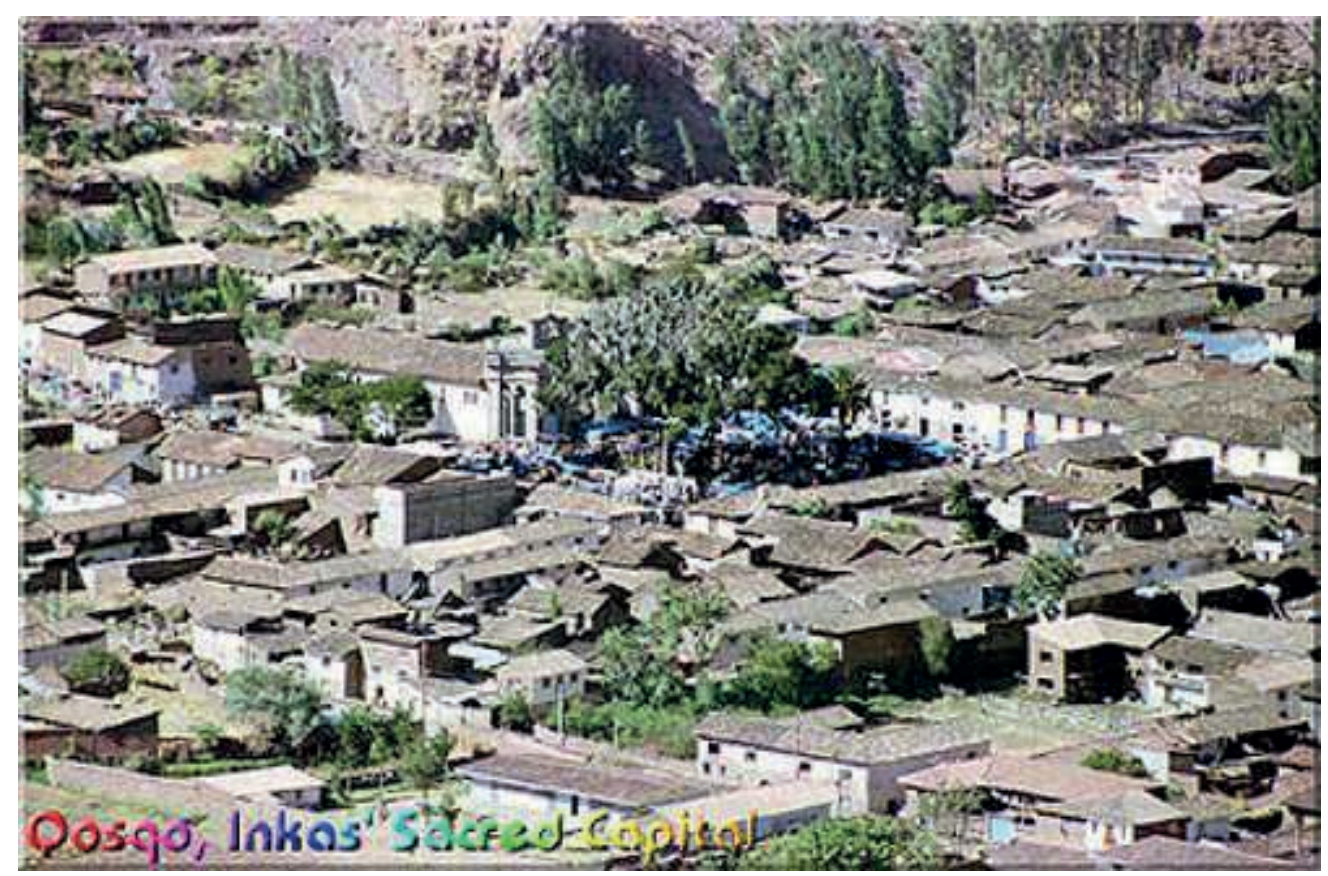

Figura 12. Pisaq fue una de las primeras reducciones de Indios establecidas por el virrey Francisco de Toledo en el Perú (1572). Este pueblo está enclavado en la entrada del llamado Valle Sagrado de los Incas, sobre la margen derecha del río Urubamba. Como sucedió con tantas otras localidades andinas, este histórico poblado alimentó por casi tres siglos los obrajes textiles cercanos al Cusco. Hoy, su famoso mercado indígena dominical es uno de los principales atractivos turísticos de esta región. Ilustración del portal Qosqo.com 


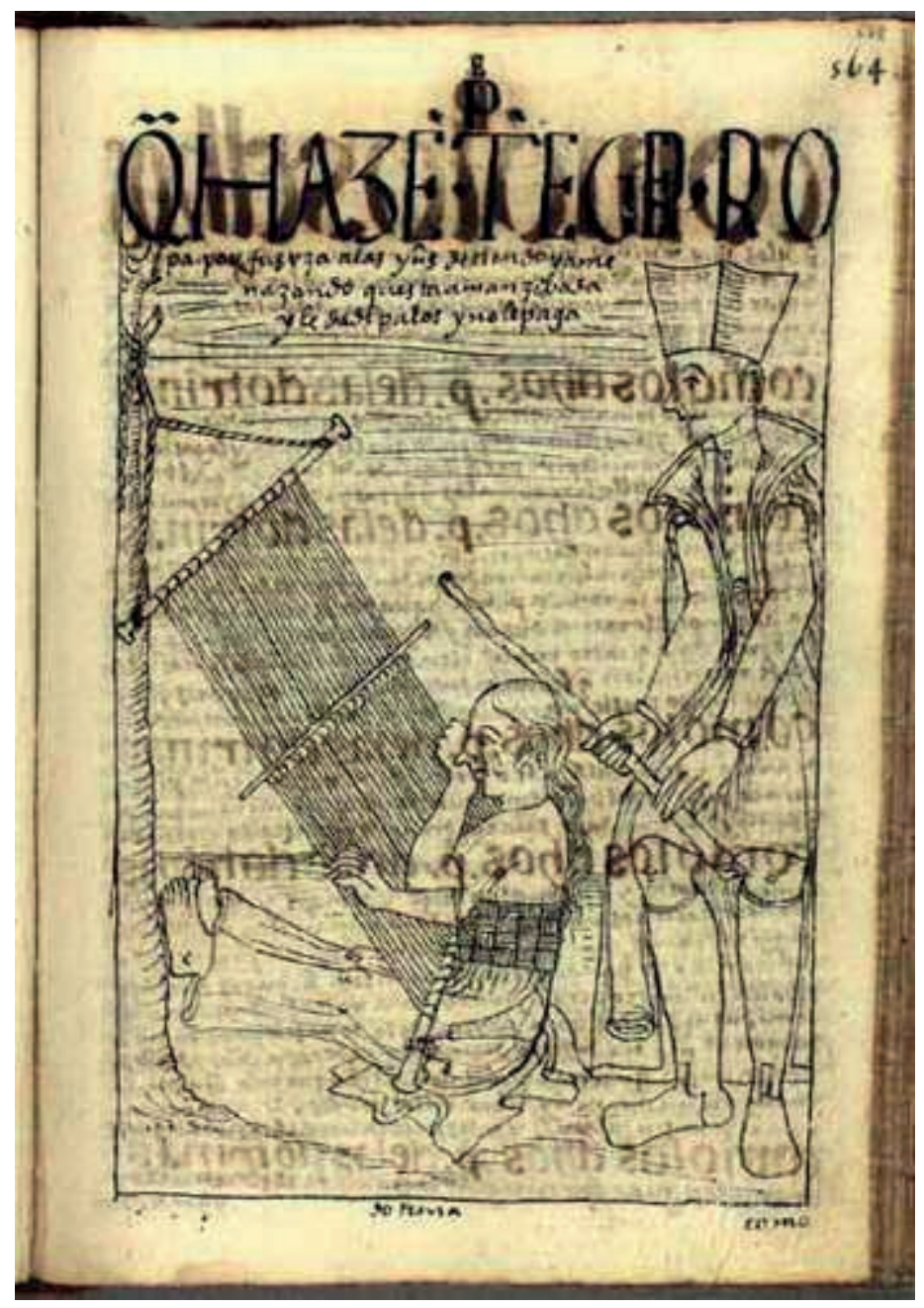

Figura 13. Un obraje y lo que pasaba adentro. La leyenda de este dibujo de Guamán Poma de Ayala lo dice todo: El padre de doctrina amenaza a la tejedora andina que trabaja por orden suyo. Ilustración de la primera edición de su obra El Primer Nueva Corónica y Buen Gobierno (1615-16).

1569 y ss.

También la Inquisición. Los negros y los andinos en el Perú no solo fueron víctimas de la opresión de los españoles, también la Iglesia les había echado el ojo. Si no que lo digan los 21 mestizos, negros y mulatos procesados y sometidos a Autos de Fe por la Inquisición española, entre estos años, por diversos "delitos" que, naturalmente, sólo estaban en la mente de los jueces religiosos de esa época. (Nota_25) 
1569 - 1581

El virrey Francisco de Toledo (n. 1515 - m. 1582) muestra su preocupación por la creciente población de esclavos de color en la capital del virreinato. Según una relación de autor desconocido, en la época de Toledo, había unos 12.000 esclavos negros al servicio de los españoles.

$1570-1600$

El cronista Juan López de Velasco, en su Geographia y Descripción de las Indias, describe como se vivía en Lima por ese entonces. Y señala, en coincidencia con la cifra citada arriba, que en esta ciudad había unos 12.000 españoles, mientras que negros había de doce mil arriba.

1570

A comienzos de las últimas tres décadas del siglo XVI, la población de negros y mulatos era algo más de la mitad de la población limeña de ese entonces.

1572

24 de septiembre. Finaliza la guerra de los incas de Vilcabamba con la rendición y muerte de su último caudillo, Tupac Amaru I (¿? - Cusco, 24 de septiembre de 1572), ajusticiado en la Plaza Mayor del Cusco, en aquella fecha. La rebelión había durado 
36 años, desde el levantamiento de Manco Inca II contra los hombres de Pizarro en 1536.

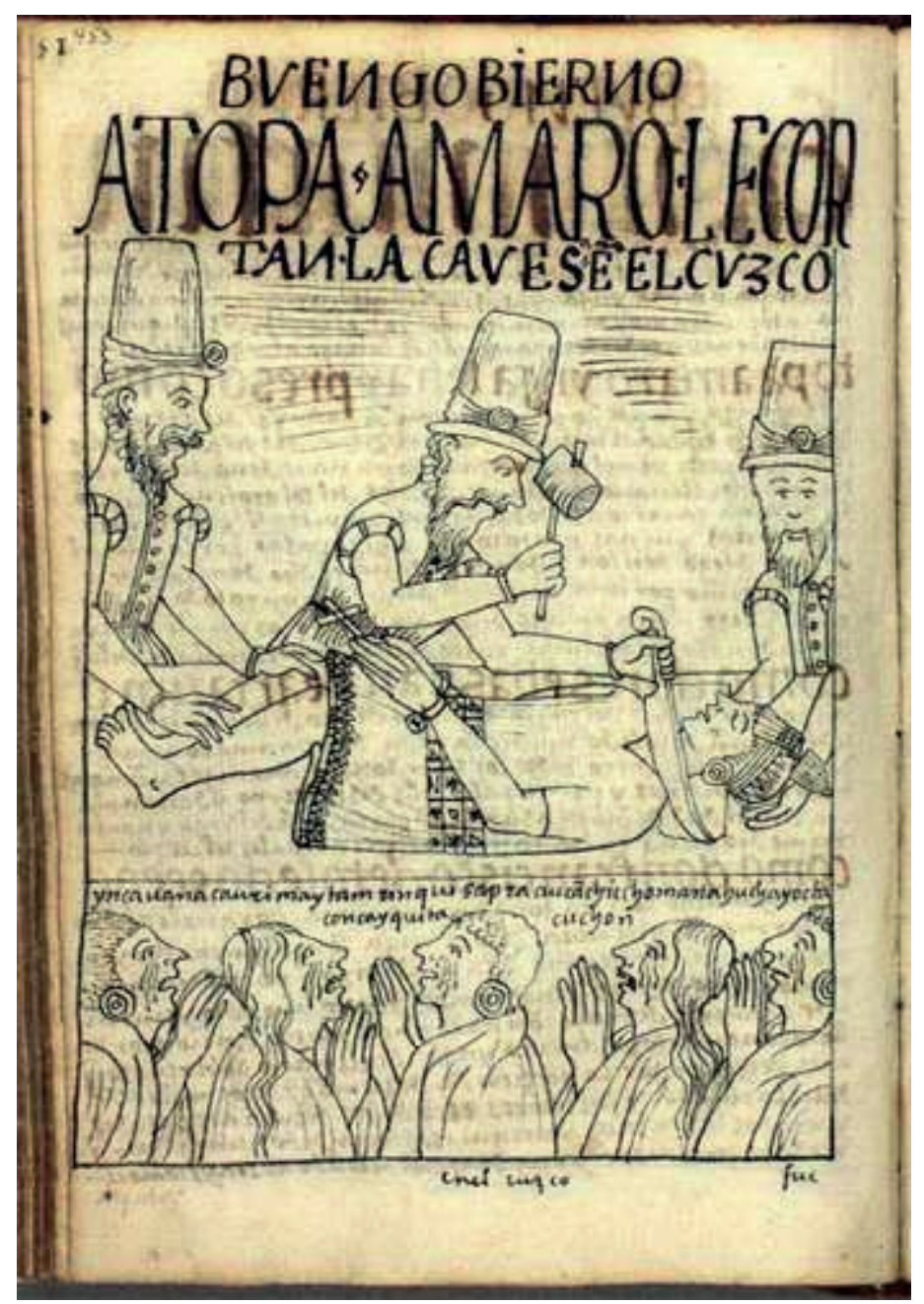

Figura 14. Le cortan la cabeza a Topa Amaro Ynga por orden del virrey Toledo y los nobles incaicos expresan su angustia por la muerte de su rey inocente. Ilustración y leyenda de Guamán Poma de Ayala para la primera edición de su obra El Primer Nueva Corónica y Buen Gobierno (1615-16).

1576

El 8 de mayo de aquel año, el arzobispo de Lima y futuro santo, Toribio de Mogrovejo (n. ¿1538? - m. 1606), describe el censo realizado en las parroquias de la 
Catedral, Santa Ana y San Sebastián. En la primera de ellas, de 8.770 fieles, 3.980 eran africanos.

1580

Los holandeses llegan a la costa de Guyana, tierra que empezarían a colonizar en 1616.

1593

Negros y verdugos. La política colonial tenía sus métodos para reprimir y controlar cualquier disidencia, peor si el levantisco era indio, negro o bandolero. La historia nos dice que, a lo largo de la colonia, quienes estaban encargados de vigilar y castigar a los indígenas de los obrajes eran negros y, cuando se trataba de ajusticiar a un condenado, quien cumplía el rol de verdugo, casi siempre, era un esclavo o liberto de raza negra.

La mita española no era la mita inca. Mientras prosperaba el comercio negrero en las Indias, en el Perú se acentuó el sometimiento a los habitantes de las zonas andinas. Y la mita inca pasó a ser sinónimo de opresión y trabajos forzados de sol a sol para los naturales. Esta modalidad de trabajo comunal paso a ser una verdadera institución básica sobre la cual se movía la economía virreinal. Ante el temor de la corona a quedarse sin el comercio americano, se formó una tácita alianza entre los hacendados y los poderosos para aplicar una verdadera tiranía sobre los poblados y zonas rurales en los valles interandinos. Sin embargo, esta modalidad tenía sus puntos débiles, puesto que había suficientes indios dispuestos a trabajar por un salario para explotar los recursos naturales, pero que, a fin de cuentas, muchas veces, ni eso recibían. 
Más de lo mismo. España autoriza a Pedro Gómez de Reyner para que pueda transportar 38.000 esclavos negros a América.

Ellos también. Primera expedición holandesa a Guinea.

\subsection{Siglo XVII}

Primeros años del siglo XVII

El cronista religioso Bernabé Cobo (n. 1582 - m. 1657) informa en uno de sus escritos que a comienzos de aquel siglo la población limeña de entonces incluía a unos 30.000 negros, una cifra que, sin embargo, se presta a la discusión.

El cimarronaje se convirtió en un verdadero problema social para la administración colonial. Las investigaciones realizadas sobre este particular centran en la región de Lima el área donde se ha establecido una relación entre negros descontentos y coyuntura agraria, esto es, sequías o malas cosechas o inundaciones que, de alguna forma, agudizaban la presión ejercida sobre el trabajo de los esclavos en las haciendas. La paranoia y el temor a revueltas de campesinos hacia creer a los españoles que los ingleses apoyaban a los negros y que se iban a aprovechar de las circunstancias para provocar una rebelión generalizada. Fue un miedo casi patológico a la rebelión negra que acosó a las autoridades de la colonia, primero, y a las republicanas, después, el mismo que perduró hasta pasada la época de la abolición de la esclavitud. 
El color de Lima. De los 14.262 habitantes de la ciudad de Lima, contabilizados por el censo encargado ese año por el virrey don Luis de Velasco (1596-1604), el 40\% correspondía a gente de color (negros y mulatos)

Andes tempestuosos. Estalla una rebelión en la provincia de Vilcabamba, donde antes habían resistido los últimos reyes incas. Aquí vivían unos 2.000 esclavos negros y la revuelta estaba destinada a atacar el Cusco, contando con los negros de esta ciudad. La revuelta fue sofocada y sus líderes ajusticiados.

Según el Padrón de los Indios de Lima de ese año, el número de esclavos negros y mulatos supera a al resto de la población (españoles, religiosos, indios y mestizos). (Nota_26)

La población indígena de la zona del Caribe prácticamente había desaparecido.

1602

El cronista indígena Felipe Guamán Poma de Ayala (¿1538? - ¿1620?), en su monumental obra Nueva Corónica y Buen Gobierno, se atreve a denunciar los abusos, el maltrato y la explotación a que son sometidos tanto indios como esclavos negros y mulatos por parte de los españoles. No escapan a sus críticas ciudadanos comunes -como mestizos y nuevos ricos -, también nobles, autoridades civiles -en especial encomenderos y corregidores blancos- y militares, lo mismo clérigos y algunos paisanos suyos encumbrados -tal es el caso de ciertos caciques, además de corregidores y encomenderos indios alineados con los colonizadores - . (Nota_27) 


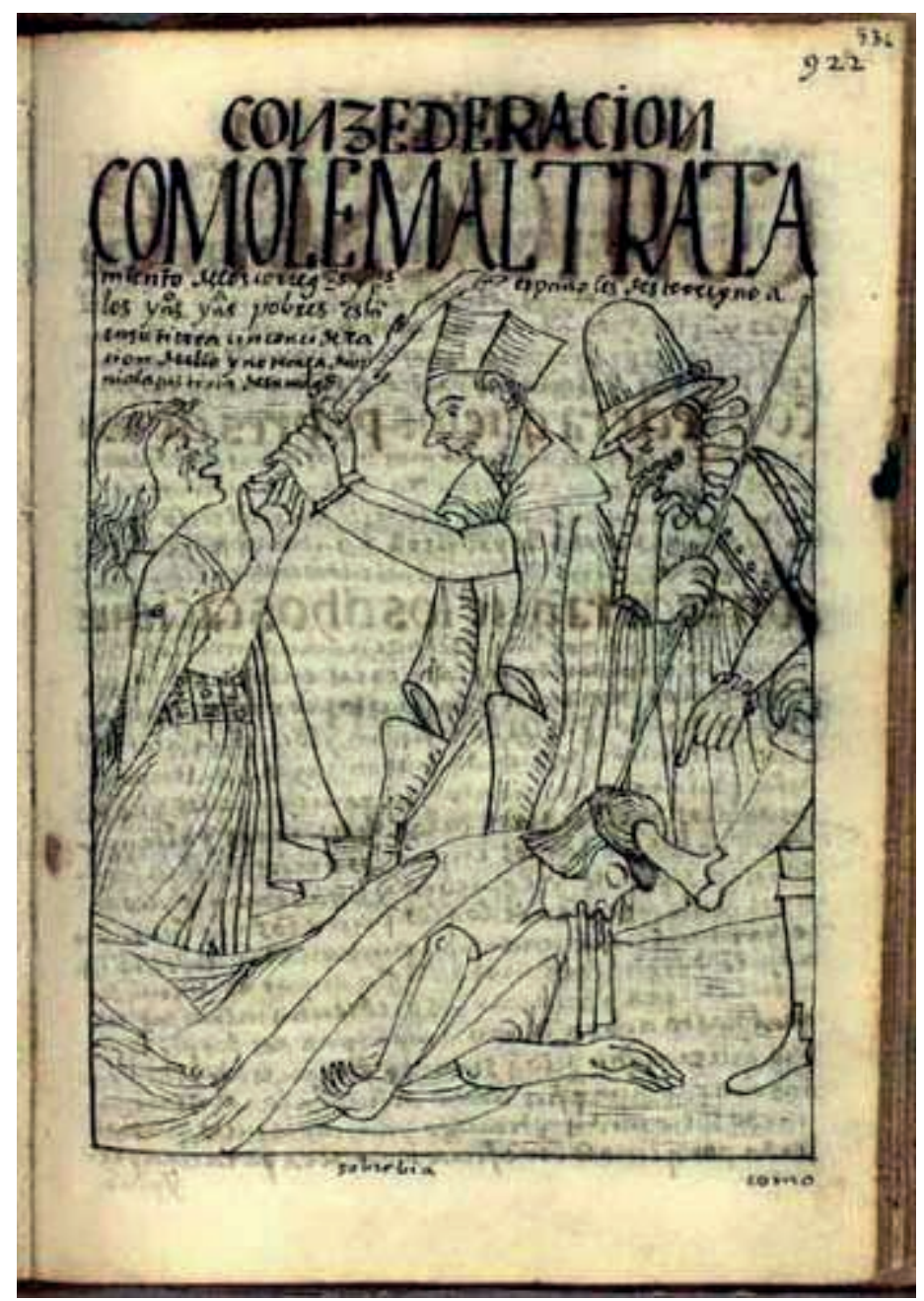

Figura 15. Los corregidores y padres españoles maltratan a los pobres indios de este reino. Ilustración y leyenda de Guaman Poma de Ayala. El Primer Nueva Corónica y Buen Gobierno (1615-16). 


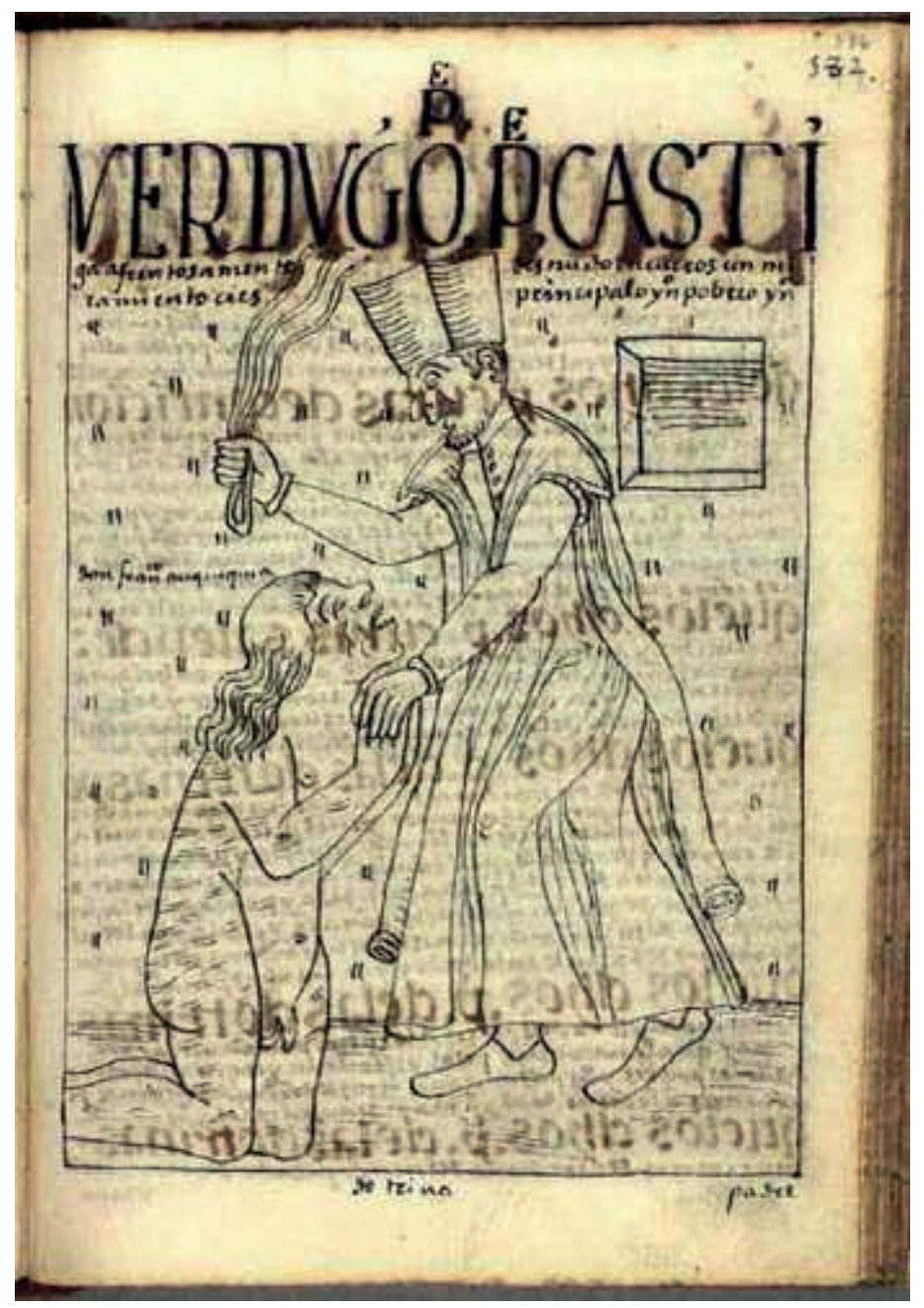

Figura 16. Verdugo: el padre de doctrina castiga cruel e indiscriminadamente. Ilustración y leyenda de Guaman Poma de Ayala. El Primer Nueva Corónica y Buen Gobierno (1615-16).

\section{2}

Los ingleses se establecen en las Bermudas.

1613 
El censo ordenado por el virrey Juan de Mendoza y Luna, marqués de Montesclaros (1607-1615), indica que, en ese año, Lima tenía 25.454 habitantes y el 40\% de esta población estaba conformada por negros y el 3\% eran mulatos.

En otro censo realizado por el arzobispado de Lima en sus cuatro parroquias señaló que la ciudad acusaba un descenso demográfico de 24.265 habitantes. De éstos, el $50 \%$ correspondía a negros y mulatos.

1614

En aquel entonces ya había 15 cofradías de negros y mulatos, según una información del arzobispado limeño enviado a la metrópoli; éstas estaban patrocinadas por órdenes religiosas; eran 6 cofradías sólo de negros, 3 de mulatos y 6 de negros y mulatos. Estas cofradías estaban consideradas dentro del rubro de obras pías reguladas por las autoridades eclesiásticas.

1617

Los holandeses arrebatan la isla de Goree (Senegal) a los portugueses, y construyen dos fuertes.

1618

Los ingleses en el río Gambia.

1619

Negreros ingleses ingresan los primeros esclavos negros en Virginia (USA). 
En ese año, otro censo realizado por el arzobispado de Lima no sólo incluye a los negros y castizos en su relación, sino también a otras etnias, así indica que, en esta ciudad, había 13.620 negros, 861 mulatos, 11.088 españoles -incluyendo a los religiosos - , 1.426 indios y 377 mestizos, los que sumados daban una población total de 27.372 habitantes.

La mitad más uno. El 50\% de la población limeña de ese año eran negros y otro 3\% mulatos.

El incidente de Jamestown. Se inicia la entrada de la población negra en Estados Unidos, con el arribo al puerto de Jamestown (Virginia) de un barco negrero holandés que se ve obligado a intercambiar esclavos negros por alimentos. Fue un ingreso adelantado, por accidente, pues la llegada de negros africanos a este país recién se "oficialicializó" en la década de 1680, cuando la corona británica regularizó la situación de los esclavos en sus colonias americanas.

La trata negrera está en su mayor apogeo en Latinoamérica. Lima se convierte en uno de los "mercados de personas" más prósperos y caros de la región. Los cronistas de época evocan escenas como la llegada de los esclavos al Callao y la venta de éstos en la capital del virreinato más rico de América. 
Figura 17a. El mercado de esclavos de Lima.

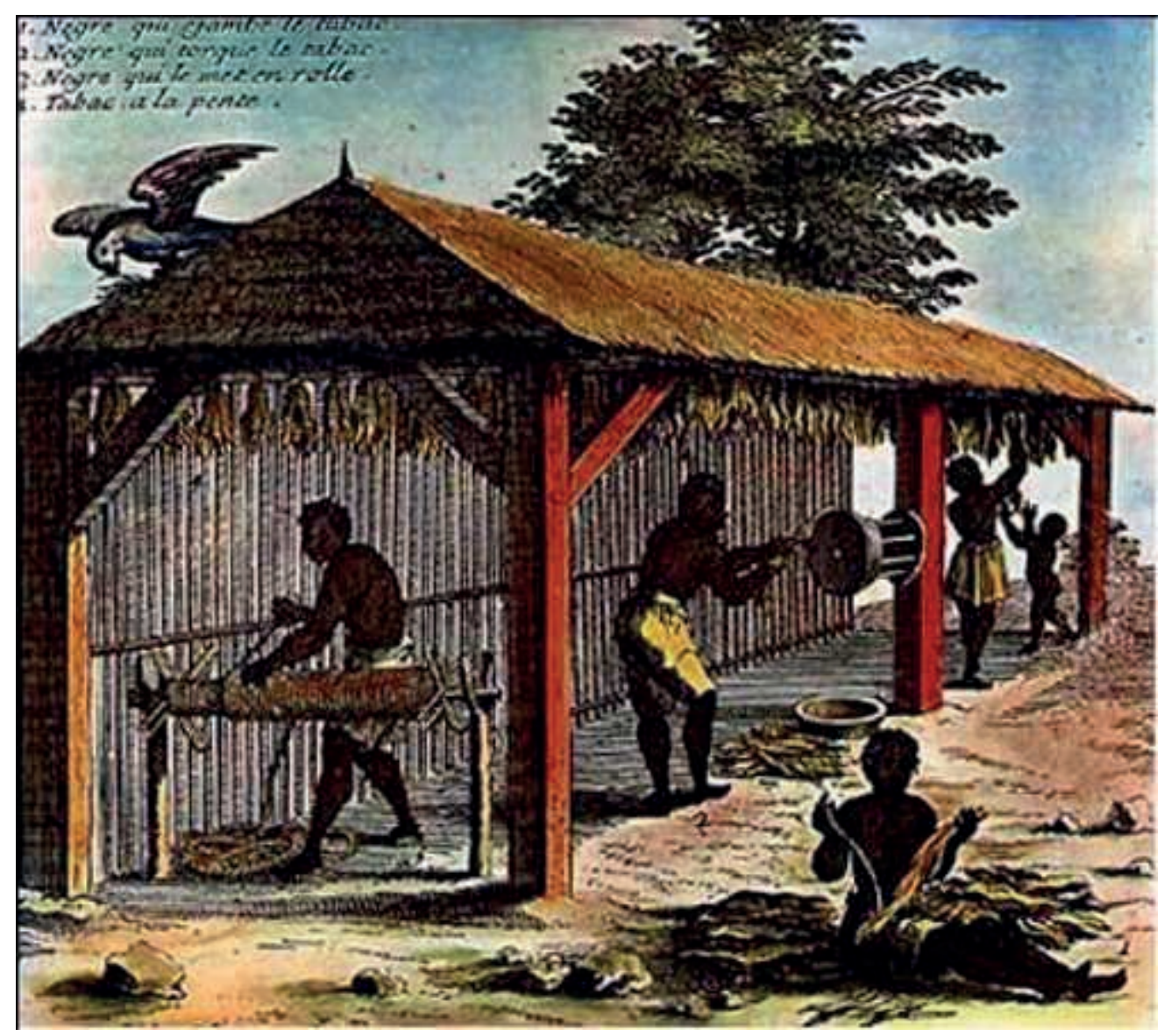

Lima, 1624: Se vende gente - ¡Camina!

${ }_{-j C o r r e !}$

- ¡Canta!

¿QQué tachas tiene?

- ¡Abre esa boca!

-¿Borracho es, o pendenciero?

-¿Cuánto ofrece, señor?

-¿Y enfermedades?

-¡Si vale el doble!

${ }_{-j C o r r e !}$ 
-¡No me engañe usted, que lo devuelvo!

-¡Salta, perro!

-¡Una pieza así no se regala!

-iQue levante los brazos!

-¡Que cante fuerte!

-Esa negra, ¿con la cría o sin la cría?

-iA ver los dientes! ...

Se los llevan de una oreja. Les marcarán el nombre del comprador en las mejillas o la frente y serán instrumentos de trabajo en las plantaciones, las pesquerías y las minas y armas de guerra en los campos de batalla. Serán parteras y nodrizas, dando vida, y, quitándola, serán verdugos y sepultureros. Serán juglares y carne de cama.

Está el corral de esclavos en pleno centro de Lima, pero el cabildo acaba de votar el traslado. Los negros en oferta se alojarán en un barrancón al otro lado del río Rímac, junto al matadero de San Lázaro. Allí estarán bastante lejos de la ciudad, para que los vientos se lleven sus aires corrompidos y contagiosos.

Fuente: Eduardo Galeano, Memoria del Fuego, tomo 1, pp.226-227. 


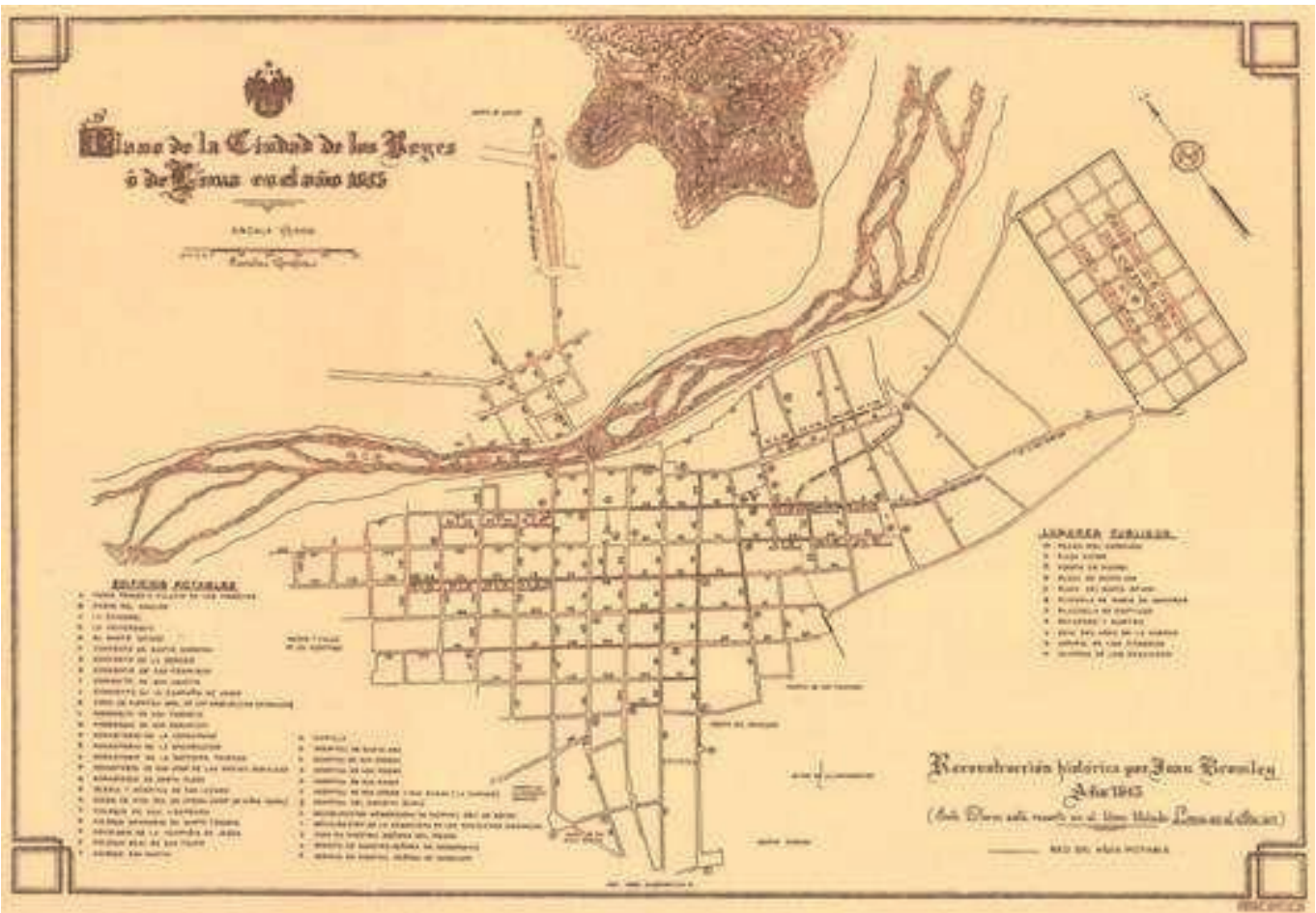

Figura 17b. Plano de la ciudad de Lima en 1613. En la parte superior de la ilustración, arriba del río Rímac, se encontraba el barrio de Malambito (aún sigue allí). Colección de la Biblioteca de la Municipalidad Metropolitana de Lima. 


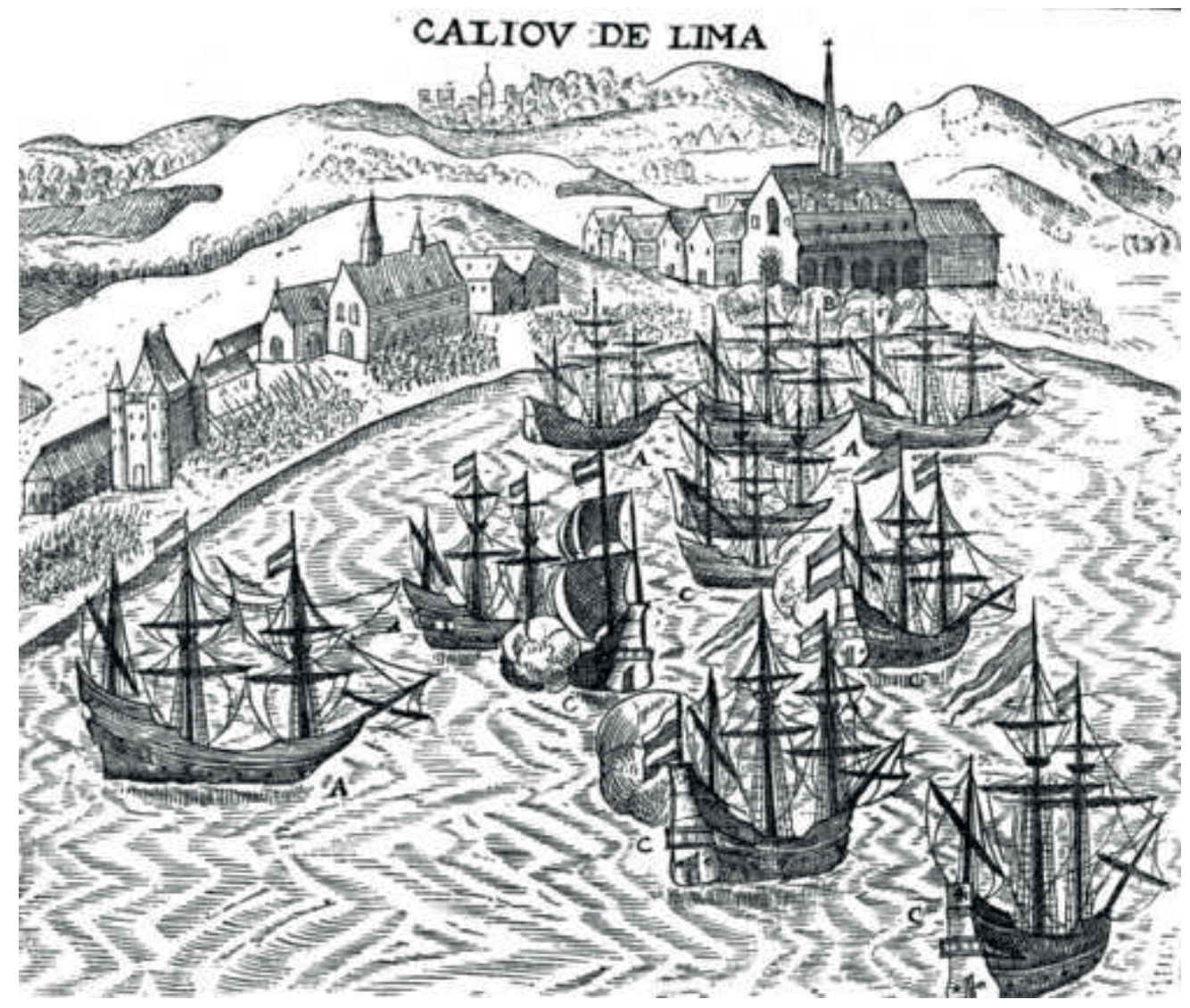

Figura 17c. Callao de Lima. Una sugestiva visión de artista anónimo del siglo XVII. Imágenes Antiguas. Redperuana.com

Haití cae en manos de los franceses.

1630

La industria del azúcar y la esclavitud. Los ingleses introducen los primeros ingenios azucareros en Barbados. La explotación de los esclavos negros provocaría, décadas después, una rebelión en toda esta isla que fue sofocada a sangre y fuego (1692). 
De Santiago matamoros a Santiago mataindios. Según un estudio realizado sobre las tasas de crecimiento poblacional en el virreinato peruano, el brutal descenso de habitantes en las zonas andinas, un fenómeno que también afectó a países como México o República Dominicana durante el mismo periodo histórico, fue producto no sólo de las guerras del Siglo XVI -entre conquistadores, entre encomenderos, entre españoles e indígenas, etc.-, sino también de los auténticos genocidios perpetrados contra poblaciones nativas durante la época de la conquista y primeros años de la colonia. A esto habría que agregar otros factores, tales como la política de extirpación de idolatrías llevada a cabo por curas fanáticos, reclutados al efecto por la Iglesia Católica, los rigores de la Inquisición, cuyos fallos muchas veces derivaron en injusticias, y las enfermedades traídas por los europeos -como fue el caso de la viruela, que diezmó comarcas enteras (hay quienes afirman que los españoles propagaron ésta y otras enfermedades a propósito, para apoderarse de las tierras dejadas por los nativos) - .

Las reducciones de indios, la explotación, los abusos y los trabajos forzados a que fueron sometidos millones de indígenas convertidos en mitayos, para laborar en minas y obrajes, también dejaron su doloroso saldo, despoblando valles y comunidades enteras. Se dice que incluso, cuando se formaba una reducción, los habitantes de las comarcas vecinas abandonaban sus tierras para huir de los trabajos forzados. La importación de esclavos africanos sólo le hizo un parco favor a la carencia de mano de obra indígena en el campo, pues éstos nunca se habituaron totalmente a la altura. Al sometimiento y la explotación del hombre por el hombre en los Andes se le achaca, entonces, la desaceleración del crecimiento demográfico en el Perú, que pasó de 6 a 1,1 millones de personas, entre 1532 y 1626. La leyenda negra de España fue, precisamente, ésta; leyenda o, mejor, cruel realidad, que no sólo fue criticada por el padre Bartolomé de las Casas, cuyas denuncias fueron desoídas en las 
Indias -a pesar del tibio intento de la Corona española por remediar las cosas - , sino que, además, tal coyuntura social fue aprovechada por algunos críticos de las gestas conquistadoras, que terminaron por tildar a los hombres de Pizarro -y demás paisanos - de asesinos crueles y ambiciosos, dejando constancia de que éstos, al pasar de Europa a las Indias, habían pasado de Santiago matamoros a Santiago mataindios. Algo como para enrojecer al buen apóstol de Jesús que, por cierto, nada tuvo que ver con esto.

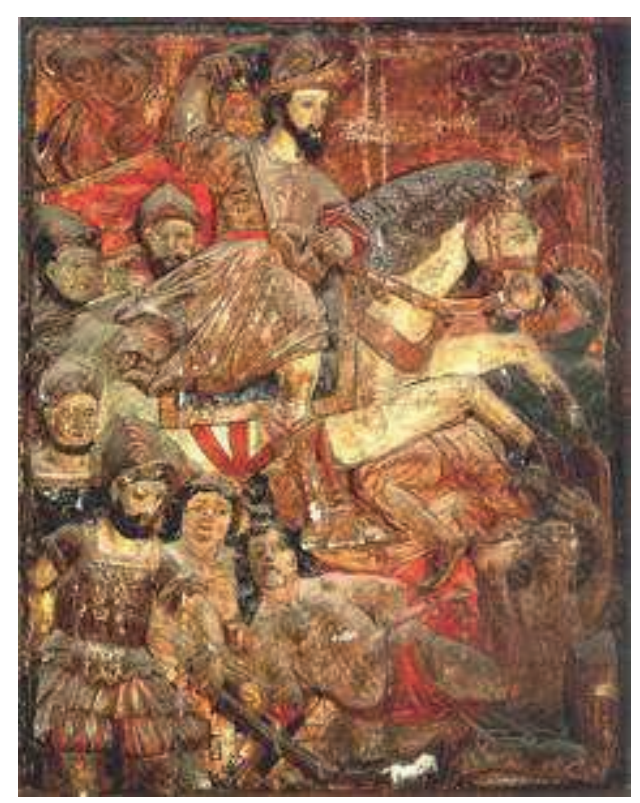

Figura 18. Santiago Mataindios. El caballo de Santiago aterrorizó a los indígenas y se convirtió durante siglos en un símbolo de conquista de la Nueva España. Los primeros indios en divisar caballos corrían aterrorizados. Creían que se trataban de hombres con dos cabezas y cuatro patas. Muy rápidamente, la aparición del caballo en la colonización de América tuvo intervenciones milagrosas.

Óleo que se conserva en la pinacoteca de la Biblioteca del Convento de Ocopa (Junín, Perú). Texto de Louis Cardaillac. 
Para ese año, Bowser calculó que el número de negros -tanto en el ámbito rural cuanto en el urbano - ascendía a 20.000, cifra que, por cierto, parece contrastar con la indicada por el padre Cobo a principios de este siglo, en vista de que Bowser se basó en investigaciones suyas para llegar a esta conclusión demográfica. (Nota_28)

1637

Construcción del fuerte de San Luís del Senegal por parte de unos comerciantes franceses de Dieppe. En ese mismo año, los daneses le quitan Arguin, Garea (Goree) y Elmina a los portugueses.

1640

El historiador Manuel García, cuando habla de las duras condiciones del transporte de esclavos a la América española, se remite al testimonio del padre Alonso de Sandoval como testigo de los negros... "van de seis en seis, encadenados por argollas en los cuellos, asquerosos y maltratados, y luego, unidos de dos en dos con argollas en los pies. Van debajo de la cubierta, con lo que nunca ven el Sol o la Luna. No se puede estar allí una hora sin grave riesgo de enfermedad. Comen de 24 en 24 horas una escudilla de maíz o mijo crudo y un pequeño jarro de agua. Reciben mucho palo, mucho azote y malas palabras de la única persona que se atreve a bajar a la bodega, el capataz". Esta situación provocaba como era de esperar verdaderas mortandades a bordo de los barcos negreros, si no enfermedades que luego eran arrastradas de por vida, durante el cautiverio que solía terminar con la muerte. Al respecto, el propio García añade: Sobre un cómputo de 29 barcos llegados a las Indias de forma consecutiva, de los 7.143 esclavos en las lejanas costas de África, sólo 5.551 llegaron vivos. La travesía duraba 50 días desde Angola a Cartagena de Indias y 40 desde 
Guinea. Debido al elevado número de muertes se autorizó al principio un recargo del 20 por ciento sobre el número de cabezas autorizadas por la licencia, en concepto de demasía para pasar más tarde al 40 por ciento. En los almacenes de destino fueron frecuentes las epidemias, incluidas las de viruela. Los esclavos continuaban viaje con destino a minas y plantaciones. De Veracruz a México aún quedaba un viaje de 17 días en mula. Desde Cartagena embarcaban para Buenos Aires, Tucumán y Potosí. La ruta a Chile era la más penosa. Comenzaba desde Portobelo a Panamá y después de cruzar el istmo se embarcaba en Callao. (Nota_29)

Suecia se suma al comercio internacional de la trata.

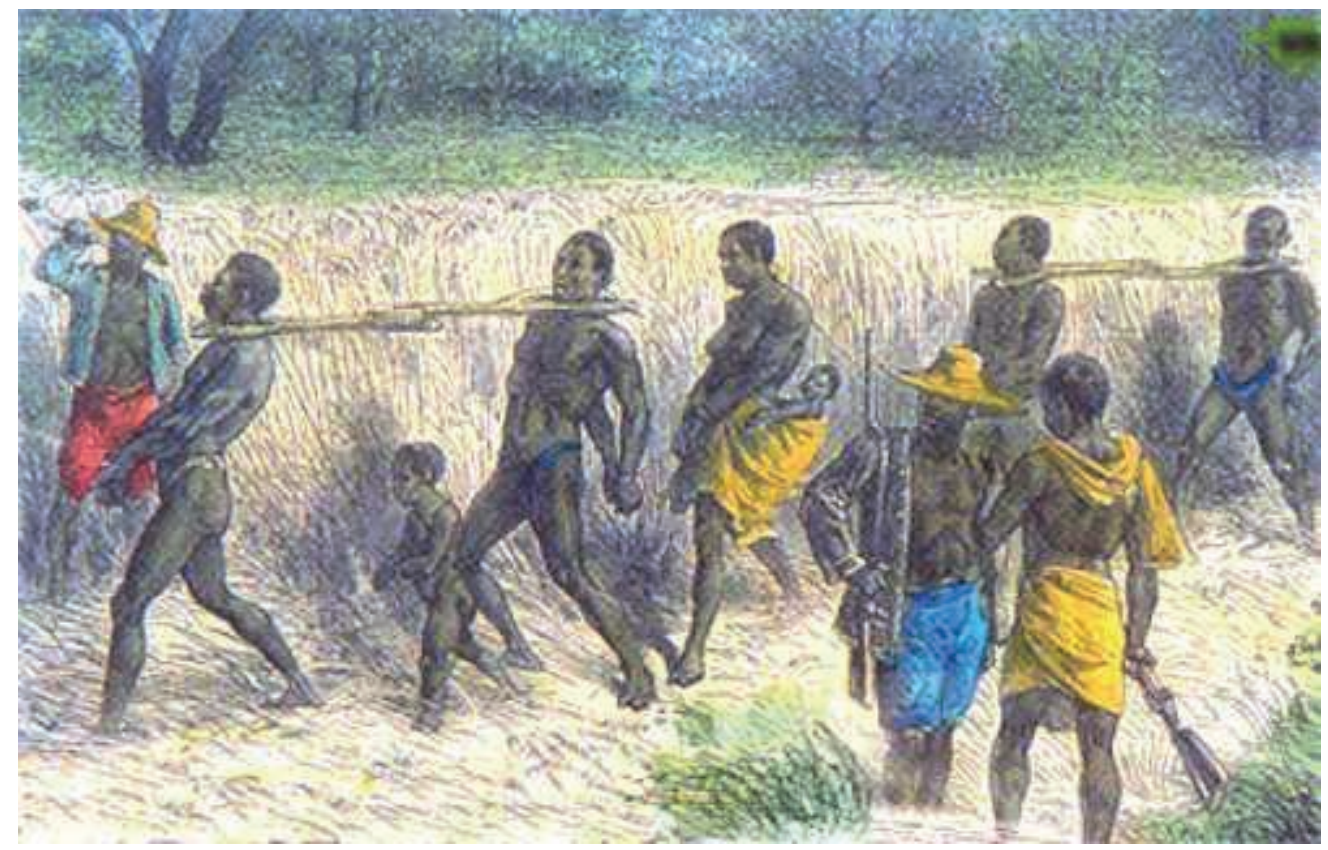

Figura 19a. Razzia: cacería humana. Esta escena se repitió una y mil veces en lugares tan dispares del continente negro como Gambia o Nigeria.

Grabado del siglo XVIII según una descripción de Mungo Park. Tomado del Proyecto de la UNESCO: La ruta del esclavo. Schomburg center for Research in Black Culture, New York. 


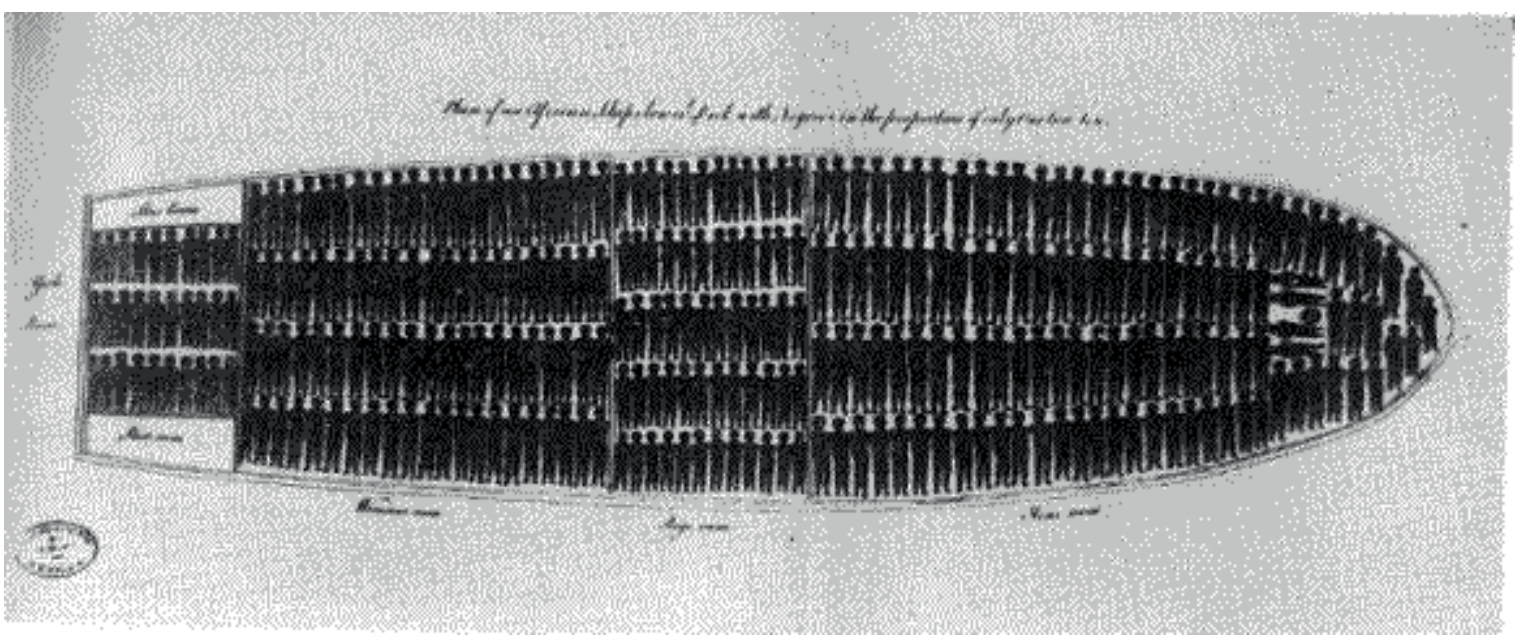

Figura 19b. Un barco similar a este, cuyo diagrama ofrecemos aquí, era pan de cada día en las rutas marítimas entre África y el Nuevo Mundo. En este dibujo podemos apreciar la disposición de los compartimientos interiores del navío y la forma en que viajaban sus hacinados pasajeros; algo semejante a lo descrito por el autor citado por Manuel García. Ilustración de un documento del siglo XVII que se conserva en el Archivo General de Colombia.

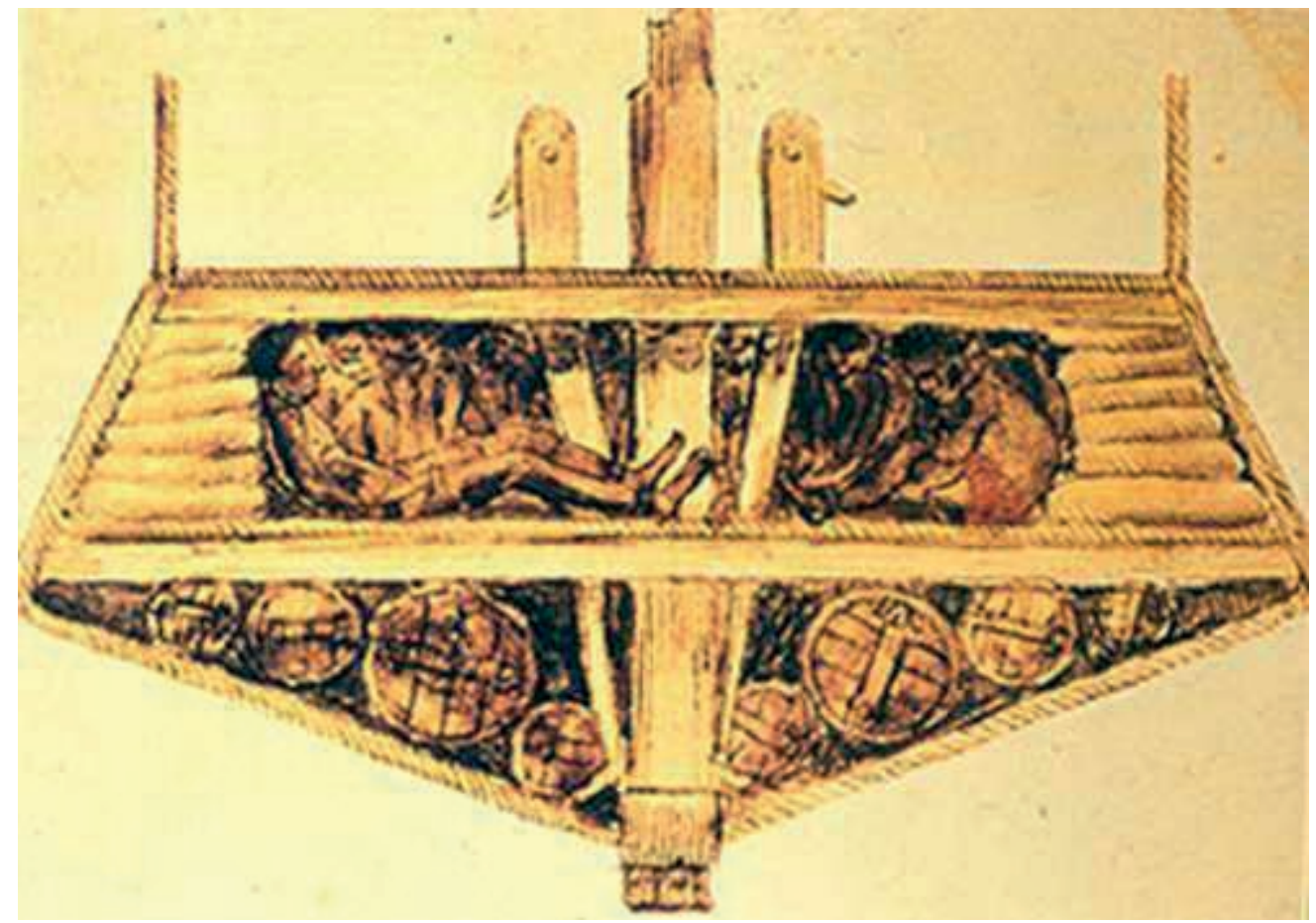


Figura 20. ¿Clase turista? Desde luego que no era una forma tan cómoda de viajar. Los esclavos negros capturados en alguna parte de África eran introducidos en las bodegas de los barcos negreros, donde se sentaban en grupos, encadenados y acurrucados o recostados en los húmedos tablones del piso. Así permanecían inmovilizados hasta llegar al puerto de destino, donde les esperaba una triste existencia. Tomado del Proyecto de la UNESCO: La ruta del esclavo.

$1642-1645$

Los franceses introducen esclavos negros en la Martinica.

1645

Costa de Oro. Suecia construye el fuerte de Christianborg.

Segunda mitad del S. XVII

Sobre la creencia en la inferioridad del hombre africano, Javier Sierra se remite a fuentes que ilustran la deshumanización a la que fueron sometidos los africanos por el color de su piel: En una descripción de la época se les califica de "grandes monos, tan hábiles que, bien adiestrados, son capaces de ocupar el lugar de un criado". Las crónicas de los descubridores suelen ser muy subjetivas: "caníbales bárbaros, que sacrifican a sus prisioneros", "negros, que adoran al demonio", "desde la más tierna infancia tienden a la inmoralidad y se hacen cortes lastimosamente en el rostro y en el cuerpo y se los pintan de colores para mayor ostentación". El desconocimiento inicial fue seguido de justificaciones interesadas. (Nota_30) 
31 de marzo. Un pavoroso terremoto destruye la ciudad del Cusco, el mismo que se sintió en Lima con gran intensidad, causando mucha destrucción y heridos. Después del sismo, se cuenta que un negro angoleño, perteneciente a una de las varias cofradías organizadas en el barrio de Pachacamilla bajo la advocación de un santo, pintó una imagen de Jesús crucificado en una tosca pared. Éste fue el origen de una de las cofradías de negros más célebres en el Perú colonial: la que se formó en torno a la pintura y procesión del Señor de los Milagros. Lo singular fue que esta añeja devoción surgió en una de las zonas más deprimidas de la ciudad, donde vivía una gran población de color. La milagrosa resistencia a los sismos del muro de adobe donde estaba pintada la imagen motivó la expansión de este culto por todo el Perú. Sobre la venerada imagen del Cristo Morado -por el color de los hábitos que suelen llevar sus fieles seguidores en octubre, el mes en que se celebra su fiesta - el padre Vargas Ugarte dice que ésta ya estaba pintada en 1651. Ver: ¿qué era una cofradía? (Nota_31)

Carlos II, rey de Inglaterra, Escocia e Irlanda (n. 1630 - m. 1685), se convierte en el principal propulsor de la esclavitud en Europa por su apoyo a la Real Compañía Africana, que traficó con millones de esclavos negros de Guinea entre sus factorías en el continente negro y América del Norte e islas del Caribe. 


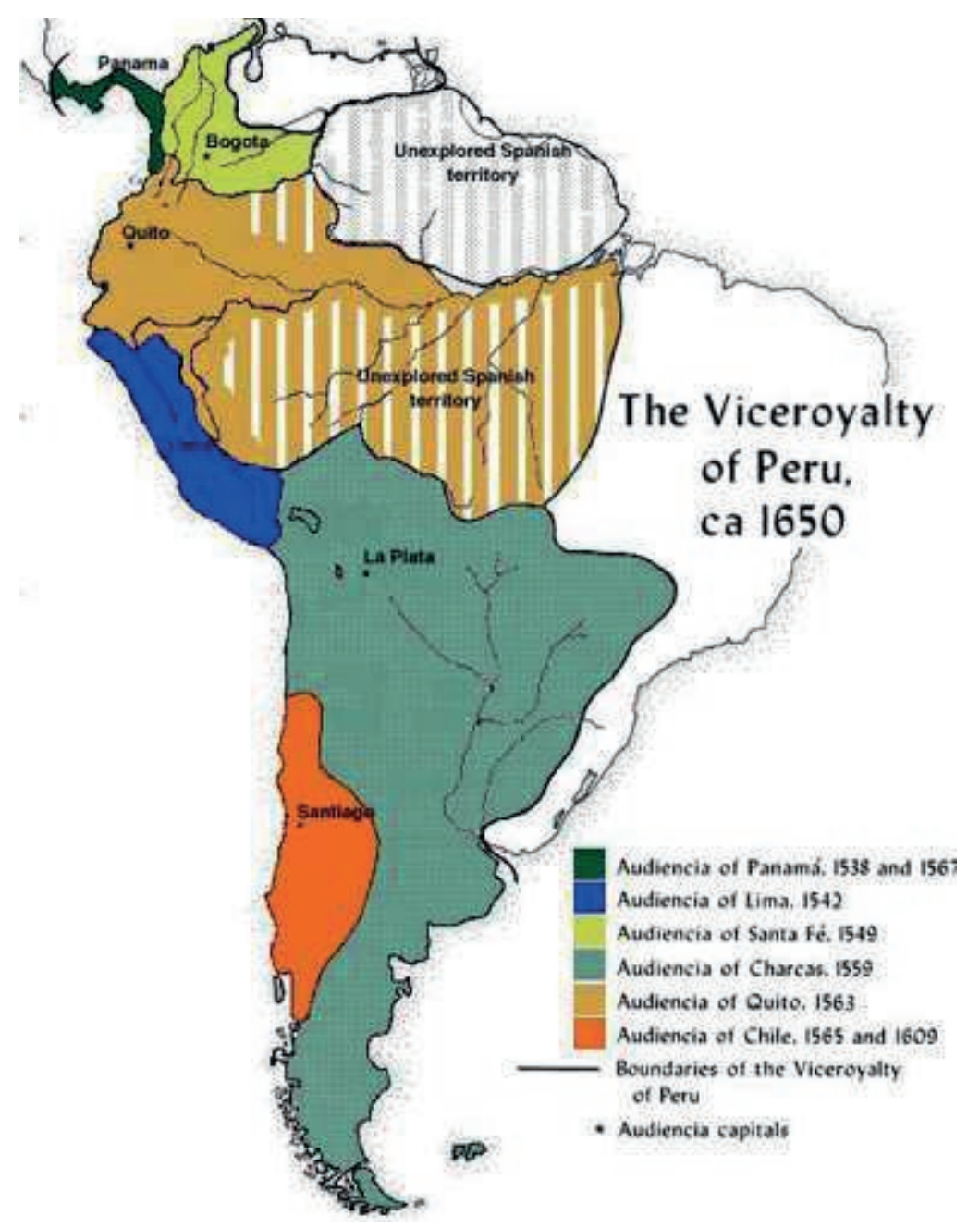

Figura 21. El virreinato del Perú hacia 1650. Mapa del portal Age of European Exploration Weblinks.

Se consolida en Lima el culto al Cristo de Pachamamilla; en este año se institucionalizó el culto al Señor de los Milagros que ahora moviliza a millones de devotos, en su famosa procesión de octubre, 353 años después. Paralelamente, surgen devociones a otros cristos, santos y vírgenes -siempre promovidos por cofradías negras - en todo el Perú, como sucede en Ica con el Señor de Lurén. 
Inglaterra promulga la primera ley de navegación, que contempla el transporte de esclavos.

Los ingleses de La Compañía Británica de las Indias Orientales asaltan y arrebatan la isla de Santa Elena a los holandeses.

1652

Los holandeses se apoderan del Cabo de Buena Esperanza, donde instalan la Compañía Holandesa de las Indias Orientales para la trata.

1657

Los daneses se apoderan del castillo de Christianborg, que estaba en poder de Suecia.

1663

Grillo y Lornelin, unos tratantes italianos, consiguen del rey de España un permiso para transportar 24.000 esclavos negros a América.

La colonia británica de Maryland emite sus famosas normas legales donde se señala que todos los negros importados deberán ser considerados como esclavos. Al año siguiente, se indica que los esclavos deben servir hasta la muerte, prohibiéndose además el matrimonio entre mujer blanca y hombre negro. 
Los franceses arrebatan Goree a los daneses y se inicia una disputa territorial con Inglaterra.

1673

Aparece en Roma la obra Lima Limata Conciliis Constitucionalibus, el Aliis Monumentis, que da la sorprendente cifra de 40.000 esclavos negros viviendo en la capital virreinal y sus alrededores.

El rey Álvare, del Congo, se convierte en el mejor aliado de los tratantes de negros portugueses, al proporcionarles esclavos de su propio pueblo.

1686

El rey de Benín cede a los apetitos mercantilistas de los europeos (portugueses, ingleses, franceses...) y acepta vender esclavos de su propia gente, cuando sus antepasados siempre se opusieron a la trata.

1685

Luís XIV, rey de Francia (n. 1638 - m. 1715), también conocido como el Rey Sol, fue el primero en iniciar el otorgamiento de premios e incentivos a los tratantes de esclavos negros. Además, en aquel año, se promulga el Code Noir para regular la esclavitud en el Caribe francés.

1690

¿Esclavos con suerte? Una investigación de Alejandro Reyes Flores, publicada en la revista del Instituto de Investigaciones Histórico Sociales de la Facultad de Ciencias 
Sociales de la UNMSM, en Lima, al referirse al caso particular de los esclavos en el valle de Cañete, al sur de Lima, escribe lo siguiente: La relación amo (Orden de la Buena Muerte) con sus esclavos fue paternalista, entendiendo ésta como aquella en la que los amos cuidan a sus esclavos y les rodean de garantías para que puedan vivir y reproducirse. Esta es la actitud que, en general, adoptaron los padres administradores de las haciendas y también la política que se impartió desde Lima. (Nota_32)

1685

La Corona española otorga un asiento o permiso al traficante Baltasar Coyman para transportar 10.000 esclavos a la América hispana.

1695

El gobierno español contrata a la compañía del traficante de negros Cachu para Introducir 4.000 esclavos anuales en América.

\subsection{Siglo XVIII}

1700

El famoso censo del virrey Melchor Portocarrero Lasso de Vega, conde de Monclova (1689-1705), dio para Lima la cifra de 37.724 habitantes; de éstos, 7.182 eran esclavos negros y mulatos, el 25\% de la población total.

$1702-1713$ 
La Guerra de Sucesión Española enfrenta a Inglaterra y España.

1711

España autoriza a la Compañía Francesa de las Indias Orientales para transportar, por tiempo indefinido, esclavos negros a la América española.

Francisco Congo fue tal vez uno de los esclavos negros más famosos en la historia del Perú virreinal. (Nota_33 y Nota_34)

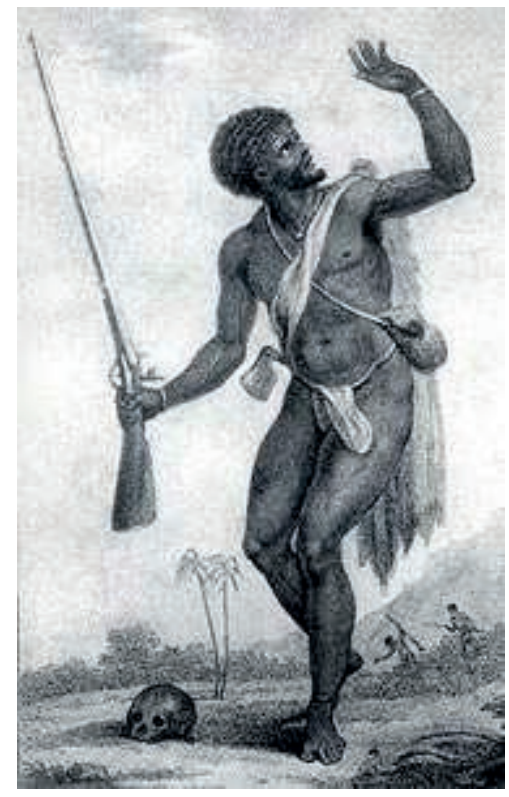

Figura 22. El cimarronaje fue un fenómeno social común a todas las posesiones españolas de América. Es probable que Francisco Congo, a falta de un retrato, haya sido físicamente parecido a esta concepción artística que idealiza a los bandoleros cimarrones que se convirtieron en el azote de los territorios coloniales.

Ilustración de The West Indies - A Slave Ship Speaks The Wreck of the Henrietta Marie. Mel Fisher Maritime. Heritage Society and Museum in Key West, Florida (USA).

13 de julio. España e Inglaterra firman el tratado de Utrech, que pone fin a la Guerra de Sucesión Española que ambos países libraban desde 1702. Uno de los puntos de 
este acuerdo estipula encargarse la compañía de Inglaterra sobre la introducción de Esclavos negros en la América española, por tiempo de treinta años. (ver siguiente)

1715

Gracias al mismo tratado (de Utrech), se consolida en Londres la Compañía del Mar del Sur o Compañía de los Mares del Sur (en inglés The South Sea Company), una organización comercial privada, formada en 1711 por Robert Harley. Esta compañía recibió los derechos exclusivos para realizar actividades comerciales con América del Sur, como parte de los acuerdos firmados al finalizar la guerra de Sucesión Española. Las especulaciones económicas que se generaron en torno a esta organización disparó el valor de las los títulos por nueve en el primer semestre de 1720. Este fenómeno financiero, conocido como la Burbuja del Mar del Sur, fue una de las crisis bursátiles más devastadoras de la historia del capitalismo. Casualmente, mientras duró esta "burbuja", se dio el acuerdo entre España e Inglaterra. Y, como de una empresa capitalista se trataba, se le concedió el monopolio para realizar el comercio de esclavos entre África y la América española, con el fin de encarar la competencia de las compañías negreras portuguesas, francesas, holandesas y danesas.

El magnate Ricardo O'Farni establece en La Habana la primera factoría para la trata de esclavos negros.

$1720-1730$ 
Grandes cantidades de esclavos negros son transportados a Minas Gerais (Brasil) por los barcos negreros portugueses.

El diputado y gobernador del Banco de Inglaterra, Humprey Morice, es en esa época el principal tratante de esclavos de Londres.

1734

En Jamaica, tras casi un siglo en poder de los ingleses, convertida la isla en emporio de la caña de azúcar, sus autoridades no pueden contra las constantes sublevaciones de esclavos negros.

1742

Surge en la selva central peruana (Chanchamayo) el movimiento separatista del caudillo indígena Juan Santos Atahualpa (n. ¿circa 1710? - m. ¿circa 1756?), de claro tinte milenarista e idealista, pues había comparado el viejo mundo con el mundo dominado por la corona española. Había sido educado por los jesuitas, que le enseñaron castellano y latín, y había viajado a España, Inglaterra, Angola y Francia. Contó con el apoyo de otros pueblos como el ashaninka y se hizo proclamar Apu Inca, descendiente de Atahualpa. Su meta era restaurar el estado inca aniquilando a los españoles y sus costumbres. El movimiento, por cierto, puso en jaque a la administración colonial de entonces y tuvo grandes repercusiones históricas, como lo fue la rebelión a posteriori de José Gabriel Condorcanqui, Tupac Amaru II. (Nota_35) 

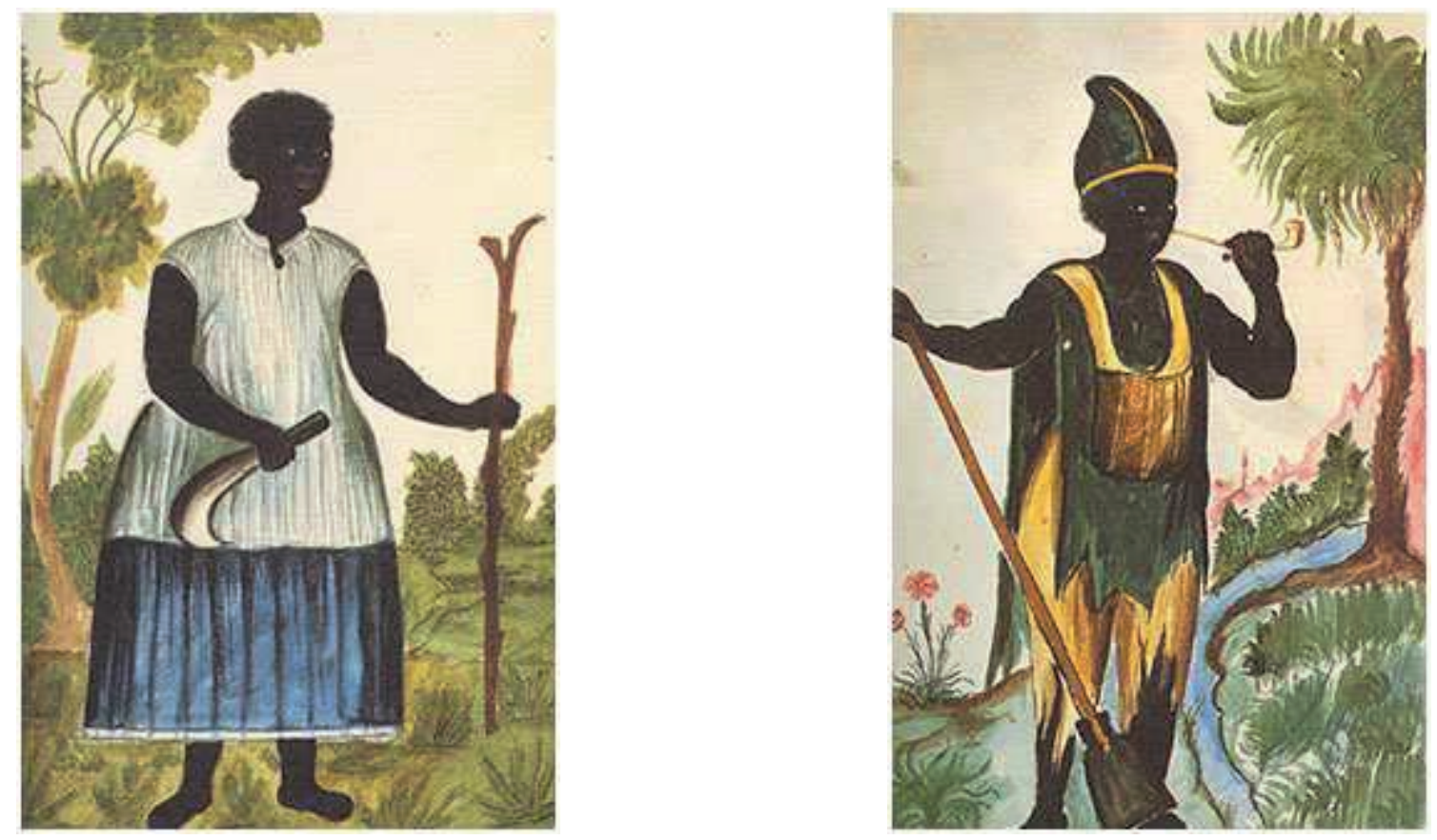

Figura 23 y Figura 24. Una negra y un negro, según acuarelas del obispo de Trujillo y cronista, Martínez Compañón. Primera mitad del siglo XVIII.

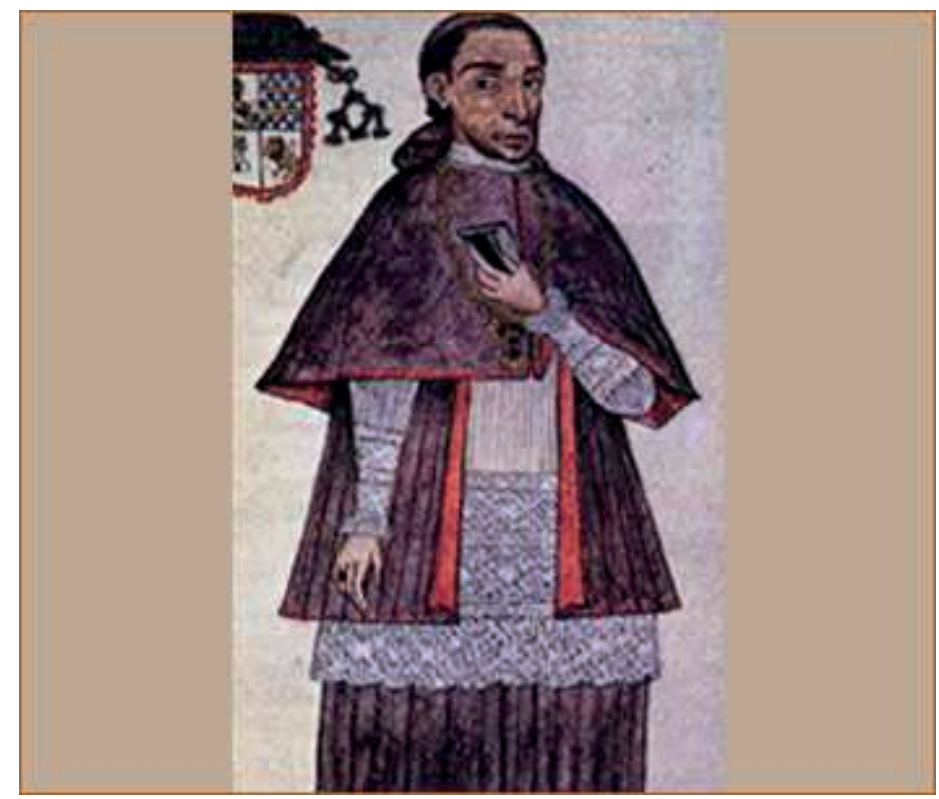

Figura 25a. Juan Santos Atahualpa. Estudió con los jesuitas en el Cusco y gracias a ellos viajó por España, Francia, Inglaterra y Angola. Se dice también que además del castellano y el quechua, hablaba el latín y varios dialectos selváticos. 
Acuarela de Martínez Compañón. El siglo XVIII en el Perú - Rebeliones indígenas.

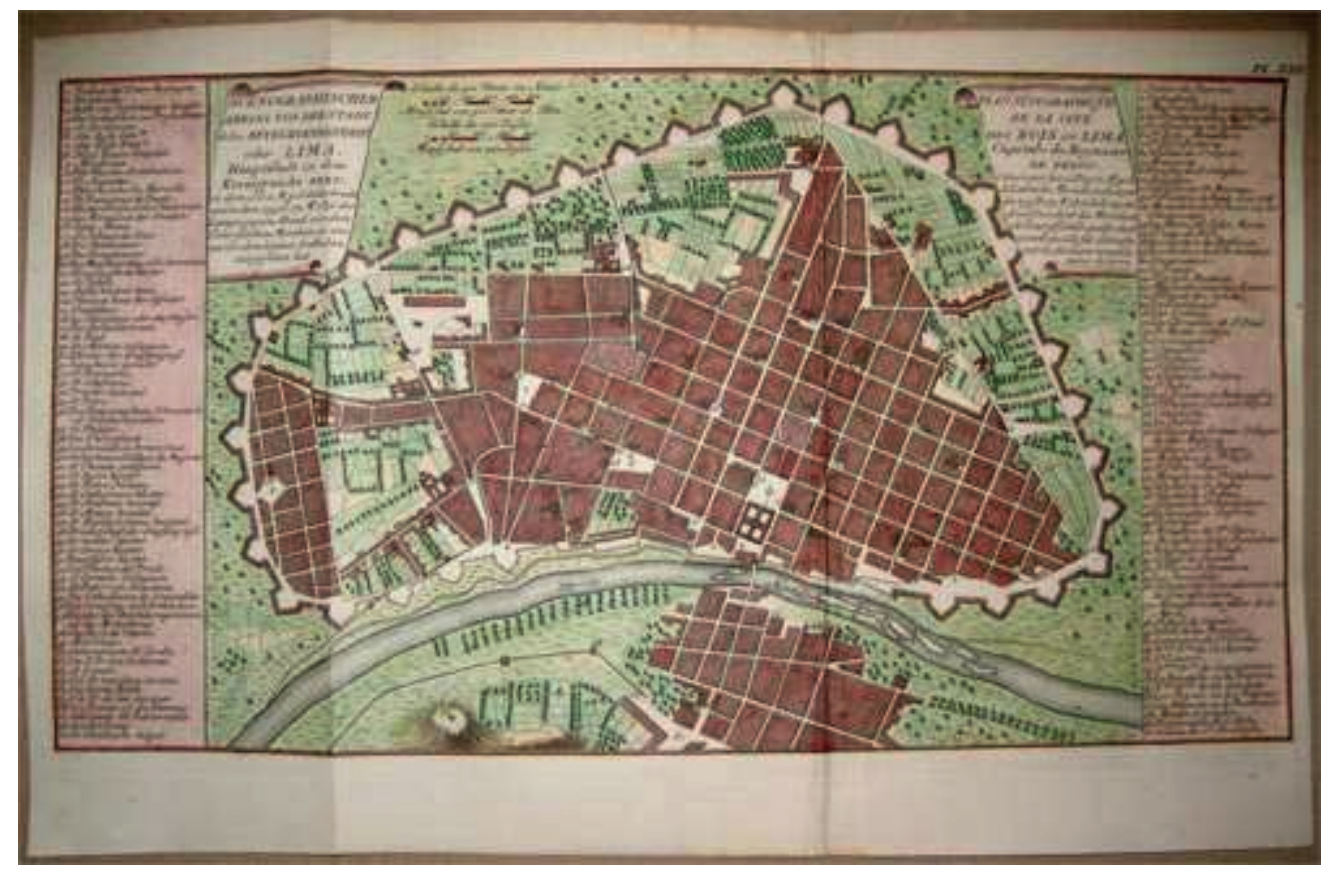

Figura 25b. Plano de la ciudad de Lima amurallada en 1750. Ilustración del cartógrafo francés Nicolas Jaques Bellin. Vikipedia.

Segunda mitad del S. XVIII

El triángulo de las penas. Las sociedades de indias orientales españolas, portuguesas e inglesas organizan en el Atlántico la llamada ruta triangular del comercio de esclavos, que empezaba en la costa oeste de África, de allí se dirigía a La Española, llevando esclavos que eran comercializados aquí. Luego, la ruta seguía hasta Boston, llevando a los africanos vendidos o comprados en el Caribe. Finalmente, los mismos traficantes regresaban a África para repetir el proceso.

1750 y ss.

Braceros y mayordomos. En el campo, los esclavos eran mucho más numerosos que en las zonas urbanas, sobre todo en la costa. En estos años, la proporción español- 
esclavo en Lima podía llegar a 1-34 (es decir, 34 esclavos por cada castizo de la ciudad), mientras que, en algunas haciendas, esta cifra era mucho mayor, así, por ejemplo, en el norte chico -Chancay, Huaral, Huacho, Huaura, Barranca, Pativilca, etc-, la proporción podía llegar a 1-600; las cifras se justifican, pues había hacendados dueños de cientos de trabajadores esclavos que laboraban sus tierras. Por otro lado, las relaciones ente amo y esclavo era mediante el mayordomo que, generalmente, era un mulato. En este periodo, el promedio de esclavos por chacra iba de 6 a 7 hombres, hasta 120, aunque había haciendas, como las de Villa, San Pedro y Surco (sur de Lima), que alcanzaban a tener 400 esclavos. Cabe resaltar que, cuando los jesuitas fueron expulsados de las colonias españolas en 1767, éstos mantenían haciendas cuya población de esclavos sobrepasaba los 5.000 individuos.

1762

La Habana (Cuba) se ha convertido en el mayor puerto negrero del mundo, y así seguirá siéndolo durante casi todo ese siglo y el siguiente. Su comercio negrero es un emporio tanto en la recepción de esclavos como en la organización de viajes de la trata.

1768

El 10 de agosto de este año estalla una revuelta en la Hacienda San Jacinto (Valle de Nepeña - Ancash), liderada por dos esclavos negros, Francisco Margarito (Hacienda San José) y Lorenzo Mombo (Hacienda San Jacinto).

1770

Figura 26 
1. Población negra en América a fines del siglo XVIII

$\begin{array}{llll}\text { Región } & \text { esclavos } & \text { libres } & \text { total } \\ \text { Brasil } & 1.000 .000 & 399.000 & 1.399 .000\end{array}$

Caribe no ibérico.

Colonias francesas

Colonias inglesas

Estados Unidos

América Hispana*

Totales
575.000 467.000

575.420

271.000

2.888 .420
30.000

13.000

32.000

650.000

1.124 .000
1.085 .000

607.420

921.000

4.012 .000

*Esclavos en México y América central, 19.000; Panamá, 4.000; Nueva Granada, 54.000; Venezuela, 64.000; Ecuador, 8.000; Perú, 89.000; Chile, 12.000; Río de la Plata, 21.000

Estos cuadros estadísticos de la esclavitud negra en América explican no poco algunas cuestiones comparativas, pues las enormes diferencias cuantitativas que se aprecian de unas a otras regiones proceden y al mismo tiempo causan ciertas diferencias cualitativas.

Fuente: Algunas notas sobre la esclavitud en América. Revista Arbil, anotaciones de pensamiento y critica. \# 42 (Nota_36)

Los modelos raciales. En su afán de disociar los diferentes grupos étnicos -producto de los infinitos cruzamientos entre individuos de color y entre éstos y gente de otras razas-, que poblaban el territorio del virreinato del Perú, don Manuel de Amat y Junyet, vigésimo quinto virrey del Perú (1761 - 1776), optó por diseñar una sarta de clasificación, en la que el blanco occidental pasó a ser el "modelo" racial al cual aspirar; de esta forma se elaboró, hasta inicios de la república (1800), una serie de 
parámetros étnicos para cada color de piel o tipo racial; y así, como explica el CEDET, había el mestizo prieto, negro chino, mulato, mulato claro, mulato oscuro, mulato morisco, mulato pardo, mulato lobo, tercerón, cuarterón, zambaigo, chino, rechino, chino prieto, chino claro, zambo, zambo claro, zambo prieto, "ahí te estás", "tente en el aire", "salto atrás", "no te entiendo", sacalagua, etc.(Nota_37)

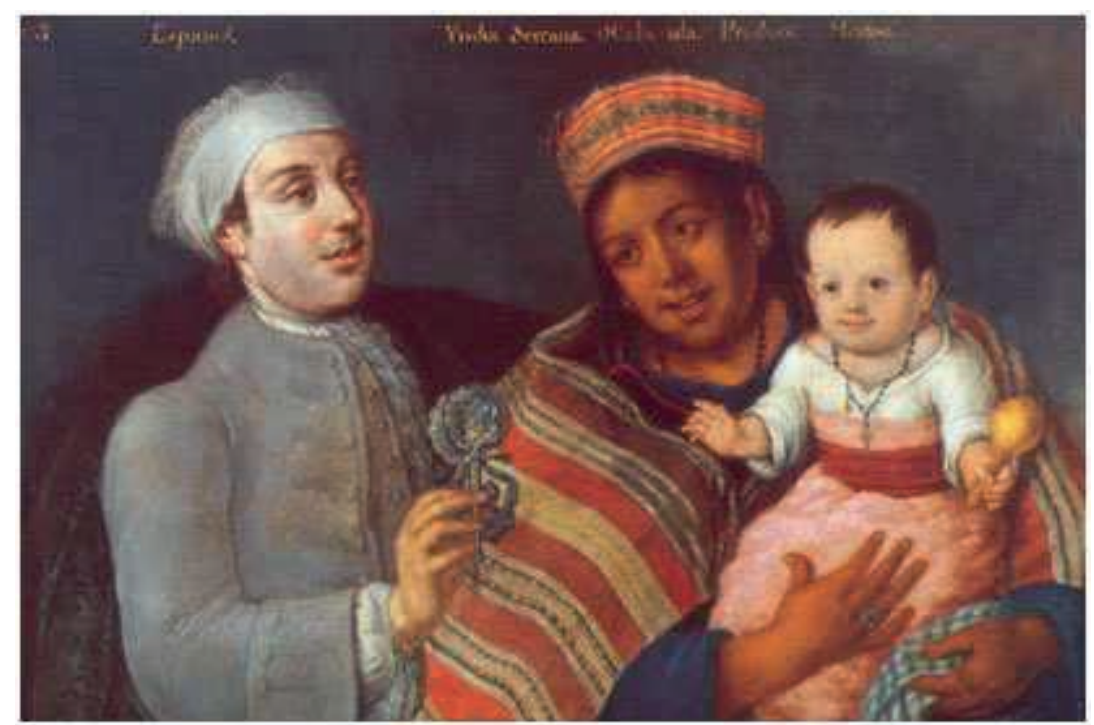

Figura 27. Los modelos raciales 1 (un detalle). Español. Yndia Serrana o café(t)ada. Produce Mestizo". De los lienzos sobre castas remitidos por el virrey Manuel Amat al rey Carlos III en 1770. Los cuadros de mestizaje del Virrey Amat. La representación etnográfica en el Perú colonial. Museo de Arte de Lima. 2000. 


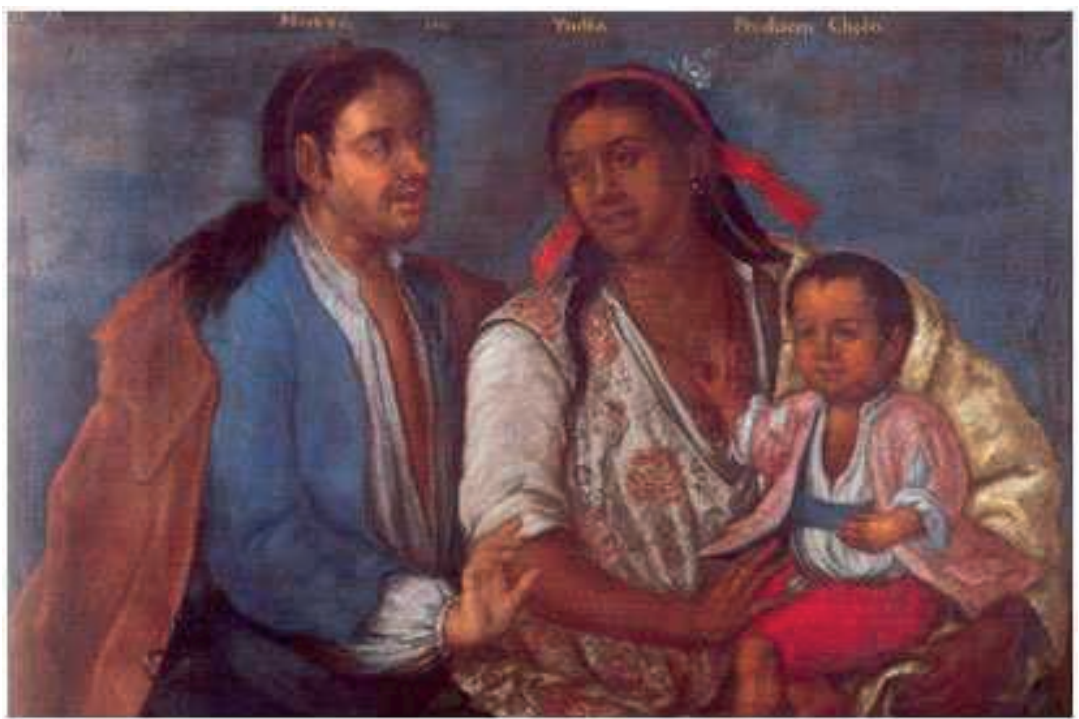

Figura 28. Los modelos raciales 2 (otro detalle). "Mestizo. con Yndia. Producen cholo". De los lienzos sobre castas remitidos por el virrey Manuel Amat al rey Carlos III en 1770. Los cuadros de mestizaje del Virrey Amat. La representación etnográfica en el Perú colonial. Museo de Arte de Lima. 2000.

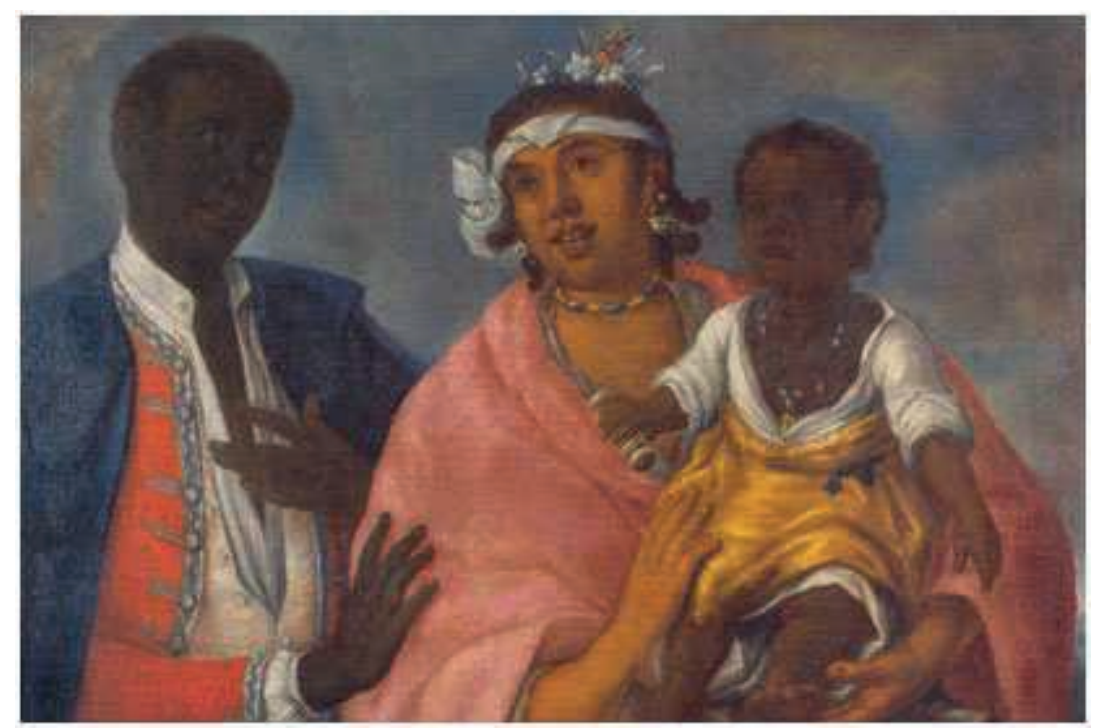

Figura 29. Los modelos raciales 3 (y este...). "Negro. con Mulata. Producen Sambo". De los lienzos sobre castas remitidos por el virrey Manuel Amat al rey Carlos III en 1770. Los cuadros de mestizaje del Virrey Amat. La representación etnográfica en el Perú colonial. Museo de Arte de Lima. 2000. 
1773

El marqués de Casa Erile tiene el monopolio de la introducción de negros en la isla de Cuba.

$1777-1778$

En virtud de los tratados de San Ildefonso y del Pardo, Portugal cede a España la temida isla de Fernando Poo, en realidad dos "pedruscos" basálticos de 2.017 kilómetros cuadrados, situados en el Golfo de Biafra, en Guinea Ecuatorial, para edificar allí una factoría para la trata negrera. Fue el infierno de los negros capturados por los españoles en el África occidental.

1779

29 de noviembre. Los esclavos Domingo Chillón, Estanislao Criollo y Úrsula Conga encabezan un levantamiento en el ingenio azucarero de San José de la Pampa (Santa - Ancash).

1780 a 1790

Nuevo periodo de auge del transporte y el comercio de esclavos desde África hasta el Nuevo Mundo. 


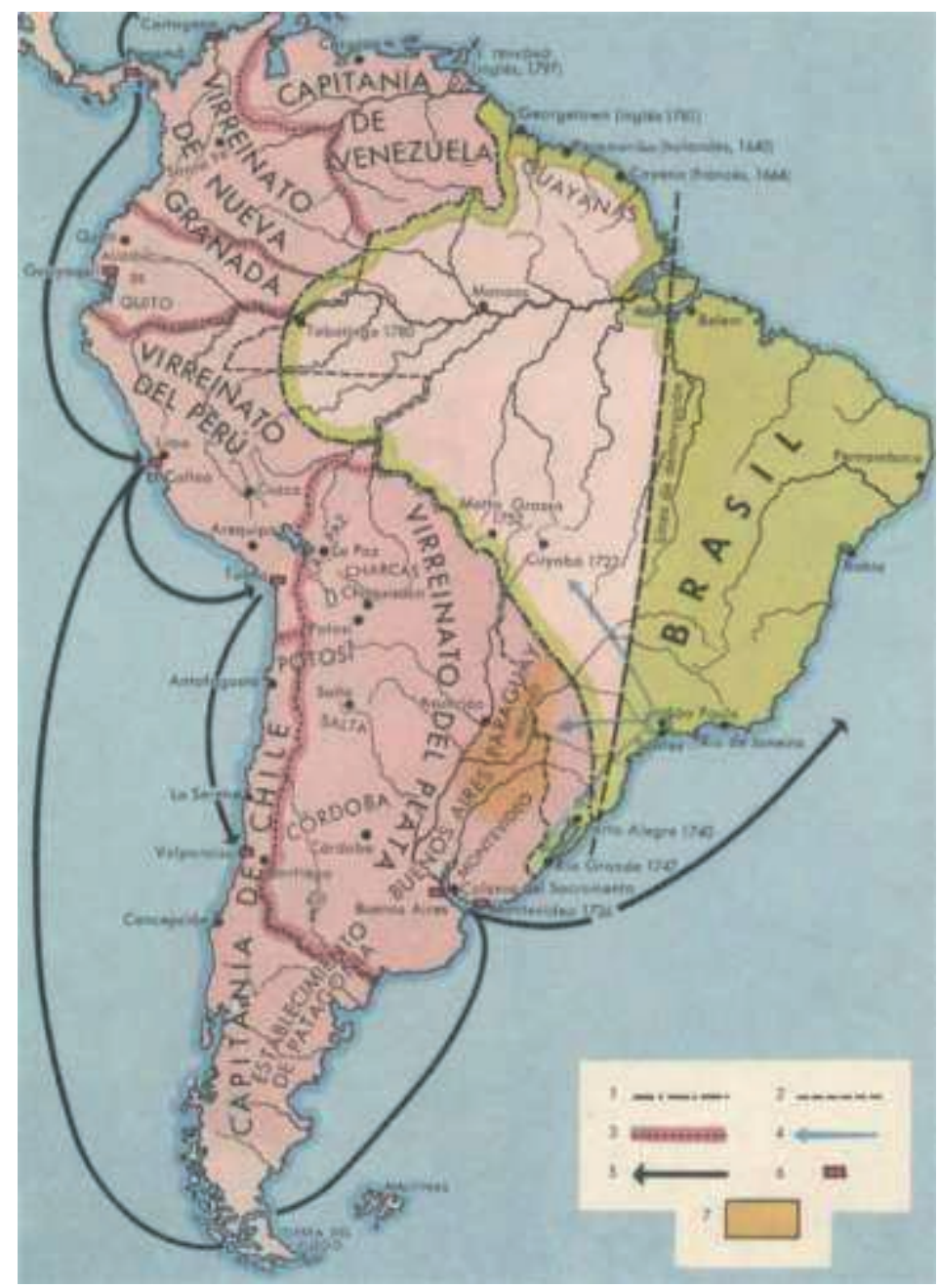

Figura 30. América del Sur después de 1750. Notas del mapa:

1) Límite entre las colonias españolas y portuguesas a comienzo del siglo XVIII;

2) Íd. del Tratado de Madrid de 1750, rectificado en 1777;

3) Límites administrativos coloniales;

4) Expansión de los "bandeirantes";

5) Rutas del comercio marítimo;

6) Puertos habilitados para el comercio con la metrópoli;

7) Territorio de las misiones jesuitas.

Tomado de Mapas de Historia Universal. Mapa LIX. América del Sur en el Siglo XVIII. 
$1780-1781$

Debido el mal gobierno, los tributos excesivos, la explotación en mitas y obrajes y los abusos cometidos por los españoles, estalla en la región del Cusco (valle de Tinta) el levantamiento indígena más grande jamás visto en el Perú colonial después de la gesta de Manco Inca y su sucesor Tupac Amaru I (n. 1536 - m. 1572): la Rebelión de José Gabriel Condorcanqui, Tupac Amaru II (n. 1738 - m. 1781), curaca de Surimana, Tungasuca y Pampamarca. (Nota_38)

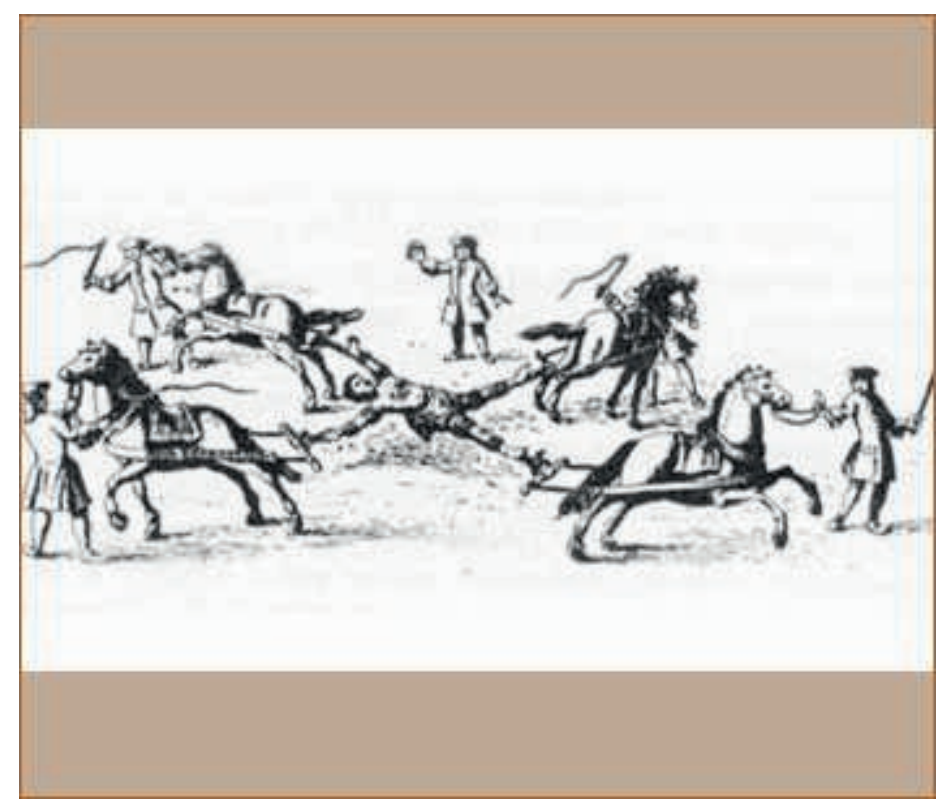

Figura 31. Muerte de Tupac Amaru II. El 18 de mayo de 1781, José Gabriel Condorcanqui fue ejecutado en la Plaza Mayor del Cusco. Fue condenado a ser descuartizado por cuatro caballos. Ilustración de época.

1783

3 de septiembre. El tratado de Versalles pone punto final a las disputas por la isla de Goree, entregándole a Francia la soberanía definitiva sobre este territorio. 
El alma en un costal. Daniel Contreras en su trabajo Esclavos y el castigo en el Perú colonial y republicano, basado en una investigación histórica, nos habla de las condiciones a que eran sometidos los esclavos negros en la ciudad de Lima. Llegaban de Panamá o Cartagena de Indias al Callao. Desde ahí eran transportados a Malambo, una suerte de depósito en el Rímac donde se cumplía la cuarentena y la espera de la venta y la subasta. La expresión "Alma de boca" significaba que un esclavo era vendido con todas sus facultades físicas y mentales, aunque si se le denominaba "costal de huesos" lo definía como enfermo o con alguna discapacidad. Todos los esclavos tenían una marca, una quemadura hecha en la piel con hierro candente, denominada "carimba", norma abolida en 1784.

Tras la aparición del Diario de Lima, las ofertas no dudaban en imprimirse a la caza de nuevos esclavos. En la edición del 16 de mayo de 1792 se anunciaba "Ventas. Quien quisiere comprar una criada preñada en días de parir, bozal, reformada, ocurra a la calle de Bodegones la primera casa, donde fue café. Arriba en los altos vive su ama en la segunda mampara". Esclavos desde la placenta. (Nota_39 Nota_40) 


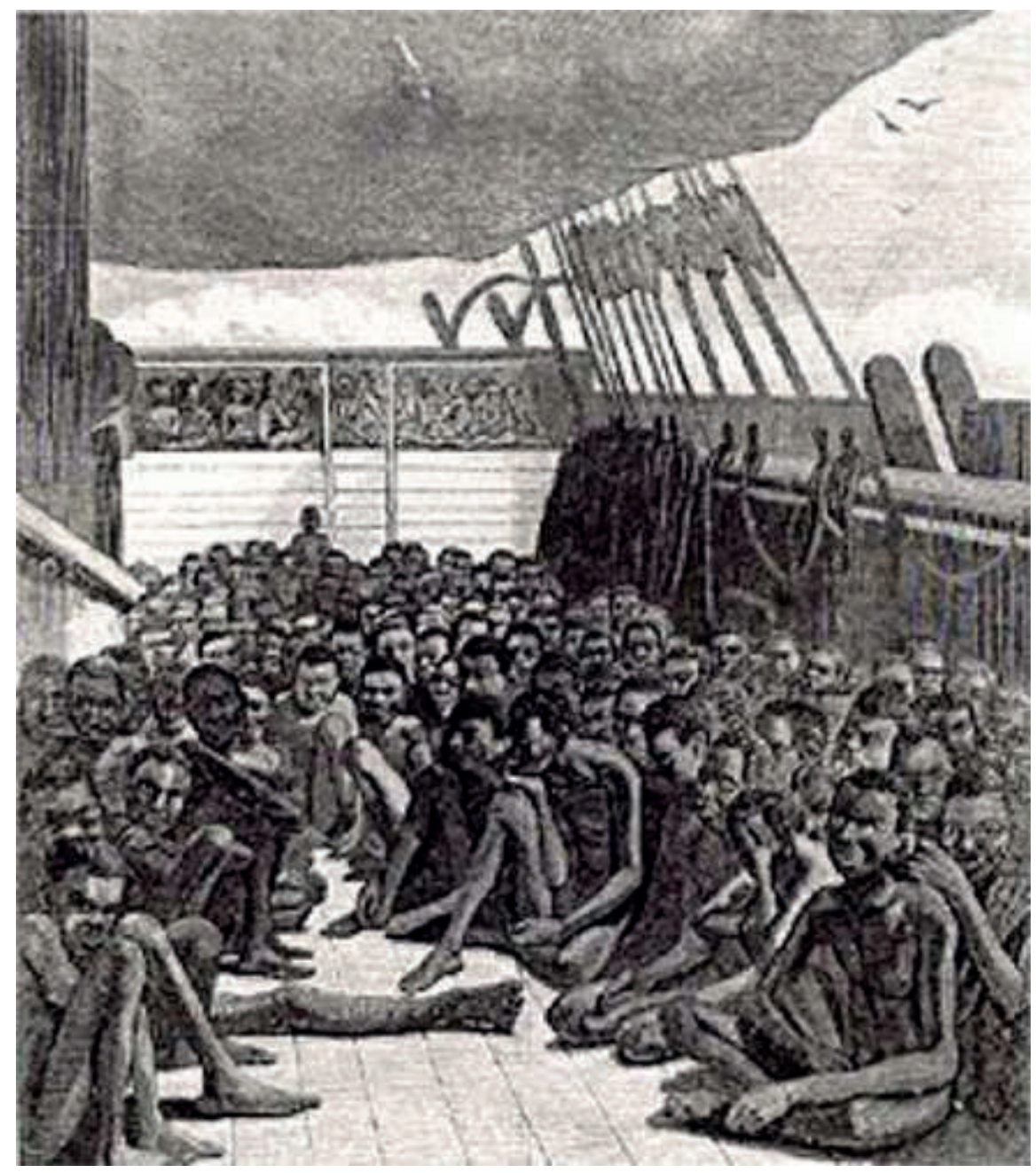

Figura 32. Los esclavos llegaban al Callao en navíos generalmente fletados por los traficantes negreros. La escena corresponde a un barco portugués procedente de Angola y Congo, del siglo XVIII. Tomado del sitio Web Capoeira Angola Center of Mestre João Grande, portal de uno de los cultores más importantes de la música afrobrasileña.

1786

Estalla otra revuelta, otra vez de negros, en la Hacienda Motocachi, en el valle de Nepeña (Ancash). 
Erile es reemplazado por la casa Baker y Dawson en el "negocio" negrero en La Habana (hasta 1789).

1787

La fobia del virrey. Debido a los constantes alzamientos de caudillos indígenas que pretendían restaurar el viejo orden incaico, Teodoro de la Croix (1784 - 1790), vigésimo octavo virrey del Perú, decide abolir el cargo hereditario de los curacas y prohibir la usanza de la vestimenta real incaica, además, penó la exhibición de toda iconografía o pintura alusiva a los incas.

Anti esclavista. Bajo la presencia de Greenville Sharp, se forma el primer comité inglés para la abolición de la esclavitud.

Marzo de ese año en la ciudad de Londres. Clarkson y un grupo de colaboradores, entre estos Sharp y Ramsay, fundan la primera asociación inglesa para la abolición de la esclavitud. Con el apoyo de Lord Abraham, consiguieron que el diputado William Wilberforce se conviertiera en el líder político de este movimiento.

Los primeros en volver a casa. Los ingleses ocupan Sierra Leona para repatriar a esclavos negros leales.

1789

España. Como parte de las Reformas Borbónicas iniciadas por su padre, Carlos III (n. 1718 - m. 1788), Carlos IV (n. 1748 - m. 1819) firma una trascendental "Real Cédula de su Magestad concediendo libertad para el comercio de Negros con las islas de Cuba, Santo Domingo, Puerto Rico, y Provincia de Caracas, a Españoles y Extrangeros." De 
este modo, España rompía de este modo su monopolio mercantilista de seres humanos en Iberoamérica a favor de las otras potencias.

La palabra de la libertad. Al mando de la sociedad antiesclavista inglesa, Wilberforce presenta una moción en la cámara de los Comunes, cuyo voto fue aplazado por quienes se oponían su objetivo de abolir la trata, es decir, la captura y venta de esclavos negros africanos. Consideraban que acabar con la trata significaba el fin de la esclavitud.

1791

Bajo el espíritu de la Real Cédula de 1789, España autorizaba a cualquier ciudadano hábil a comprar esclavos en cualquier lugar con escritura pública. Esto permitió abrir el mercado en las colonias. En el Perú, por ejemplo, los hacendados comenzaron a encargar directamente a compañías negreras la adquisición de "piezas de ébano" para trabajar sus tierras, o simplemente se dirigían a un mercado de esclavos, donde estos eran ofrecidos al mejor postor.

Los esclavos se rebelan en Haití. En 1804 declararían su independencia.

La negritud en Lima. Según el censo ordenado por Francisco Gil de Taboada y Lemos, vigésimo noveno virrey del Perú (1790-1796), había 40.347 esclavos negros y mulatos en todo el virreinato del Perú, es decir, el 3,7\% de la población total. La mayor parte de éstos estaba concentrada en la región de la costa.

Las denominaciones de Terranovos, Minas y Véngueles procedían de los puertos de embarque o llegada; muchos Ashantis, Ewes o Yorubas eran denominados Minas por el fuerte El Mina en Ghana. En 1791 el Mercurio Peruano señalaba que " las castas 
principales de los negros que nos sirven son diez: la de los Terranovos, Lucumés, Mandingas, Cambundas, Carabalíes, Cangaes, Chalas, Huarochiríes, Congos y Mucangas". A fines del virreinato arribaron a Lima mozambiques y tanganicas por el puerto de Buenos Aires.(Nota_41)

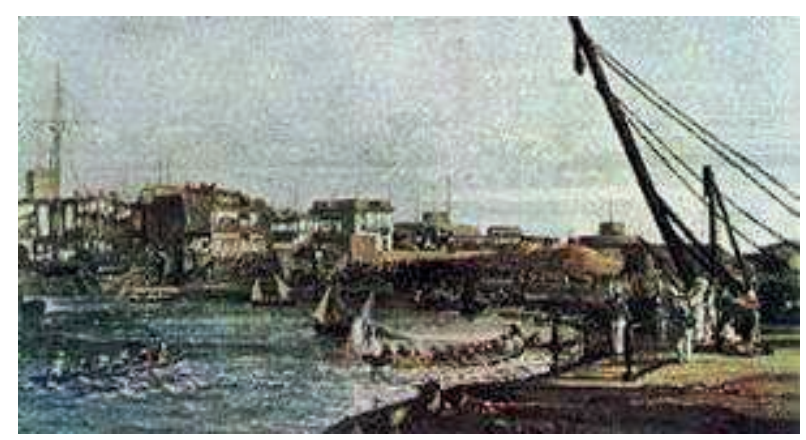

Figura 33. El puerto del Callao en una acuarela del Siglo XVIII. Tomado del portal Todo Callao - Fotos antiguas del Callao - Revista Cosas y Casos de La Punta.

1792

Dinamarca suprime la trata de negros.

1793

Según documentos de la época, en el Perú había una población de negros y pardos de 81.841 habitantes, y a fines del siglo XVIII eran unos 100.000. (Nota_42)

1794

4 de febrero. La Convención Francesa vota la abolición de la esclavitud negra en las Antillas Francesas. 
1795

Inglaterra arrebata el Cabo de Buena Esperanza a los holandeses. Con ello el territorio de Sudáfrica pasa a formar parte del imperio británico.

1797

Según una fuente de ese año, el 28\% de los 61.910 habitantes de la Lima de ese entonces eran esclavos (17.881)

1799

El 27 de mayo estalla una revuelta de negros a bordo del navío Santo Domingo encabezado por Babo, un esclavo procedente de Senegal que pretendía regresar al África, pero éste es debelado y los rebeldes juzgados en Lima, en septiembre de ese mismo año.

1775 a 1800

Libertos y esclavos en el virreinato del Perú. La población liberta en todas sus variedades étnicas: negros, pardos, mulatos, zambos, cuarterones, quinterones etc., se encontró diseminada a nivel colonial-nacional, con preeminencia en la costa central, superando ampliamente en algunos lugares en número a los esclavos, con quienes siguió manteniendo relaciones amicales, de vecindad y parentesco. La documentación demuestra que no existió mayor separación del liberto con relación al esclavo, no obstante su situación jurídica diferente de ambos sectores sociales. Abonaba a la unión de libertos y esclavos, la raza, el pelo ensortijado, nariz ancha, 
costumbres, sus cofradías, el aislamiento, discriminación racial y económica en que se encontraron ambos, lo que influyó para su acercamiento e identidad.

Lima. La opulenta capital del virreinato, concentró el mayor número de esclavos y libertos y ello es explicable porque en Lima residió la nobleza terrateniente-rentista, los más altos funcionarios civiles y eclesiásticos, comerciantes, artesanos e incluso indios que necesitaron, por conveniencias económicas o sociales, el uso de personas de color negroide, Además, Lima, como era obvio, concentraba también la mayor riqueza que procedía de todo el reino. Por ello, afirmar que en Lima la "gente de color" negra y liberta, bordeó a fines del siglo XVIII del 40 a 45\% de la población total es correcto: Pardos libres 10.231 (16.2611/6) esclavos 17.881 (28.42\%) de un total de 62.910 habitantes (Arrelucea 1999:58).

Arequipa. Diferente es la realidad en la ciudad de Arequipa, donde la presencia, tanto de esclavos como libertos, es poco significativa como puede observarse en el siguiente cuadro resumen: Tabla 5

Como se aprecia, existe un buen número de negros en calidad de libertos a nivel nacional-colonial, interesa saber ahora, cuáles son los mecanismos que permiten a los esclavos acceder a su libertad. La respuesta más sencilla, para algunos especialistas en el tema, es que los esclavos consiguen su libertad, comprándola mediante un dinero que proviene de su trabajo en diferentes sectores de la economía peruana en especial como "jornaleros" o en "huertos" concedidos por sus amos, lo que es cierto, pero, en nuestra opinión, no fue la vía más frecuentada para que los esclavos se conviertan en libertos. Considero que un buen porcentaje de esclavos lograron su libertad por la "gracia" de sus amos, tema que pasamos a desarrollar. (Nota_43)

Últimos años del S. XVIII 
Muy "caros". El próspero mercado de esclavos de Lima tenía tal vez los precios más altos por la mercadería humana en la región, así, un negro de entre 16 y 30 años, estaba cotizado entre 400 y 650 pesos (mientras que en Buenos Aires se pagaba por el mismo concepto unos 200 pesos). Un precio altísimo, si se toma en cuenta que, para ese entonces, una calesa sin caballos costaba 300 pesos. En 1800, un cerdo costaba 12 pesos, un esclavo 500, una esclava 350 y una niña 80 pesos. Al culminar las guerras de independencia, el precio mayor era de 400 pesos (cuando un precio de 200 ó 300 era considerado "muy alto"); después de la abolición, paradójicamente, los precios habían "bajado"Así, en Lima, se cobraba 333,5 pesos por un mozo negro y para una mujer 303,7 pesos. La edad promedio considerada óptima para comprar o vender a un hombre o mujer solía fijarse entre 20 y 25 años.

\subsection{Siglo XIX}

1800

Superpoblación. En las últimas décadas de la colonia, el partido de Lima (el actual departamento del mismo nombre) concentraba el 60\% de la población esclava del Perú, mientras que a la ciudad capital del virreinato le correspondía la tercera parte de este total.

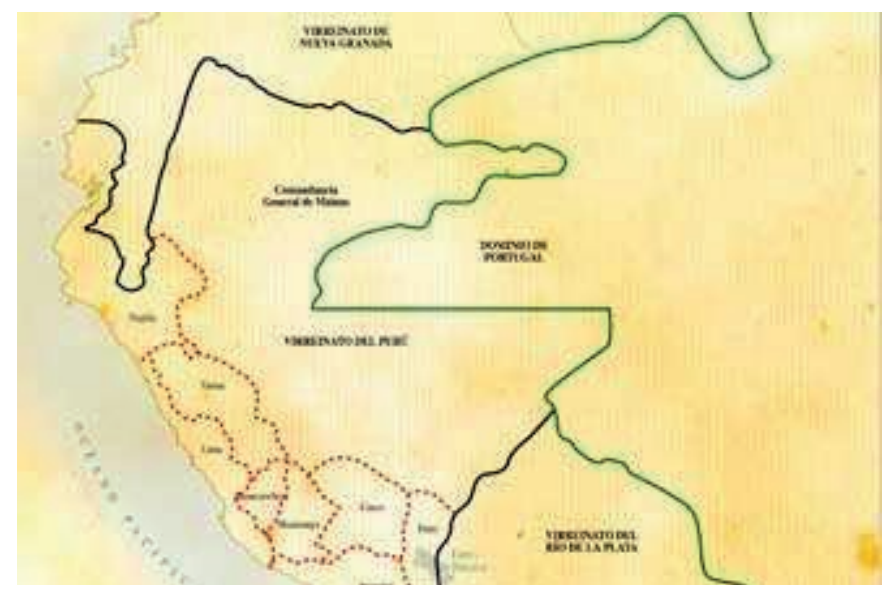

Figura 34. El virreinato del Perú en 1803. Detalle de las intendencias. Ilustración del portal La Independencia del Perú. Educared.edu.pe. 
Pierre-Dominique Toussaint Louverture, uno de los líderes de la revolución haitiana y gobernador de la provincia de Saint Dominique (n. ¿1743? - m. 1803), se apodera de La Española y acaba con la esclavitud. Era un negro liberto, cuyo padre había sido vendido al conde de Breda, un propietario muy humanitario que le dio la libertad a los 33 años. Se convirtió en un gran jinete y pronto dio muestras de su liderazgo. Después de participar en la independencia haitiana, se adueñó de Santo Domingo y decretó la abolición de la esclavitud. Se supone que era de la etnia arrada del África Occidental. Hoy día, Louverture es considerado un héroe nacional tanto para Haití como para República Dominicana.

1803

Dinamarca es el primer país moderno que prohíbe el comercio de esclavos.

1807

Desde 1700, el puerto de Liverpool es el mayor enclave negrero de Europa. Se hizo famoso por sus empresas especializadas en la trata, que tenían incluso sucursales de ultramar y sus propios astilleros para construir barcos a pedido del cliente. Sus tratantes enviaron un promedio de cuatro mil expediciones al continente negro durante 107 años. La abolición de la esclavitud por parte del rey inglés puso en jaque al "negocio". 
Inglaterra declara abolida la esclavitud mediante el Abolition Act, pero sin efectos hasta casi treinta años después. De paso, prohíbe el transporte de esclavos por mar en sus dominios.

1808

Los traficantes negreros no pueden introducir esclavos en los dominios del imperio británico.

Estados Unidos prohíbe la importación de esclavos.

$1809-1811$

Casi dos décadas después de la rebelión de Tupac Amaru II, en ese año estalló el levantamiento del Alto Perú. Chuquisaca y La Paz en 1809; los insurgentes fueron derrotados por los realistas en octubre de ese mismo año. Otros dos levantamientos estallaron en Guayaquil (1809) y en Quito (1811), el primero a favor del rey de España (Fernando VII) y el otro independentista: ambos fueron derrotados por tropas enviadas desde Lima por Fernando de Abascal (1813). A la par, surgieron otros levantamientos independentistas en Nueva Granada y el Río de la Plata (1810), también sofocados por el largo brazo de Lima. La capital del virreinato peruano seguía siendo el bastión realista en Hispanoamérica. Quienes entonces conspiraban contra la Corona se dieron cuanta de que la única forma de vencer al poder español era tomar la capital del opulento virreinato del Perú. 
Poderoso caballero es don dinero. Se estima que entre los años 1500 y 1810 llegó un millón de esclavos africanos a Hispanoamérica, cifra que es poca comparada con Brasil que, en ese mismo periodo, recibió a 2'5 millones de esclavos (Norteamérica sólo 350.000). Se importaban más hombres que mujeres, porque los esclavos varones tenían un precio más alto.

Miguel Hidalgo (n. 1753 - m. 1811) decreta la abolición de la esclavitud en México.

$1810-1811$

El mayor levantamiento ocurrido en el Perú por estos años fue el de Tacna. Este movimiento estuvo relacionado con los sucesos en el Alto Perú, donde las tropas bonaerenses avanzaban hacia el río Desaguadero. Mientras los argentinos se dirigían a Puno, un grupo de criollos tacneños, bajo el mando de Francisco de Zela, asaltó los cuarteles de la milicia realista el 20 de junio de aquel año. Pero la derrota de las tropas bonaerenses ese mismo día desbarató el alzamiento que fue debelado dos días después. Su líder fue apresado y fusilado por los españoles.

1811

Se establecen los primeros tribunales contra la trata en Sierra Leona. Muchos traficantes comenzaron a ser juzgados y enviados a prisión.

El 11 de octubre, el Congreso chileno publica un decreto sobre la libertad de vientres, es decir, todo aquel que naciera de una madre esclava, a partir de la promulgación de esta ley, era libre para todos sus efectos. 
Se sofocan rebeliones en Puerto Rico y Cuba, ante el temor de los esclavistas de que se repitieran en estas posesiones españolas los sucesos de Haití de comienzos del siglo XIX.

$1812-1813$

En febrero de 1812, un grupo de criollos e indígenas huanuqueños se levantaron en contra del régimen colonial. La inusual alianza entre indígenas y criollos, empero, se vino abajo cuando los segundos entraron en desacuerdo con los indígenas e incluso ayudaron a reprimirlos. Los indígenas yanaconas y unos cuantos tomaron la ciudad de Huánuco y la saquearon, además de ahuyentar a sus habitantes. En ese momento, la facción criolla y mestiza del movimiento se separa y se enfrenta a los indios en Huamalíes. Gracias a la existente militarización de la zona, desde la rebelión de Juan Santos Atahualpa, los realistas dieron fin al levantamiento en marzo de 1813. Sus cabecillas, Juan José Crespo y Castillo, José Rodríguez y Norberto Haro, fueron ejecutados.

El empadronamiento realizado por estas fechas en el Perú, arroja un $21 \%$ de esclavos en la ciudad de Lima.

1813

El 3 de octubre de ese año ocurre otro levantamiento en Tacna, también relacionado por una incursión rioplatense por el Alto Perú (1812), bajo el mando de Manuel Belgrano, que tomó Tacna; pero, como en la anterior oportunidad, los bonaerenses fueron vencidos en noviembre de ese año por las tropas lideradas por Joaquín de la Pezuela, lo que provocó el fin del levantamiento y la fuga de sus líderes al Alto Perú. 
1814

Milenarismo y rebelión. El levantamiento del Cusco de ese año fue el más importante por su envergadura y, sobre todo, por involucrar a la antigua capital de los incas. En este movimiento, los hermanos Vicente y José Angulo, Gabriel Béjar, Manuel Hurtado y el clérigo José Días Feijóo, miembros de la clase media criolla y mestiza educada y letrada, se rebelaron en contra de la Audiencia del Cuzco, al no acatar la Constitución liberal de 1812, y por implantar un régimen absolutista que limitaba sus derechos. Rápidamente, Mateo Pumacahua convocó a los indígenas para que se unieran al movimiento y se dieron manifestaciones de nacionalismo indio, a la vez que los líderes explotaban los códigos andinos milenaristas, pues tenían la idea de crear un imperio independiente al de Lima, con sede en el Cusco. Este gran movimiento terminó siendo reprimido el 11 de marzo de aquel año, en la batalla de Umachiri, y sus líderes fueron ejecutados, incluyendo los hermanos Angulo, el cacique Mateo Pumacahua, antiguo aliado colonial durante la rebelión tupacamarista, y el conocido poeta arequipeño Mariano Melgar, quien luego fue fusilado. La envergadura de este movimiento fue tal que algunos investigadores han afirmado que, si el apoyo de los criollos hubiese continuado, lo más probable es que la rebelión del Cusco hubiera logrado una victoria en contra del poder central, consiguiendo así la caída del régimen virreinal limeño y, por consecuencia, la independencia de España. Jorge Basadre escribe que, de no haber mediado una mayor cohesión entre sus componentes, esta rebelión habría logrado la creación de una república multiétnica, mucho más popular que la que se concibió después de 1821.

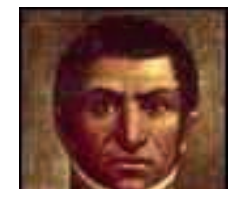


Figura 35. El prócer indígena Mateo Pumacahua (n. 1748 - m. 1815). Fue fusilado tras participar en el mayor levantamiento precursor de la Independencia del Perú en el siglo XIX. Ilustración del portal Peru.com.

Portugal suprime la esclavitud al norte del Ecuador, pero la mantiene en Brasil y otras de sus posesiones.

Declaración de las Potencias para la abolición de la trata de negros (Viena, 8 de febrero de 1815). Los países que firman son: Austria, España, Francia, Gran Bretaña, Noruega, Portugal, Prusia y Suecia. Pero también se afirma que esta "Declaración no debe influir en el término que cada Potencia participante juzgue conveniente fijar para la extinción definitiva del comercio de negros" (Mesa 135). (Nota_44)

"El rey del monte" fue un esclavo negro fugado que formó una banda para dedicarse al pillaje. Éste fue el bandolero más famoso del Perú colonial y, por varios años, puso en jaque a hacendados y españoles de la región de Lima. Convertido en una verdadera leyenda -una simbiosis entre bandolero y "Robin Hood" a la vez-, este personaje era hijo de mamá Salomé, una negra apodada la reina de los terranovos limeños, quien, por el año 1799, se hizo célebre porque repartía parte de lo robado a los pobres. Apresado en una celada, el bandolero fue fusilado frente al Callejón de Petateros -hoy Pasaje Olaya - , en la Plaza Mayor de Lima. 


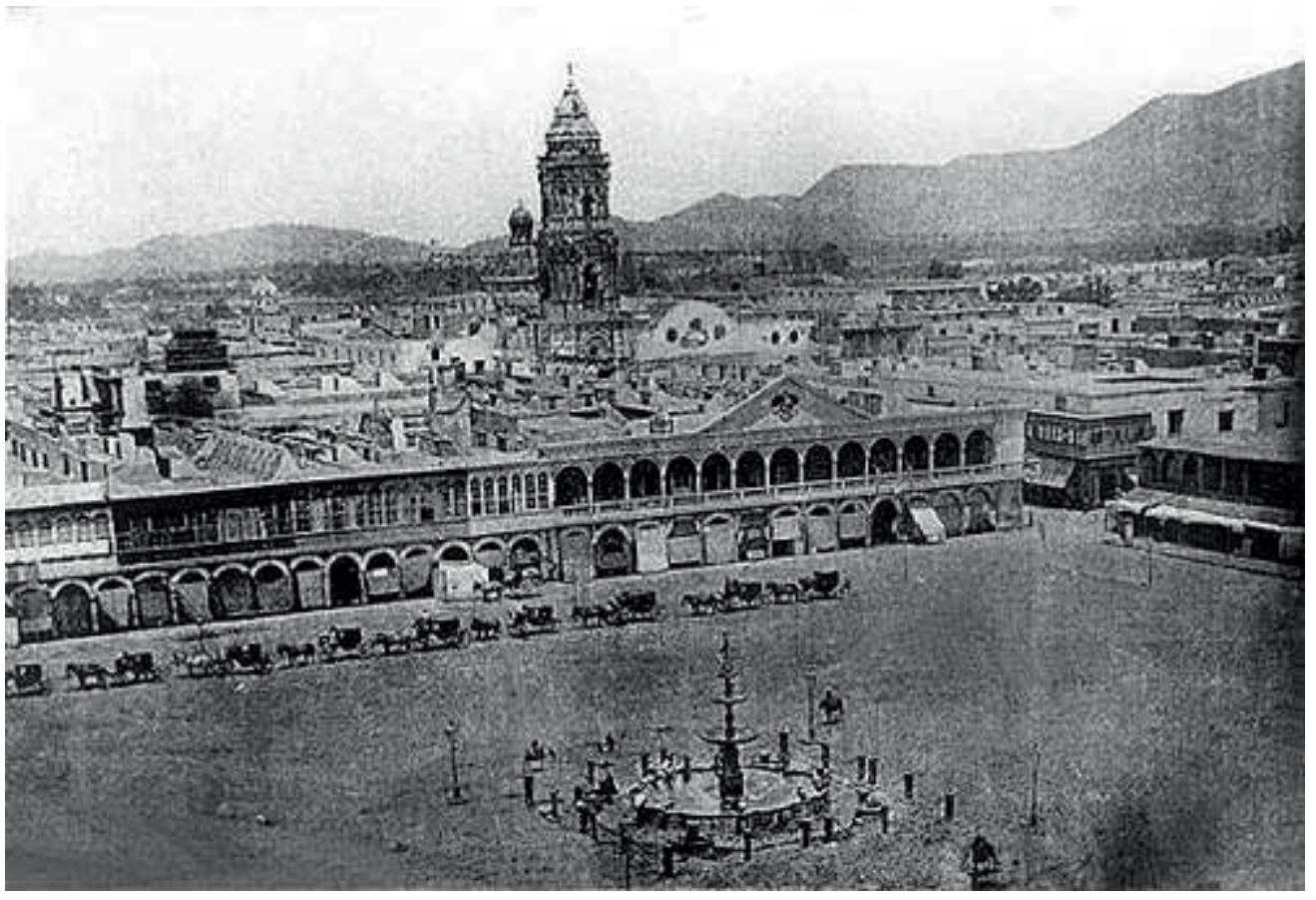

Figura 36. La Plaza Mayor de Lima a mediados del siglo XIX con la fachada de la Municipalidad y, al costado centro-izquierdo, la entrada al Callejón de Petateros, hoy conocido como Pasaje Olaya. Este callejón tenía la triste fama de ser el lugar donde se ajusticiaba a los condenados por algún delito grave. A la derecha se puede ver la calle Palacio -hoy Jirón de la Unión - y parte de los tendidos del viejo Palacio presidencial. Al fondo se aprecia la torre de la iglesia de Santo Domingo.

Ilustración tomada del Artículo: ¿Cuál Plaza? Revista Caretas, edición \# 1426 del 8 de agosto de 1996.

Suecia decreta el fin de la trata de negros en este país y en sus dominios de ultramar.

1816

Caracas. Un decreto de Simón Bolívar (n. 1783 - m. 1830) ordena la abolición de la esclavitud; vuelve a plantear la situación de la esclavitud en el "Discurso de Angostura" de 1819, y nuevamente en el Congreso de Cúcuta en 1821. (Nota_45) 
Comienzan a llegar las últimas "remesas" de barcos negreros al Callao. Es notorio el aumento del contrabando de esclavos debido a las restricciones que algunas potencias europeas han comenzado a imponer en el Atlántico.

España firma con Inglaterra un tratado internacional mediante el cual se comprometía a suprimir la trata y abolir la esclavitud en un plazo de tres años. El acuerdo, sin provisiones específicas, quedó únicamente en expresión diplomática. No fue hasta 1867 cuando se publicó un decreto condenando e imponiendo penas para el tráfico negrero; para estas fechas los esclavos en Cuba habían ascendido de 199.145 en 1817, a 369.000 en 1867. (Nota_46)

Una Real Cédula, del 17 de diciembre de ese año, de la Corona española prohíbe definitivamente la compra de esclavos negros en las costas de África.

1818

El 18 de marzo de aquel año llega al Callao la fragata "Rita", con el último cargamento oficial de esclavos africanos a Lima. El navío tenía registro del puerto de Santander, norte de España, y había recalado en África para traer su "mercadería".

En Chile, en el Proyecto de Constitución Provisoria de 1818 se reitera el decreto de 1811 sobre la libertad de vientres: "Artículo 12.- Subsistirá en todo vigor la declaración de los vientres libres de las esclavas, dada por el Congreso, y gozarán de ella todos los de esta clase nacidos desde su promulgación." (Nota_47) 
Dimensiones del más grande de los comercios de esclavos: Hacia 1818 casi la mitad de la población de Brasil, que se componía de 4.000 .000 de habitantes, era de esclavos, en 1847 más de la mitad de los 9.000 .000 de cubanos eran esclavos. Los franceses también se comprometieron en este comercio y llevaron muchos negros esclavos a Haití, donde en 1950 sólo 2.000 de los 3.500.000 habitantes de la isla eran blancos y el resto eran descendientes de esclavos. En 1560 John Hawkins introdujo en Inglaterra el negocio esclavista. Durante el s. XVII la English Adventure Trading Company utilizaba la mano de obra de esclavos negros en su industria de la caña de azúcar en las Indias Occidentales. En el período 1700-86 unos 610.000 negros fueron transportados a Jamaica y 2.130 .000 a otros lugares de las Indias Occidentales Británicas. El estallido de la Guerra de Independencia norteamericana dio fin, por algún tiempo, al comercio británico de esclavos en Norteamérica, donde los esclavistas habían ya transportado 500.000 personas. Pero el tráfico prosiguió y en 1800 había alrededor de 1.000.000 de esclavos negros en Estados Unidos, que en 1860 se convertirían en 4.500.000 dentro de una población total de 30.000 .000 de individuos. Los holandeses, que asolaban el África, vendían la mayor parte de los esclavos capturados a los españoles, y en el s. XVII, al conquistar Indonesia, esclavizaron a su población. (Nota_48) 


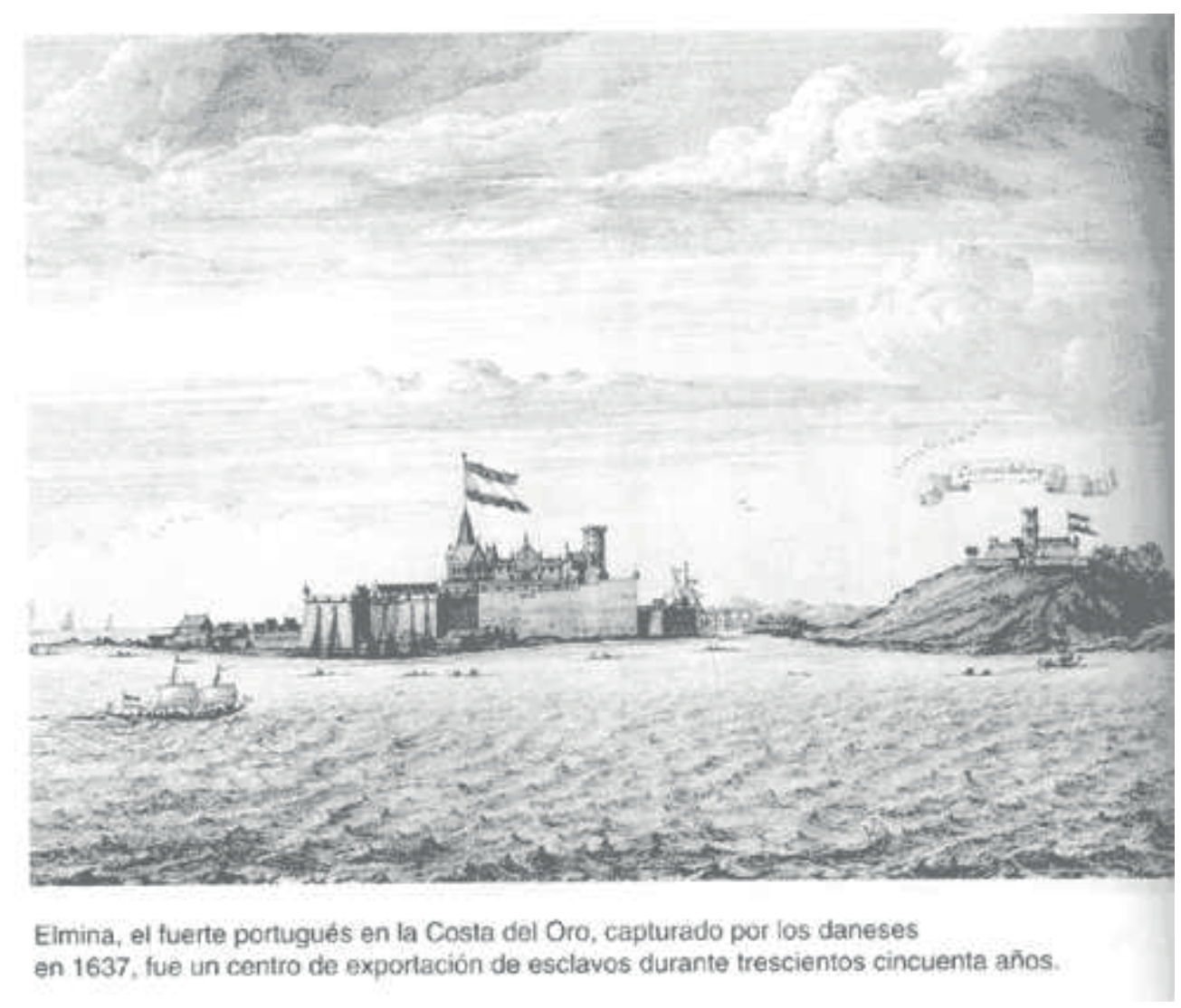

Figura 37a. De aquí partieron para no volver. Junto con Cape Coast, en la Costa de Oro (fundado por los ingleses en el Siglo XVII), el fuerte portugués de Elmina, que en 1637 cayó en poder de los daneses, fue el mayor centro de exportación de esclavos del África Occidental hacia América y otras latitudes durante 350 años.

Ilustración de Thomas Hugh, La trata de esclavos. Altres materials del tema 6. Escenas de la trata. 


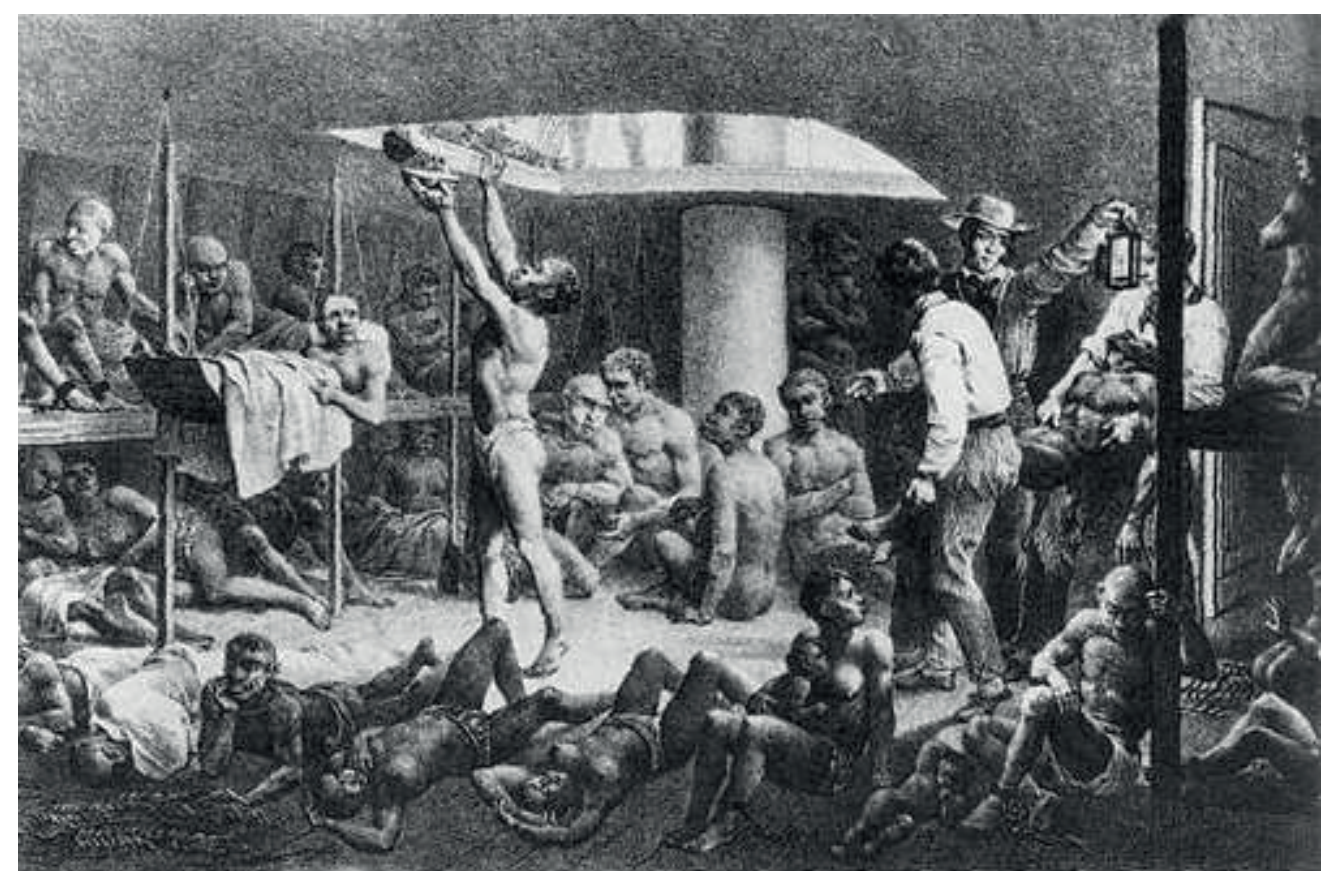

Interior de una bodega de esclavos (c. 1815).

Figura 37b. Interior de una bodega de esclavos en un barco negrero de la época (h. 1815). Ilustración de Thomas Hugh, La trata de esclavos. Altres materials del tema 6. Escenas de la trata.

1818 a 1847

En plena transición entre la época previa a la Independencia y la República, la paranoica imagen del miedo al complot negro sigue martillando a hacendados y gobiernos de turno. Esto se reflejó durante los procesos judiciales, seguidos entre 1827 y 1829, al negro libre Juan de Dios Algorta, quien fue acusado de complotar contra los blancos y conspirar contra el entonces Presidente conservador Agustín Gamarra (n. 1785 - m. 1841). 
Según el registro poblacional de ese año, había en Lima 8.589 esclavos, es decir, el 13\% de la población total. (Nota_49)

1821

Wilberforce constituye en Inglaterra la Sociedad Antiesclavista.

15 de julio. San Martín entra en Lima y es triunfalmente recibido. Firma del Acta de Independencia del Perú. (Nota_50)

28 de Julio. El general don José de San Martín proclama la Independencia del Perú con una célebre declaración. (Nota_51) 


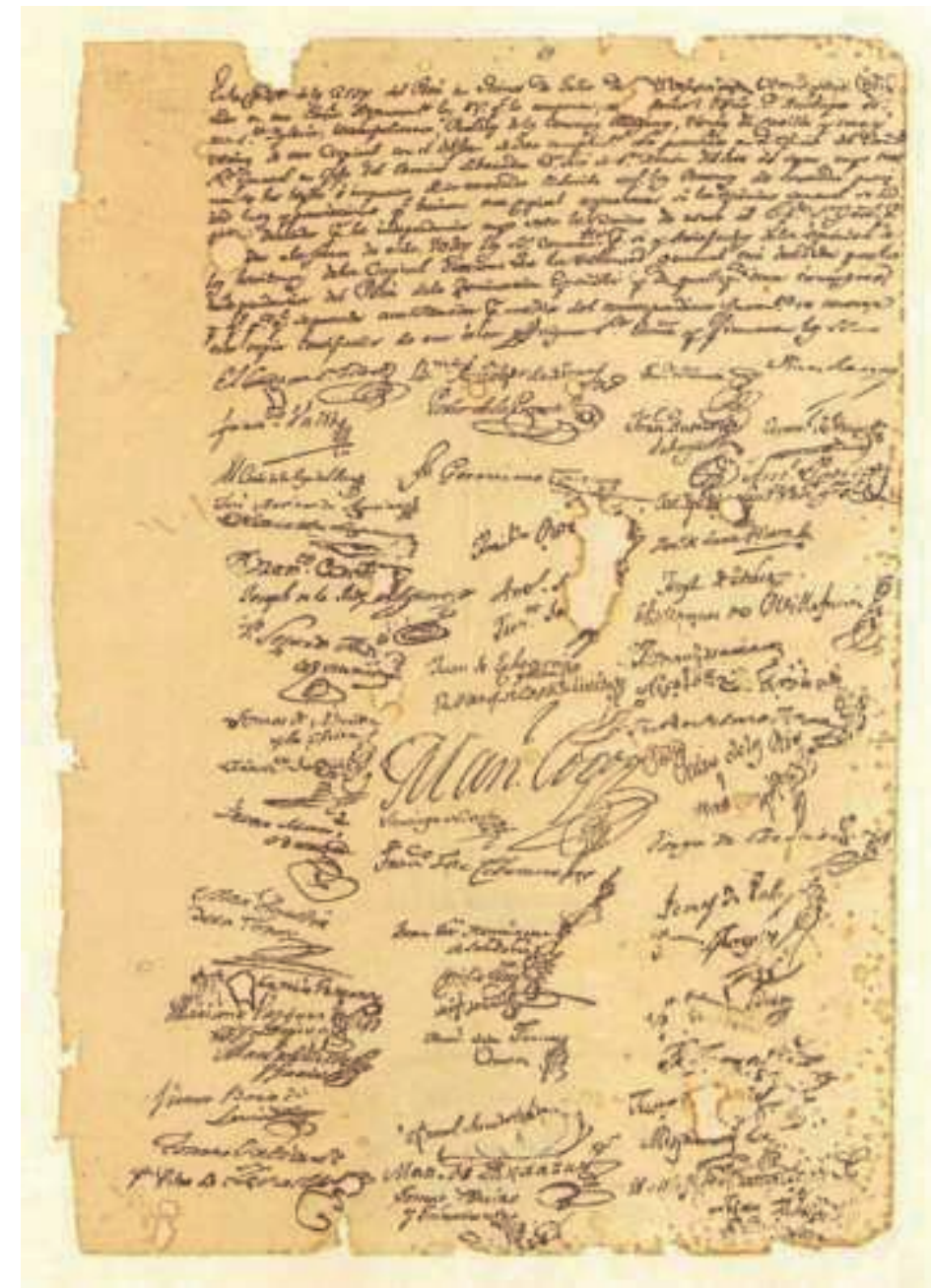

Figura 38a. Detalle del Acta de la Independencia del Perú. Manuscrito cuyo original se guarda en la Biblioteca de la Municipalidad de Lima Metropolitana. 


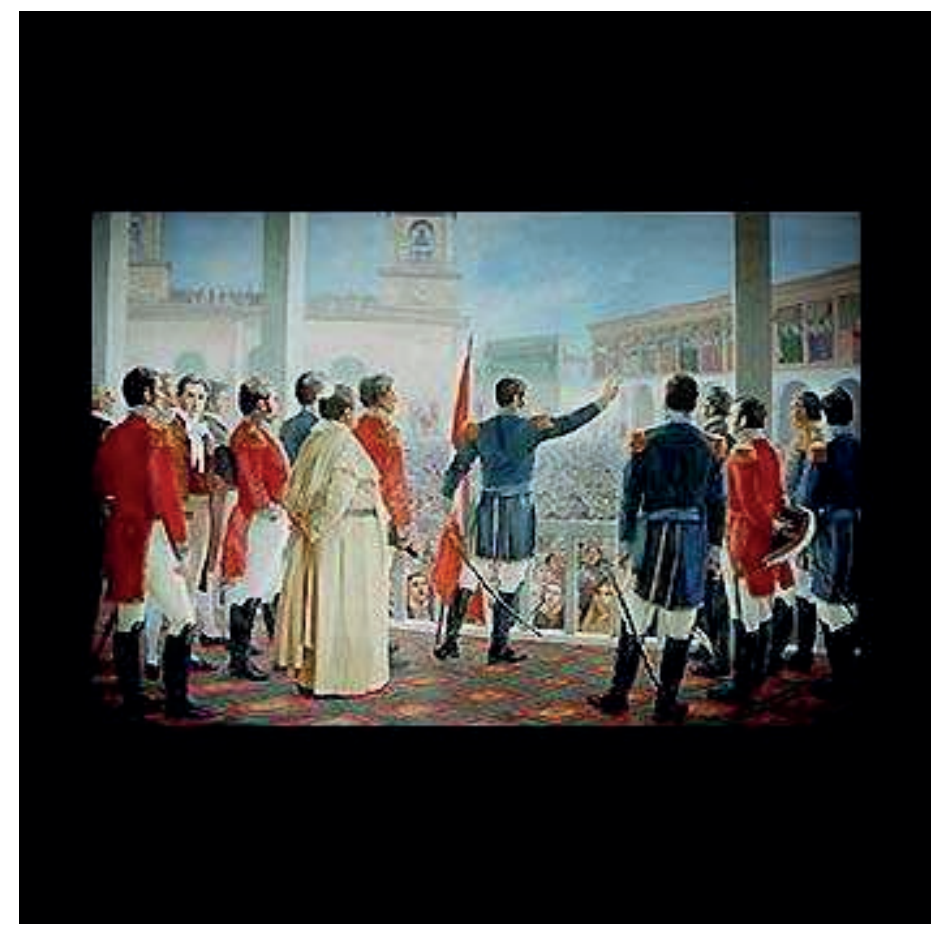

Figura 38b. San Martín proclama la Independencia del Perú. Óleo sobre lienzo de Juan Lepiani. Roma, 1904. Pinacoteca del Museo de Arqueología, Antropología e Historia del Perú.

En el momento estelar de la Independencia, había unos 50.000 esclavos en todo el territorio del virreinato del Perú, la mayor parte se encontraba en el campo (región de la costa y en algunas localidades de la sierra).

El 12 de agosto de aquel año, el general don José de San Martín se adelanta a su época al decretar en Huaura (norte de Lima) que aquellos hombres y mujeres nacidos de padres esclavos después del 28 de julio eran considerados libres bajo el concepto jurídico de la libertad de vientre.

6 de noviembre. San Martín decreta la inmediata libertad de los esclavos de españoles para que se incorporen a su ejército. 
23 de noviembre. San Martín decreta la libertad de todos los esclavos del extranjero llegados al Perú. Esta norma fue recogida por las Constituciones de 1823 y 1828. (Nota_52)

Costa de los Granos, Liberia. La American Colonization Society desembarca el primer cargamento de negros libres repatriados.

Un negro en Palacio. Entre 1821 y 1854, el Perú es escenario de un largo periodo donde los bandoleros y salteadores de caminos hacen de las suyas. El caso más sonado fue el protagonizado por el negro León Escobar, quien, con una partida de hombres armados, hizo lo que no habían logrado ni los realistas ni los patriotas en sus buenos tiempos: tomó por asalto la ciudad de Lima (20 de diciembre de 1835) e ingresó al Palacio de Gobierno para sentarse en el sillón presidencial. Semejante "hazaña" le costó caro, pues fue detenido de inmediato y fusilado once días después.

$1822-1824$

Los negros y las gestas de la Independencia del Perú. Bajo la promesa de libertad si la campaña militar contra los realistas era un éxito, miles de negros participaron y tuvieron una destacada actuación en las luchas por la Independencia del Perú. Incluso se sabe de regimientos enteros conformados sólo por negros. 


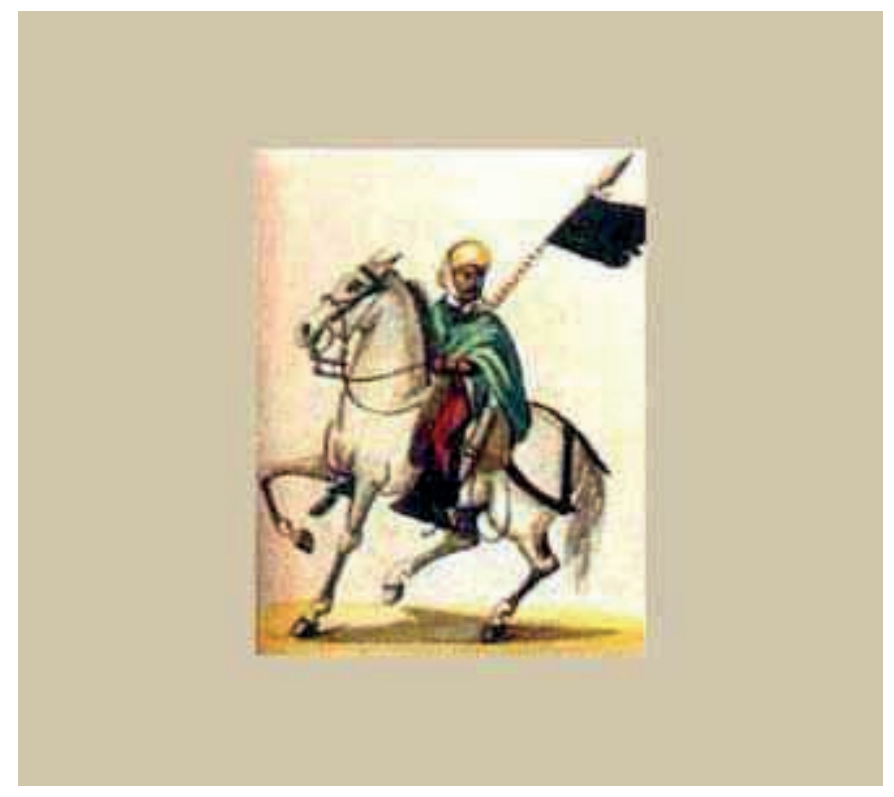

Figura 39. Montonero de color peruano de la época de la Independencia. Acuarela de Pancho Fierro. La Independencia del Perú. Educored.edu.pe.

Chile. La Constitución de 1823 se pronuncia contra la esclavitud: "Artículo 8.- En Chile no hay esclavos: el que pise su territorio por un día natural será libre. El que tenga este comercio no puede habitar aquí más de un mes, ni naturalizarse jamás." Esclavitud y Trata de Negros en América. (Nota_53)

9 de diciembre. La batalla de Ayacucho sella la independencia de Perú de España, mientras en Lima se elevaban voces interesadas que pedían la anulación de los decretos de San Martín, aduciendo conveniencia privada y pública. 


\section{Notas al margen de la primera parte}

(Advertencia al amable lector: Los hipervínculos que siguen a continuación estaban operativos en la fecha de cierre de este trabajo: 1 de octubre de 2006)

(Nota 1) Algunas notas sobre la esclavitud en América. Revista Arbil, anotaciones de pensamiento y critica. \# 42 http://www.arbil.org/(42)irab.htm

(Nota 2) Tupaj Amaru, un indomable guerrero que se pasea en los Andes. http://www.pusinsuyu.com/html/tupaj_amaru.html

(Nota 3) Historia de la República del Perú. La falaz prosperidad del guano (18421866) Tomo 6. Empresa Editora El Comercio. Lima, 2005.

Párrafo de esta obra citado en el artículo: La inmigración china al Perú. Portal de la Asociación Peruano China (APCH) http:/ /apchjovenes.com/blog/?p=11

(Nota 4) Fuente: Trabajo forzoso en América Latina.

Artículo publicado el 13 de mayo de 2005.

http://news.bbc.co.uk/hi/spanish/specials/newsid_4537000/4537895.stm

(Nota 5)

Figura 58

Dimensión Gráfica de la Trata de Esclavos

Escribe José Luís Gómez 
El término "trata" es un eufemismo conveniente que busca eliminar la dimensión ética del concepto implícito en "la trata de esclavos". Un término mucho más apropiado es el de "comercio negrero", pues la palabra "negrero" ha conservado la carga de infamia que implica rebajar al ser humano a la categoría de mercancía. En cualquier caso, ambos términos se nos presentan en el siglo XXI como lejanos, como desprovistos de verdadero significado. Y ese es precisamente el objetivo de esta dimensión gráfica: aproximar a nosotros el concepto de la esclavitud, procurar, en lo posible a través de la fotografía, que adquiera vida la institución de la esclavitud. Por ello mismo he creído conveniente agrupar las imágenes en dos secciones: La trata (las distintas fases de la comercialización de los esclavos negros), y el negrero. Repitamos que no se trata de procesos distintos, son únicamente dos perspectivas de presentar un mismo proceso deshumanizante.

La primera fase de la trata era la captura de los negros en sus propias aldeas. Según incrementó la demanda de esclavos, se extendió también a lo largo del continente africano. Aunque llegaban esclavos de las más diversas regiones de África, la inmensa mayoría provenían de la costa occidental, de Senegal a Angola; sobre todo de la región al norte del río Congo. Las consecuencias inmediatas fueron la despoblación, el aumento de la población anciana, el abandono de la agricultura, la corrupción de las estructuras sociales.

Se calcula que para 1600 se habían transportado 900.000 esclavos africanos. La demanda iba en aumento y los portugueses pierden el monopolio que poseían en el transporte de esclavos. Para 1700 se calcula que otros 2.750 .000 de esclavos negros había sido transportados a América. Para entonces habían entrado ya en el comercio negrero los holandeses, los ingleses, los daneses y los franceses. A lo largo de la costa africana existían ahora 40 "factorías" de esclavos (Meltzer). Por lo general los esclavos 
eran primero vendidos a intemediarios que los transportaban a las "factorías" donde negociaban las ventas a los europeos.

Desde el comienzo se prestó especial cuidado a la "calidad de la mercancía". Se preferían esclavos fuertes, sanos y jóvenes, no sólo en vistas al precio que aportaría su venta, sino también en vistas a los rigores de una travesía transatlántica de semanas (a veces meses). Resulta en este contexto de interés el grabado de un "cargamento" de esclavos liberados por el barco británico el Undine (destaca sobre todo el predominio de adolescentes).

El esclavo negro, como mercancía, era también marcado con hierro caliente, de modo semejante al usado para marcar el ganado. Esta práctica continuó hasta mediados del siglo XIX. La deshumanización de este proceso se acentúa cuando se considera el texto del siguiente anuncio reproducido en 1853 en los Anti-Slavery Tracts:

"Veinte dólares de recompensa.- Joven negra huida, de nombre Molly, 16 ó 17 años de edad; marcada recientemente en el carrillo izquierdo con ' $R$ ', $y$ con un trozo cortado de su oreja del mismo lado; la misma letra en la parte interior de sus dos piernas".

Este diseño pertenece al barco negrero Brookes cuya capacidad máxima era de 451 esclavos, destinando a cada uno de ellos un espacio de $183 \mathrm{~cm}$. por $40 \mathrm{~cm}$. (menos espacio para las mujeres y niños). Según acusaciones de la Asociación Abolicionista en 1789, el Brookes llegó a llevar "cargamento" de 609 esclavos (en la fotografía ampliada se encuentran más detalles sobre el diseño del barco y la disposición de su "cargo" de esclavos). El transporte en estas condiciones llevaba consigo un alto índice de mortandad, que queda bien dramatizado en los siguientes datos de cuatro barcos negreros capturados durante el inicio de la prohibición de la trata en la década de los 30 (Martínez).
Buques
Embarcados
Muertos 


$\begin{array}{llc}\text { Cintra } & 970 & 214 \\ \text { Brillante } & 621 & 214 \\ \text { Commodore } & 685 & 300 \\ \text { Explorador } & 560 & 300\end{array}$

Un grabado en el Harper's Weekly de 1860 muestra la extensión de este "cargamento" de seres humanos, en varias dimensiones, pero sobre todo en dos pertinentes para nuestro propósito: a) el espacio limitado en compartimentos dónde sólo podían estar sentados, y b) Las condiciones físicas en que llegaban los que sobrevivían a la travesía. Estas condiciones sirven para colocar en perspectiva las estadísticas anotadas más arriba. Los principales puertos oficiales de llegada en el Caribe fueron Cartagena de Indias y Veracruz.

La muerte de los esclavos negros durante la travesía transatlántica se debía en ocasiones a cusas todavía más siniestras que las de la muerte por las condiciones en las que eran transportados. Antes de la prohibición de la trata, estas causas incluían entre otras el miedo a las enfermedades o la falta de alimentos. En ambos casos se arrojaban al mar a los esclavos, bien para evitar el posible contagio bien para aligerar la "carga" (los seguros no se hacían cargo de los esclavos que perecían por enfermedad, pero sí de los que perecían ahogados durante la travesía). Después de la prohibición de la trata, la causa podía ser simplemente la de evitar ser capturados.

El ejemplo que nos proporciona Castelar representa el punto final del tránsito, la llegada de la "mercancía" a su nuevo destino: "Se venden dos yeguas de tiro, dos yeguas del Canadá; dos negras, hija y madre; las yeguas, juntas o separadas; las negras, la hija y la madre, separadas o juntas." Con la llegada al destino sólo se iniciaba la vida en la esclavitud, una realidad difícil de comprender incluso a través de los vívidos testimonios e imágenes que nos han llegado. 
Fuente: Proyecto Ensayo Hispánico - Emilio Castelar.

(Nota 6) Gómez añade también que No obstante, recordemos que la esclavitud no era algo nuevo, se trataba más bien de una nueva etapa en una de las instituciones más poderosas de la antigüedad. En España, por ejemplo, se encontraba legislada con precisión, a mediados del siglo XIII, en Las siete partidas de Alfonso el Sabio. El título 21 de la Parte Cuarta se titula "De los siervos", cuya ley primera establece que "son tres maneras de siervos. La primera, es de los que cativan en tiempos de guerra, seyendo enemigos de la fe. La segunda, es de los que nascen de las siervas. La tercera es quando alguno es libre e se desea vender".

Fuente: Cronología: Esclavitud y trata negros en América. Antología del Ensayo Hispánico - Emilio Castelar.

http://www.ensayistas.org/antologia/XIXE/castelar/esclavitud/c-esclavitud.htm

(Nota 7) Los cronistas españoles Martín de Murúa y Miguel Cabello de Balboa recogieron esta historia según la cual el entonces príncipe y futuro inca, Tupac Yupanqui (Cusco i1471? - Cusco 1493), hijo del inca Pachacutec, en una de sus expediciones por la costa norte peruana, fue donde tuvo conocimiento de unas islas lejanas y decidió ir en pos de ellas, alistó una impresionante flota de balsas y zarpó con 20.000 hombres, llegando a unas islas llamadas Ninchumbi y Aguacchumbi. Algunos historiadores piensan que llegó a la Polinesia, específicamente a la isla Mangareval, donde, en el siglo XVIII, sus habitantes relataban una leyenda de un jefe llamado inca que venÍa del este. El mismo relato existe en las islas Marquesas. Lo cierto es que retornó a los dos años trayendo consigo gente negra, sillas de latan, pellejos y quijadas de caballos que fueron conservadas en la fortaleza de Sacsayhuamán. 
Fuentes: Tupac Yupanqui. Vikipedia, la enciclopedia libre. http://es.wikipedia.org/wiki/T\%C3\%BApac_Yupanqui

Tupac Yupanqui. El inca que descubrió Oceanía.

Peruredes.com.

http://www.peruredes.com/Historia/yupanqui.htm

(Nota 8) El mismo portal agrega que: Hernán Cortés, por ejemplo, cuando se disponía a conquistar la región de Tepeaca, después de la Noche Triste, le escribía a Carlos I con toda naturalidad: «Hice ciertos esclavos, de que se dio el quinto a los oficiales reales»... De ellos se ayudaban los conquistadores como guías, porteadores y constructores, y a veces incluso como fieles guerreros aliados. El problema moral de conciencia por entonces -como en los tiempos de San Pablo- no se planteaba, en modo alguno, sobre el tener esclavos, sino sobre el trato bueno o malo que a los esclavos se daba.

Así las cosas, «si los indios coincidían con los combatientes españoles en cuanto a considerar legítimo el derecho a tener esclavos a los que les hacían la guerra, la Iglesia y la Corona tuvieron que empeñarse no sólo en una lucha ideológica con los diversos grupos y culturas indígenas, sino que también se vieron obligados a convencer a sus propios españoles acerca de que el indio debía ser una excepción en lo que atañe a esclavitudes y servidumbres. Ambos, indios y españoles, tuvieron que ser reeducados en función de la confluencia de una nueva ética: la que se fundaba en el cristianismo y en la igualdad de trato entre cristianos» (Esteva 167).

En este sentido, «lo que aprendieron [los indios] de los españoles fue precisamente el protestar contra la esclavitud y el tener derecho a ejercer legalmente acciones contra 
los esclavistas» (168). Y éste, como veremos, fue ante todo mérito de la Iglesia y de la Corona.

Como es natural, el empeño por cambiar la mentalidad de indios y españoles sobre la esclavitud de los naturales de las Indias hubo de prolongarse durante varios decenios, pero se comenzó desde el principio. En efecto, los Reyes Católicos iniciaron el antiesclavismo de los indios cuando Colón, al regreso de su segundo viaje (1496), trajo a España como esclavos 300 indios de La Española, y le obligaron a regresarlos de inmediato, y como hombres libres.

Alertados así sobre el problema, los Reyes dieron en 1501 rigurosas instrucciones al comendador Nicolás de Ovando, en las que insistían en que los indios fuesen tratados no como esclavos, sino como hombres libres, vasallos de la Corona. Recordaremos aquí brevemente las acciones principales de la Iglesia y la Corona para la liberación de los indios.

Por parte de la Iglesia, el combate contra la esclavización de los indios vino exigida tanto por misioneros como por teólogos y juristas. La licitud de la esclavitud, según hemos visto, estaba por entonces íntimamente relacionada con la cuestión gravísima de la guerra justa, y ésta con el problema de los títulos lícitos de conquista, como ya vimos brevemente más arriba (53-56). Pero, en referencia directa a la esclavitud de los indios, hemos de recordar, por ejemplo, el sermón de Montesinos (1511), la enseñanza del catedrático salmantino Matías de Paz (1513), la carta de fray Juan de Zumárraga, primer obispo de México, al virrey Mendoza; la carta de los franciscanos de México al Rey, firmada por Jacobo de Tastera, Motolinía, Andrés de Olmos y otros; las intervenciones de Las Casas; las tesis de la Escuela de Salamanca, encabezada en esta cuestión por Diego de Covarrubias y Leyva, contra Sepúlveda, apoyadas por Soto, Cano, Mercado, Mancio, Guevara, Alonso de Veracruz (+Pereña 
95-104); y poco más tarde las irrefutables argumentaciones del jesuita José de Acosta, apoyadas en buena medida en Covarrubias.

Por parte del Estado, recordaremos primero las numerosas y tempranas intervenciones antiesclavistas de altos funcionarios reales, algunas de las cuales ya hemos referido más arriba (45-47). Núñez de Balboa, por ejemplo, en 1513, escribe al Rey desde el Darién, quejándose del mal trato que Nicuesa y Hojeda dan a los indios, «que les parece ser señores de la tierra», y que una vez que se hacen con los indios «los tienen por esclavos» (Céspedes, Textos 53-54). En 1525, a los cuatro años de la conquista de México, don Rodrigo de Albornoz, contador de la Nueva España, escribe también al Rey, denunciando que con la costumbre de hacer esclavos «se hace mucho estrago en la tierra y se perderá la gente de ella y los que pudieran venir a la fe y dominio de V. M., si no lo mandare remediar luego y que en ninguna manera se haga sin mucha causa, porque es gran cargo de conciencia» (+Castañeda 65-66). Unos diez años más tarde, don Vasco de Quiroga, oidor real en México, refuta uno tras otro con gran fuerza persuasiva todos los posibles supuestos legítimos de esclavización de los indios, en aquella Información en derecho de la que ya dimos noticia (208-209). «Naturalmente, estos autores no intentan negar el derecho de cautiverio, fruto de la guerra, sino conseguir una excepción con los indios americanos» (Castañeda 66; +68-88, 125-136).

La Corona hispana, atendiendo estas voces, prohíbe desde el principio la esclavización de los indios en reiteradas Cédulas y Leyes reales (1523, 1526, 1528, 1530, 1534, Leyes Nuevas 1542, 1543, 1548, 1550, 1553, 1556, 1568, etc.), o la autoriza solamente en casos extremos, acerca de indios que causan estragos o se alzan traicionando paces -caribes, araucanos, chiriguanos-. En 1530, por ejemplo, en la Instrucción de la Segunda Audiencia de México, el Rey prohíbe la esclavitud en 
absoluto, proceda ésta de guerra, «aunque sea justa y mandada hacer por Nos», o de rescates (+Castañeda 59-60).

Pero también llegaban al Rey informaciones y solicitudes favorables a la esclavitud de los indios, formuladas no sólo por conquistadores y encomenderos, sino también por religiosos dominicos y franciscanos, que, al menos en algunos lugares especialmente bárbaros, «aconsejaron la servidumbre de los indios», contra la primera idea de los Reyes Católicos (López de Gómara, Historia gral. I,290).

Pedro Mártir de Anglería, en una carta de 1525 al arzobispo de Cosenza, refiere: «El derecho natural y el canónico mandan que todo el linaje humano sea libre; mas el derecho romano admite una distinción, y el uso contrario ha quedado establecido. Una larga experiencia, en efecto, ha demostrado la necesidad de que sean esclavos, y no libres, aquellos que por naturaleza son propensos a vicios abominables y que faltos de guías y tutores vuelven a sus errores impúdicos. Hemos llamado a nuestro Consejo de Indias a los bicolores frailes Dominicos y a los descalzos Franciscanos, que han residido largo tiempo en aquellos países, y les hemos preguntado su madura opinión sobre este extremo. Todos, de acuerdo, convinieron en que no había nada más peligroso que dejarlos en libertad» (+Cortés 38$)$.

Los españoles de Indias aducían contra la prohibición de la esclavitud «varias razones, y al parecer, de peso: que los hombres de armas, no viendo provecho en conservar la vida de sus prisioneros, los matarían; que siendo el sistema de hueste el usual de la conquista, y siendo los esclavos parte fundamental y a veces única del botín, nadie querría embarcarse en nuevas guerras contra los indios; que si impedían los rescates se cerraban las posibilidades de que muchos indios conocieran el cristianismo y abandonaran la idolatría; que los indios, viendo que sus rebeliones no podían ser castigadas con el cautiverio, se estaban volviendo ya de hecho 
incontrolables» (Castañeda 60). Todas estas presiones teóricas y prácticas explican que la Corona española, a los comienzos, quebrase en algún momento su continua legislación antiesclavista, como cuando en 1534 autoriza de nuevo el Rey, bajo estrictas condiciones, la esclavitud de guerra o de rescate.

Pero inmediatamente vienen las reacciones antiesclavistas, y entre ellas quizá la más fuerte la del oficial real don Vasco de Quiroga: «Diré lo que siento, con el acatamiento que debo, que la nueva provisión revocatoria de aquella santa y bendita primera [1530] que, a mi ver por gracia e inspiración del Espíritu Santo, tan justa y católicamente se había dado y proveído, allá y acá pregonado y guardado sin querella de nadie, que yo acá sepa»... (+Castañeda 118). Las Leyes Nuevas de 1542, y las que siguen a la gran disputa académica de 1550 entre Las Casas y Ginés de Sepúlveda, reafirmaron definitivamente la tradición antiesclavista de la Iglesia y la Corona. Así en 1553 ordena el Rey «universalmente la libertad de todos los indios, de cualquier calidad que sean», y encarga a los Fiscales proceder en esto con energía, «de forma que ningún indio ni india deje de conseguir y conservar su libertad».

Por lo demás, «la persecución de que se hizo objeto a quienes practicaban la esclavitud de los indios se fue generalizando a medida que se acentuaba el papel de la Iglesia en Indias, y a medida también que la Corona española aumentaba sus controles funcionarios sobre los españoles» (Esteva 184). Esta persecución comenzó muy pronto, y no eximió tampoco a los poderosos, como vimos ya en el caso de Colón, o podemos verlo en el de Hernán Cortés, que en el juicio de residencia de 1548, fue acusado de tener trabajando en sus tierras indios esclavos de guerra o rescate, a los que se dio libertad.

1492, 1550... En aquel dramático encuentro de indios y españoles, es evidente que los indios, mucho más primitivos y subdesarrollados, en un marco de vida moderna 
absolutamente nuevo para ellos, vinieron a ser el proletariado de la nueva sociedad que se fue desarrollando, con todo los sufrimientos que tal condición social implicaba entonces -no mayor, probablemente, a los que, por ejemplo, se daban en el XIX durante la revolución industrial entre los mismos ingleses, o a los que en el XX se experimentan en los suburbios y lugares más deprimidos de América-.

La esclavitud, en las Indias hispanas, desde el comienzo, cedió el paso a la encomienda, con el repartimiento de indios, y ésta institución no tardó mucho en verse sustituida por el régimen de las reducciones en pueblos. En todo caso, es preciso reconocer que, ya desde 1500, al abolir la esclavitud de los indios, «la Corona española se adelantaba varios siglos a la abolición de la esclavitud en el mundo» (Pereña, Carta Magna de los Indios 106).

Fuente: http://www.corazones.org/diccionario/esclavitud.htm

(Nota 9) Fuente: Abolicionismo en América: Hacia un Estudio Comparativo de Historia Mundial, Omar H. Ali, Ph.D. Departamento de Historia. http:// pages.towson.edu/oali/CASO.htm

(Nota 10) La investigadora María Milagros Carazas Salcedo, cuando optaba por el grado de Magister en Literatura Peruana y Latinoamericana, escribe en su tesis de grado lo siguiente: La historia peruana actual afirma que eran catorce los expedicionarios de Francisco Pizarro quienes atravesaron la línea trazada con su espada en la arena, para seguir el viaje al Sur y no regresar con el Comisionado Tafur a Panamá. Una relectura más atenta y documentada corrige lo acontecido en el segundo viaje de la expedición de Almagro y Pizarro en busca del Tahuantinsuyu, entre 1525 y 1527. En realidad los que continuaron el viaje fueron más bien catorce, con mayor exactitud los trece españoles y un negro de Guinea. No se sabe con 
seguridad cuál fue su nombre pero por lo menos se tiene noticias que era un esclavo que acompañaba a Alonso de Molina.

Fuente: Introducción de la Tesis Imagen(es) e identidad del sujeto afroperuano en la novela peruana contemporánea. Facultad de Letras y Ciencias Humanas. Universidad Nacional Mayor de San Marcos (UNMSM), Lima, 2004. Documento en formato PDF:

http://sbib.unmsm.edu.pe/bibvirtualdata/Tesis/Human/Carazas_SM/PDF/

(Nota 11) Este embarque de 1529 no llegó a concretarse pero fue el inicio de la introducción de esclavos en territorio del otrora imperio inca. Ahora se sabe que quienes acompañaban a los conquistadores eran mandingas y biafranos vendidos en San Jorge de la Mina y Cabo Verde, las dos grandes factorías negreras portuguesas. De hecho, la Capitulación de Toledo (26 de junio de 1529) era un documento legal firmado entre Francisco Pizarro y el rey de España, Carlos V, mediante el cual no sÓlo se autorizaba a Pizarro a colonizar y poblar Sudamérica sino que, además de lo arriba citado respecto a los mandingas y biafranos que iban con ellos en sus viajes, otorgaba a Pizarro y sus hombres diferentes cargos, rangos y salarios para realizar la empresa conquistadora:

1. Para Francisco Pizarro: los títulos de Gobernador, Capitán General, Adelantado y Alguacil Mayor de la Nueva Castilla. Extensión de su gobernación 200 leguas $(1.110 \mathrm{~km})$ al sur del pueblo de Santiago, Ecuador (aproximadamente hasta la actual Chincha). Sueldo: 725 mil maravedíes al año.

2. Para Diego de Almagro: Gobernador de la Fortaleza de Tumbes. Título: Hidalgo. Sueldo: cien mil ducados. 
3. Para Bartolomé Ruiz: el cargo de Piloto Mayor del Sur.

4. Para Pedro de Candia: el cargo de Jefe de Artillería.

5. Para los trece caballeros de la isla del Gallo, títulos de Hidalgos.

Fuente: Capitulación de Toledo - Vikipedia, la enciclopedia libre. http:/ / es.wikipedia.org/wiki/Capitulaci\%C3\%B3n_de_Toledo

(Nota 12) Crónica del Perú, Tercera Parte, cap. LXXII, Pontificia Universidad Católica del Perú y Academia Nacional de la Historia. Lima, 1987, pp. 286.

(Nota 13) La única baja española fue la de un esclavo negro que murió arrollado por la multitud cuando los miles de indios, asustados por el estruendo de las armas y la atropellada de la caballería españolas, trataron de huir despavoridas de la plaza de Cajamarca. Fue, efectivamente, la única baja que tuvieron los españoles de Francisco Pizarro. Por el lado de los indígenas, miles murieron en tan desigual encuentro.

(Nota 14) Máx Hernández, uno de los más talentosos estudiosos de la realidad peruana, escribe al respecto: El diseño político de la metrópoli se afianzaba sobre una maraña de criterios de exclusión. El más extremo de éstos lo constituye el régimen de esclavitud que rigió para el contingente venido de África muy en los inicios de la Conquista para quienes vinieron después, y para sus descendientes. Si bien la esclavitud existía desde la Antigüedad, la magnitud del fenómeno y la asociación de esclavitud con la raza asociados a la conquista y colonización del Nuevo Mundo introdujeron -como apunta Aldo Ferrer- dimensión étnica, determinado que no existían diferencias culturales tan grandes entre los esclavistas y los esclavizados. Si 
bien el 80\% de las "piezas de ébano" traídos a la América hispano-portuguesa fueron al Brasil y al Caribe, no hubo zona del Nuevo Mundo a la que no llegaran.

Fuente: ¿Es otro el rostro del Perú? Identidad, Diversidad y Cambio. Editorial Agenda Perú. Lima, marzo de 2000.

Disponible en Internet, en formato PDF en la dirección:

http://www.agendaperu.org.pe/pdfs/pub-

02.pdf\#search=\%22\%C2\%BFEs\%20otro\%20el\%20rostro\%20del\%20Per\%C3\%BA\%3F $\% 22$

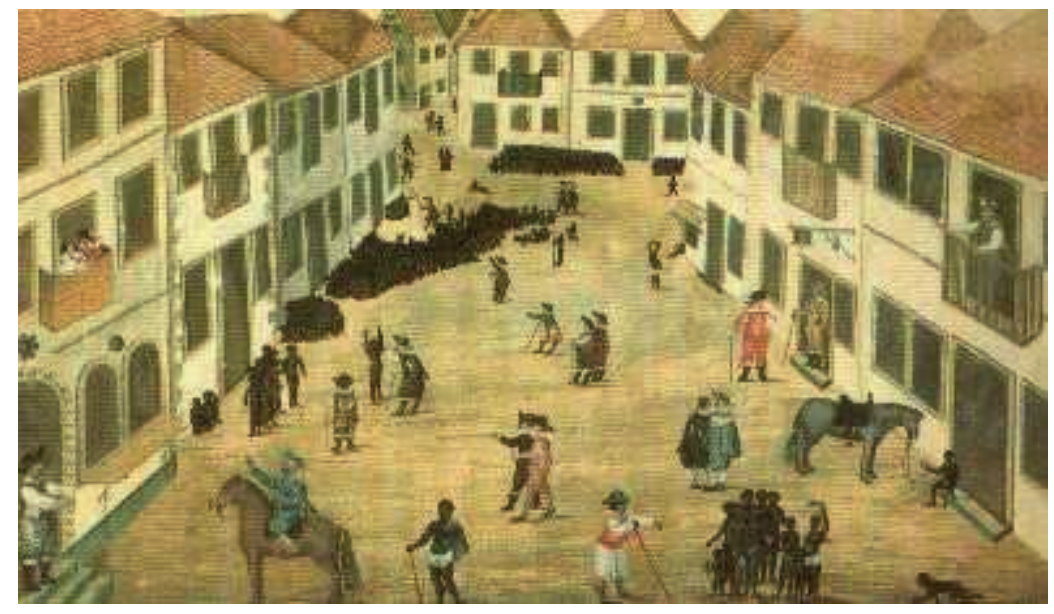

Figura 59. Piezas de ébano I: Una vez arribaba al puerto el barco negrero, los esclavos eran hacinados en lugares de ordinario húmedos, estrechos y malolientes, siendo el primer propósito engordarlos un poco para obtener un buen precio por ellos en el mercado. Grabado del siglo XVII: una escena cotidiana, venta de esclavos en el puerto de Cartagena de Indias. Colección del Archivo General de Colombia.

(Nota 15) La denuncia del dominico de Las Casas. En su obra arriba mencionada, de las Casas hace un pormenorizado recuento del acontecer en cada una de las provincias y colonias españolas en América. Bajo estas líneas, en lo que concierne al 
Perú, al autor no le tiembla la mano cuando describe las atrocidades cometidas por los españoles contra indios y esclavos:

\section{DE LOS GRANDES REINOS Y GRANDES PROVINCIAS DEL PERÚ}

En el año de mil e quinientos e treinta y uno fué otro tirano grande con cierta gente a los reinos del Perú, donde entrando con el título e intención e con los principios que los otros todos pasados (porque era uno de los que se habían más ejercitado e más tiempo en todas las crueldades y estragos que en la tierra firme desde el año de mil e quinientos y diez se habían hecho), cresció en crueldades y matanzas y robos, sin fee ni verdad, destruyendo pueblos, apocando, matando las gentes dellos e siendo causa de tan grandes males que han sucedido en aquellas tierras, que bien somos ciertos que nadie bastará a referirlos y encarecerlos, hasta que los veamos y conozcamos claros el día del Juicio; y de algunos que quería referir la deformidad y calidades y circunstancias que los afean y agravian, verdaderamente yo no podré ni sabré encarecer.

En su infelice entrada mató y destruyó algunos pueblos e les robó mucha cantidad de oro. En una isla que está cerca de las mesmas provincias, que se llama Pugna, muy poblada e graciosa, e rescibiéndole el señor y gente della como a ángeles del cielo, y después de seis meses habiéndoles comido todos sus bastimentos, y de nuevo descubriéndoles los trojes del trigo que tenían para sí e sus mujeres e hijos los tiempos de seca y estériles, y ofreciéndoselas con muchas lágrimas que las gastasen e comiesen a su voluntad, el pago que les dieron a la fin fué que los metieron a espada y alancearon mucha cantidad de gentes dellas, y los que pudieron tomar a vida hicieron esclavos con grandes y señaladas crueldades otras que en ellas hicieron, dejando casi despoblada la dicha isla. 
De allí vanse a la provincia de Tumbala, ques en la tierra firme, e matan y destruyen cuantos pudieron. Y porque de sus espantosas y horribles obras huían todas las gentes, decían que se alzaban e que eran rebeldes al rey. Tenía este tirano esta industria: que a los que pedía y otros que venían a dalles presentes de oro y plata y de lo que tenían, decíales que trujesen más, hasta que él vía que o no tenían más o no traían más, y entonces decía que los rescebía por vasallos de los reyes de España y abrazábalos y hacía tocar dos trompetas que tenía, dándoles a entender que desde en adelante no les habían de tomar más ni hacerles mal alguno, teniendo por lícito todo lo que les robaba y le daban por miedo de las abominables nuevas que de él oían antes que él los recibiese so el amparo y protectión del rey; como si después de rescebidos debajo de la protección real no los oprimiesen, robasen, asolasen y destruyesen y él no los hubiera así destruído.

Pocos días después, viniendo el rey universal y emperador de aquellos reinos, que se llamó Atabaliba, con mucha gente desnuda y con sus armas de burla, no sabiendo cómo cortaban las espadas y herían las lanzas y cómo corrían los caballos, e quién eran los españoles (que si los demonios tuvieren oro, los acometerán para se lo robar), llegó al lugar donde ellos estaban, diciendo: "¿Dónde están esos españoles? Salgan acá, que no me mudaré de aquí hasta que me satisfagan de mis vasallos que me han muerto, y pueblos que me han despoblado, e riquezas que me han robado". Salieron a él, matáronle infinitas gentes, prendiéronle su persona, que venía en unas andas, y después de preso tractan con él que se rescatase: promete de dar cuatro millones de castellanos y da quince, y ellos prométenle de soltarle; pero al fin, no guardándole la fee ni verdad (como nunca en las Indias con los indios por los españoles se ha guardado), levántanle que por su mandado se juntaba gente, y él responde que en toda la tierra no se movía una hoja de un árbol sin su voluntad: que si gente se juntase creyesen que él la mandaba juntar, y que presto estaba, que lo matasen. No obstante todo esto, lo condenaron a quemar vivo, aunque después 
rogaron algunos al capitán que lo ahogasen, y ahogado lo quemaron. Sabido por él, dijo: "Por qué me quemáis, qué os he hecho? ¿No me prometistes de soltar dándoos el oro? ¿No os di más de lo que os prometí? Pues que así lo queréis, envíame a vuestro rey de España", e otras muchas cosas que dijo para gran confusión y detestación de la gran injusticia de los españoles; y en fin lo quemaron.

Considérese aquí la justicia e título desta guerra; la prisión deste señor e la sentencia y ejecución de su muerte, y la cosciencia con que tienen aquellos tiranos tan grandes tesoros como en aquellos reinos a aquel rey tan grande e a otros infinitos señores e particulares robaron.

De infinitas hazañas señaladas en maldad y crueldad, en estirpación de aquellas gentes, cometidas por los que se llaman cristianos, quiero aquí referir algunas pocas que un fraile de Sant Francisco a los principios vido, y las firmó de su nombre enviando traslados por aquellas partes y otros a estos reinos de Castilla, e yo tengo en mi poder un traslado con su propia firma, en el cual dice así:

"Yo, fray Marcos de Niza, de la orden de Sant Francisco, comisario sobre los frailes de la mesma orden en las provincias del Perú, que fué de los primeros religiosos que con los primeros cristianos entraron en las dichas provincias, digo dando testimonio verdadero de algunas cosas que yo con mis ojos vi en aquella tierra, mayormente cerca del tractamiento y conquistas hechas a los naturales. Primeramente, yo soy testigo de vista y por experiencia cierta conoscí y alcancé que aquellos indios del Perú es la gente más benévola que entre indios se ha visto, y allegada e amiga a los cristianos. Y vi que aquéllos daban a los españoles en abundancia oro y plata e piedras preciosas y todo cuanto les pedían que ellos tenían, e todo buen servicio, e nunca los indios salieron de guerra sino de paz, mientras no les dieron ocasión con los malos tractamientos e crueldades, antes los rescebían con toda benevolencia y 
honor en los pueblos a los españoles, dándoles comidas e cuantos esclavos y esclavas pedían para servicio.

"Ítem, soy testigo e doy testimonio que sin dar causa ni ocasión aquellos indios a los españoles, luego que entraron en sus tierras, después de haber dado el mayor cacique Atabaliba más de dos millones de oro a los españoles, y habiéndoles dado toda la tierra en su poder sin resistencia, luego quemaron al dicho Atabaliba, que era señor de toda la tierra, y en pos dél quemaron vivo a su capitán general Cochilimaca, el cual había venido de paz al gobernador con otros principales. Asimesmo, después déstos dende a pocos días quemaron a Chamba, otro señor muy principal de la provincia de Quito, sin culpa ni haber hecho por qué.

"Asimesmo quemaron a Chapera, señor de los canarios, injustamente. Asimesmo a Luis, gran señor de los que había en Quito, quemaron los pies e le dieron otros muchos tormentos porque dijese dónde estaba el oro de Atabaliba, del cual tesoro (como pareció) no sabía él nada. Asimesmo quemaron en Quito a Cozopanga, gobernador que era de todas las provincias de Quito. El cual, por ciertos requerimientos que le hizo Sebastián de Benalcázar, capitán del gobernador, vino de paz, y porque no dió tanto oro como le pedían, lo quemaron con otros muchos caciques e principales. Y a lo que yo pude entender su intento de los españoles era que no quedase señor en toda la tierra.

"Ítem, que los españoles recogieron mucho número de indios y los encerraron en tres casas grandes, cuantos en ellas cupieron, e pegáronles fuego y quemáronlos a todos sin hacer la menor cosa contra español ni dar la menor causa. Y acaesció allí que un clérigo que se llama Ocaña sacó un muchacho del fuego en que se quemaba, y vino allí otro español y tomóselo de las manos y lo echó en medio de las llamas, donde se hizo ceniza con los demás. El cual dicho español que así había echado en el fuego al 
indio, aquel mesmo día, volviendo al real, cayó súbitamente muerto en el camino e yo fuí de parecer que no lo enterrasen.

"Ítem, yo afirmo que yo mesmo vi ante mis ojos a los españoles cortar manos, narices y orejas a indios e indias sin propósito, sino porque se les antojaba hacerlo, y en tantos lugares y partes que sería largo de contar. E yo vi que los españoles les echaban perros a los indios para que los hiciesen pedazos, e los vi así aperrear a muy muchos.

Asimesmo vi yo quemar tantas casas e pueblos, que no sabría decir el número según eran muchos. Asimesmo es verdad que tomaban niños de teta por los brazos y los echaban arrojadizos cuanto podían, e otros desafueros y crueldades sin propósito, que me ponían espanto, con otras innumerables que vi que serían largas de contar.

"Ítem, vi que llamaban a los caciques e principales indios que viniesen de paz seguramente e prometiéndoles seguro, y en llegando luego los quemaban. $\mathrm{Y}$ en mi presencia quemaron dos: el uno en Andón y el otro en Tumbala, e no fuí parte para se lo estorbar que no los quemasen, con cuanto les prediqué. E según Dios e mi conciencia, en cuanto yo puedo alcanzar, no por otra causa sino por estos malos tractamientos, como claro parece a todos, se alzaron y levantaron los indios del Perú, y con mucha causa que se les ha dado. Porque ninguna verdad les han tractado, ni palabra guardado, sino que contra toda razón e injusticia, tiranamente los han destruido con toda la tierra, haciéndoles tales obras que han determinado antes de morir que semejantes obras sufrir.

"Ítem, digo que por la relación de los indios hay mucho más oro escondido que manifestado, el cual, por las injusticias e crueldades que los españoles hicieron no lo han querido descubrir, ni lo descubrirán mientras rescibieren tales tractamientos, 
antes querrán morir como los pasados. En lo cual Dios Nuestro Señor ha sido mucho ofendido e su Majestad muy deservido y defraudado en perder tal tierra que podía dar buenamente de comer a toda Castilla, la cual será harto dificultosa y costosa, a mi ver, de la recuperar".

Todas estas son sus palabras del dicho religioso, formales, y vienen también firmadas del obispo de Méjico, dando testimonio de que todo esto afirmaba el dicho padre fray Marcos.

Hase de considerar aquí lo que este Padre dice que vido, porque fue cincuenta o cien leguas de tierra, y ha nueve o diez años, porque era a los principios, e había muy pocos que al sonido del oro fueran cuatro y cinco mil españoles y se extendieron por muchos y grandes reinos y provincias más de quinientas y setecientas leguas, que las tienen todas asoladas, perpetrando las dichas obras y otras más fieras y crueles. Verdaderamente, desde entonces acá hasta hoy más de mil veces más se ha destruido y asolado de ánimas que las que han contado, y con menos temor de Dios y del rey e piedad, han destruído grandísima parte del linaje humano. Más faltan y han muerto de aquellos reinos hasta hoy (e que hoy también los matan) en obra de diez años, de cuatro cuentos de ánimas.

Pocos días ha que acañaverearon y mataron una gran reina, mujer del Inga, el que quedó por rey de aquellos reinos, al cual los cristianos, por sus tiranías, poniendo las manos en él, lo hicieron alzar y está alzado. Y tomaron a la reina su mujer y contra toda justicia y razón la mataron (y aun dicen que estaba preñada) solamente por dar dolor a su marido.

Si se hubiesen de contar las particulares crueldades y matanzas que los cristianos en aquellos reinos del Perú han cometido e cada día hoy cometen, sin dubda ninguna 
serían espantables y tantas que todo lo que hemos dicho de las otras partes se escureciese y paresciese poco, según la cantidad y gravedad dellas.

Fuente: Brevísima relación de la destruición de las Indias. Por los cronistas Fray Bartolomé de las Casas y Sebastián Trujillo (impresor de libros). Sevilla, Año de MDLIL.

http:// presencias.net/indpdm.html

http:// presencias.net/miscel/ht4028d.html

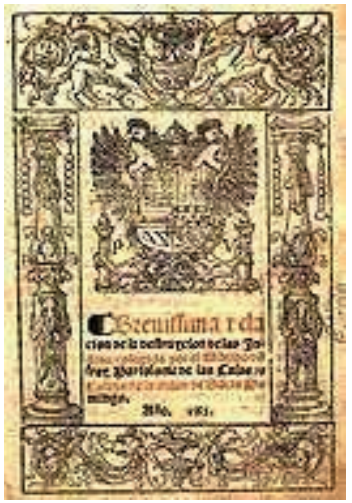

Figura 60. Tapa de la primera edición de Brevísima relación de la destruición de las Indias, Sevilla 1552. Historiadores de Indias. Del portal spanisharts.com

(Nota 16) Las Leyes Nuevas de Indias representaron un total giro en la vida de las nuevas colonias de la metrópoli, pero sólo en los lugares donde fueron plenamente cumplidas.

El texto original, en sus puntos concernientes a los indígenas decía:

...7. Y porque nuestro principal intento y voluntad siempre ha sido y es de la conservaçión y agmento de los indios y que sean instruidos y enseñados en las cosas de nuestra sancta Fée cathólica y bien tratados como personas libres y vasallos nuestros, como lo son, encargamos y mandamos a los del dicho nuestro Consejo [de las Indias] tengan siempre muy gran atençión y espeçial cuidado sobre todo de la 
conservaçión y buen govierno y tratamiento de los dichos indios y de saber cómo se cumple y executa lo que por Nos está ordenado y se ordenare para la buena governaçión de las nuestras Indias y administraçión de la justiçia en ellas, y de hazer que se guarde, cunpla y execute, sin que en ello haya remissión, falta, ni descuido alguno.

20. Porque una de las cosas mas prinçipales que en las Abdiençias han de servirnos es en tener muy espeçial cuidado del buen tratamiento de los indios y conservaçión dellos, mandamos que se informen siempre de los exçesos y malos tratamientos que les son o fueren fechos por los governadores o personas particulares, y cómo han guardado las Ordenanças e Instruçiones que les han sido dadas y para el buen tratamiento dellos están fechas, y en lo que se oviere exçedido o exçediere de aquí adelante tengan cuidado de lo remediar castigando los culpados por todo rigor, conforme a justiçia; y que no den lugar a que en los pleitos de entre indios o con ellos se hagan proçessos ordinarios ni aya alargas, como suele acontesçer por la maliçia de algunos abogados y procuradores, sino que sumariamente sean determinados, guardando sus usos y costumbres, no siendo claramente injustos, y que tengan las dichas Abdiençias cuidado que así se guarde por los otros juezes inferiores.

21. Iten, ordenamos y mandamos que de aquí adelante por ninguna causa de guerra ni otra alguna, aunque sea so titulo de revelión ni por rescate ni de otra manera, no se pueda hazer esclavo indio alguno, y queremos sean tratados como vasallos nuestros de la Corona de Castilla, pues lo son.

22. Ninguna persona se pueda servir de los indios por vía de naburia ni tapia ni otro modo alguno contra su voluntad. 
23. Como avemos mandado proveer que de aquí adelante por ninguna vía se hagan los indios esclavos, ansí en los que hasta aquí se han fecho contra razón y derecho y contra las Provissiones e Instruçiones dadas, ordenamos y mandamos que las Abdiençias, llamadas las partes, sin tela de juizio, sumaria y brevemente, sóla la verdad sabida, los pongan en libertad, si las personas que los tovieren por esclavos no mostraren título cómo los tienen y poseen ligítimamente. Y porque a falta de personas que soliciten lo susodicho los indios no queden por esclavos injustamente, mandamos que las Abdiençias pongan personas que sigan por los indios esta causa, y se paguen de penas de Cámara, y sean hombres de confiança y diligençia.

24. Iten, mandamos que sobre el cargar de los dichos indios las Audiençias tengan espeçial cuidado que no se carguen. $\mathrm{O}$ en caso que esto en algunas partes no se pueda escusar, seha de tal manera que de la carga inmoderada no se siga peligro en la vida, salud y conservaçión de los dichos indios; y que contra su voluntad dellos y sin ge lo pagar, en ningund caso se permita que se puedan cargar, castigando muy gravemente al que lo contrario hiziere. $\mathrm{Y}$ en esto no ha de ayer remisión por respecto de persona alguna.

25. Porque nos ha sido fecha relación que de la pesquería de las perlas averse hecho sin la buena orden que convenía se an seguido muertes de muchos indios y negros, mandamos que ningund indio libre sea llevado a la dicha pesquería contra su voluntad, so pena de muerte. Y que el obispo y el juez que fuere a Veneçuela hordenen lo que les paresçiere para que los esclavos que andan en la dicha pesquería, ansí indios como negros, se conserven y çessen las muertes. Y si les paresçiere que no se puede escusar a los dichos indios y negros el peligro de muerte, çesse la pesquería de las dichas perlas, porque estimamos en mucho mas, como es razón, la conservaçión de sus vidas que el interese que nos pueda venir de las perlas. 
Dentro de este contexto, citando a los españoles y sus intereses en el Nuevo Mundo, así como nuevas reglas de juego entre los colonizadores (en este caso, el de Francisco Pizarro y sus socios), la norma contemplaba, a resumidas cuentas, los siguientes puntos:

* La creación de un Consejo de Indias para cautelar la vida socioeconómica en las colonias americanas.

* La fundación de dos nuevas audiencias (la de Perú y la de Confines, entre Guatemala y Nicaragua).

* La prohibición de la esclavitud de los indios.

* Todos los indios repartidos quedaban bajo la jurisdicción de la Corona.

* La moderación en los repartimientos adquiridos legalmente.

* Se prohíbe la creación de nuevas encomiendas, lo que implicó el fin de la criticada institución de los encomenderos, cuya corrupción provocaba verdaderos excesos por parte de quienes detentaban estos altos cargos.

* Además, las expediciones de descubrimiento debían contar con una autorización, es decir, una licencia de la audiencia local; por otro lado, éstas debían estar acompañadas por un religioso; esto, empero, no impidió que estas expediciones descubridoras continuasen siendo empresas capitalistas -como lo fue la de Francisco Pizarro y sus socios Diego de Almagro y Hernando de Luque - en las que el pillaje era algo corriente. 
* También se establecieron las condiciones en que debía realizarse el asentamiento de colonos en nuevas tierras, y los tributos y servicios que los indios debían pagar como súbditos del rey.

Estas nuevas normas, sin embargo, no fueron bien recibidas en las colonias españolas de ultramar. En el Perú provocó levantamientos de armas entre encomenderos y una guerra civil.

Fuentes: Miscelánea de textos breves relativos a la época del emperador. 1542, 20 de noviembre. Leyes Nuevas de Indias. Biblioteca Virtual Miguel de Cervantes.

http://www.cervantesvirtual.com/historia/CarlosV/9_15.shtml 


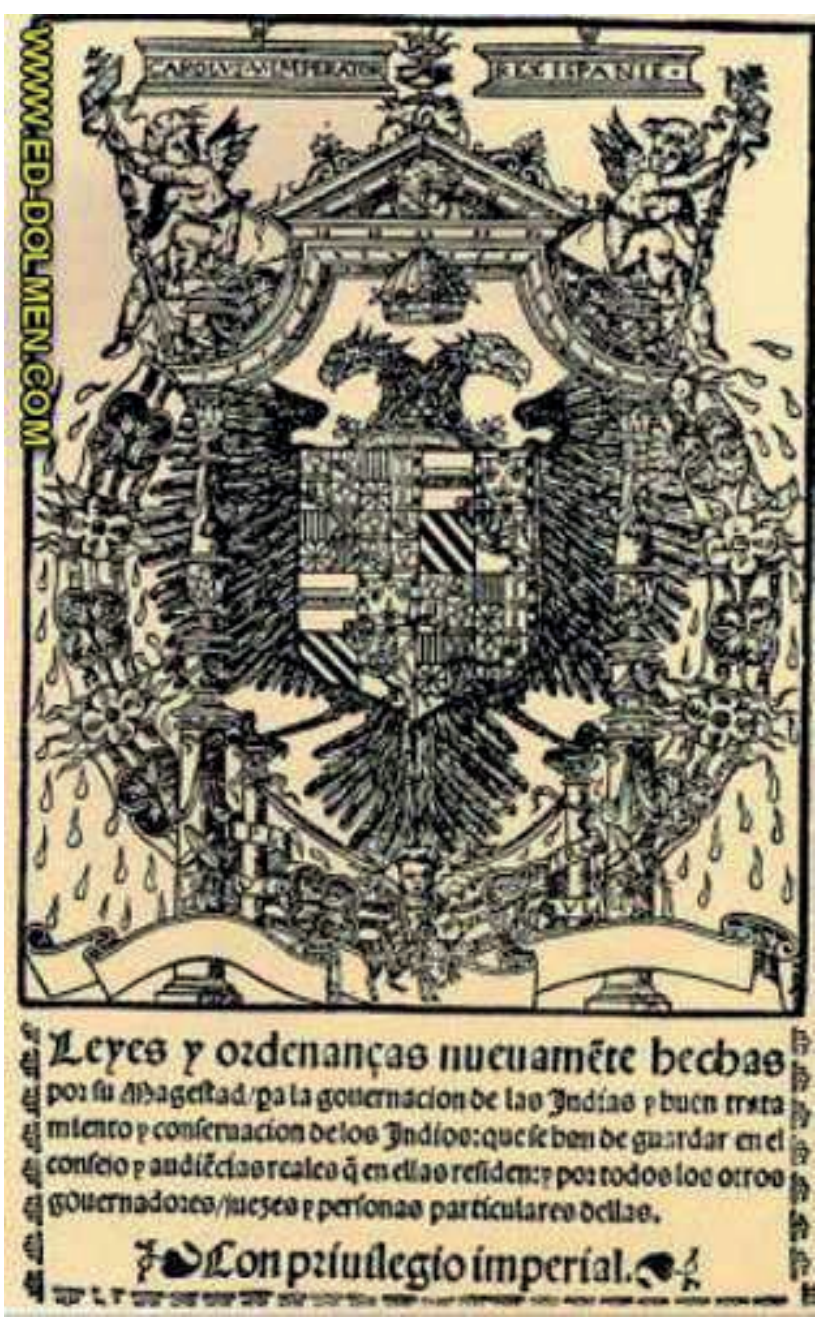

Figura 61. Portada de las Leyes Nuevas de Indias. Barcelona, 1542. Portal Antehistoria.com

(Nota 17a) La América Española Colonial. Siglos XVI, XVII y XVIII.

La Economía colonial - Trabajo.

http:/ / enciclopedia.us.es/index.php/Leyes_Nuevas_de_Indias

(Nota 17b) (ampliación) La misma fuente citada sobre estas líneas, indica también que... En el contexto del proceso de conquista se esclavizó al nativo, capturado en "guerra justa", para que trabajara en la extracción de metales preciosos y proporcionara alimento a los conquistadores. Las presiones ejercidas por sectores de 
la Iglesia y la disminución de la población indígena, determinaron que la corona permitiese el ingreso de negros africanos para que sustituyeran a la mano de obra aborigen.

Fuente: La América Española Colonial. Siglos XVI, XVII y XVIII.

La Economía colonial - Trabajo.

http://www.puc.cl/sw_educ/historia/america/html/2_1_4.html

(Nota 18) Un embrollo de encomiendas, encomenderos y mitayos. El sostén de la economía colonial fue el indígena americano, considerado legalmente súbdito de la corona y, por tanto, hombre libre. La categoría de súbdito implicaba el pago de un tributo o, en su defecto, un servicio personal a los representantes de la autoridad monárquica en América.

En los dos primeros siglos coloniales la encomienda reguló la fuerza de trabajo y la distribución de la mano de obra. "La encomienda era una vieja institución de carácter feudal, que establecía servidumbre a los señores a cambio de protección para los siervos. Se estableció entregando una comunidad de indios a un español (benemérito) a cambio de los servicios prestados por éste", explica Lucena Salmoral.

El historiador Guillermo Céspedes del Castillo agrega que "el beneficiario (encomendero) cobra y disfruta el tributo de sus indios, en dinero, en especie (alimentos, tejidos, etc.) o en trabajo (construcción de casas, cultivo de tierras o cualquier otro servicio); a cambio de ello, debe amparar y proteger a los indios encomendados e instruirles en la religión católica, por sí o por medio de una persona seglar o eclesiástica (doctrinero) que él mantendrá". 
Por lo tanto, la encomienda no implicaba la propiedad sobre los nativos; era una concesión no heredable. Al quedar vacante (sin poseedor) ésta volvía al monarca, quien podía retener a los indígenas bajo administración real o entregarlos a otro encomendero.

Paralelamente a la encomienda funcionó el sistema del repartimiento forzado, que consistió en el trabajo rotativo y obligatorio del indígena en proyectos de obras públicas o trabajos agrícolas considerados vitales para el bienestar de la comunidad. Esta modalidad de trabajo se basaba en reclutamientos laborales precolombinos, como fueron el coatequitl mexicano y la mita peruana, que los españoles aplicaron con un sentido diferente al que tenía en las sociedades nativas.

Las encomiendas paulatinamente fueron perdiendo su razón de ser, entre otros motivos, por la caída de la población aborigen, la desaparición de los conquistadores ávidos de recompensa y la paz que imperó en la mayoría de las provincias. En cambio, los repartimientos persistieron hasta el fin del período colonial.

La corona fue incapaz de conceder encomiendas indígenas al cada vez mayor número de españoles. Por ello, muchos de éstos se vieron forzados a recurrir a otras alternativas para proveerse de mano de obra. Aparecieron de esa manera diversas formas de peonaje y trabajadores libres remunerados.

Especialmente desde finales del siglo XVI, estos sistemas laborales predominaron en gran parte de la América española. Mientras en las haciendas laboraban peones, jornaleros y capataces, en las minas obreros libres ofrecían sus servicios. En las ciudades, por su parte, se constituyó una mano de obra libre calificada, compuesta por plateros, carpinteros, carreteros y gremios de artesanos en general. 
Todas las categorías laborales descritas -esclavismo, encomienda, repartimiento, etc.operaron de manera muy diversa de acuerdo a costumbres y regiones muy variadas. Por ello, las generalizaciones no dan necesariamente cuenta de muchas situaciones locales.

Fuente: La América Española. El Virreinato del Perú. Los funcionarios Locales. http://www.puc.cl/sw_educ/historia/america/html/2_1_4.html

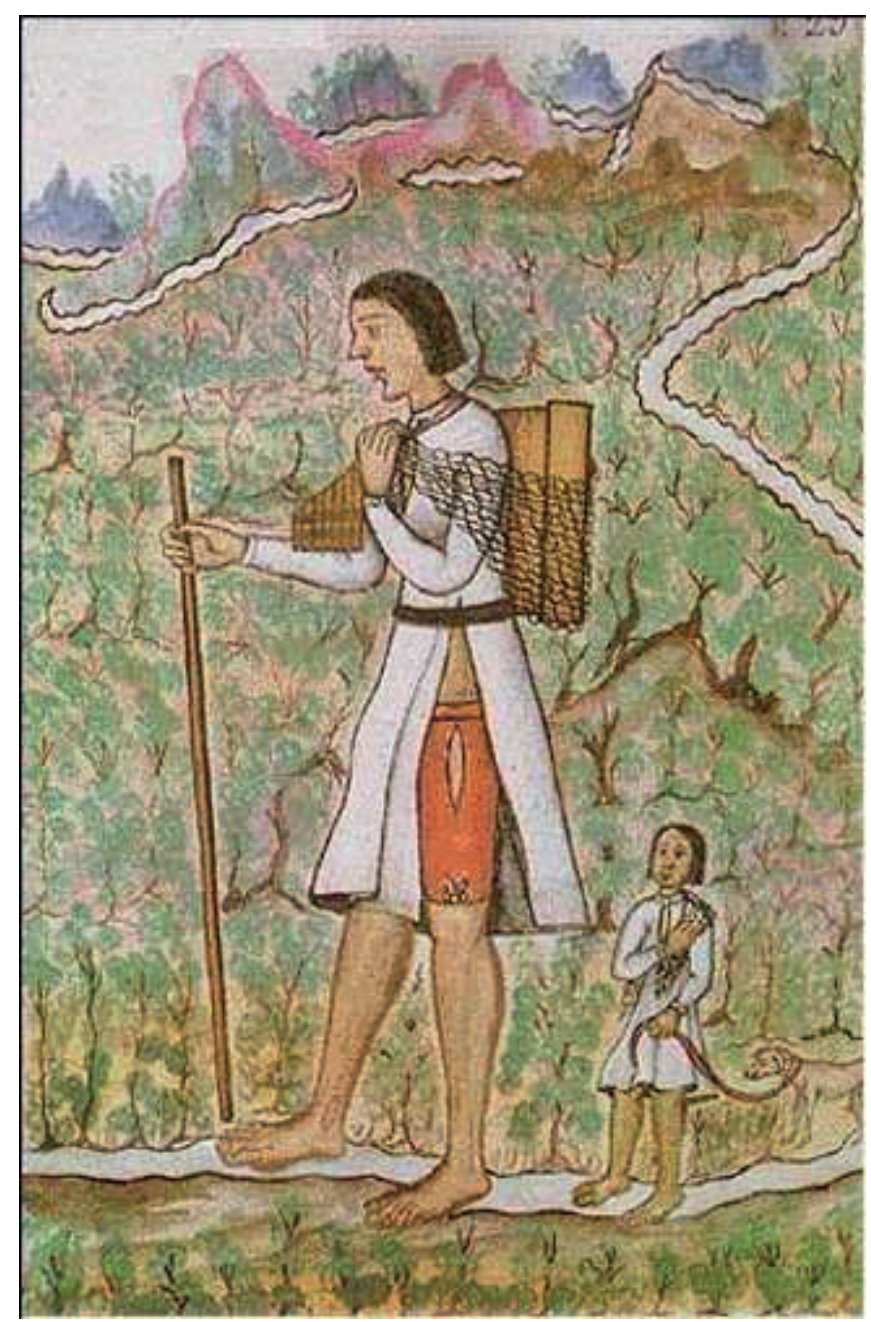

Figura 62. Indio mitayo en labores agrícolas. América Española Colonial. El Virreinato del Perú. Trabajo. 
(Nota 19) Bajo este sistema los indios debían laborar de sol a sol con sólo una hora de descanso. Ello, sumado a los malos tratos, la insalubridad y la pésima alimentación, terminó por diezmar poblaciones enteras. Con el tiempo, extensas regiones quedaron abandonadas porque sus habitantes emigraban huyendo de la mita. Por otro lado, no fueron pocas las revueltas que provocó esta explotación del hombre por el hombre.

(Nota 20) Es decir, en la misma categoría de los ganados y animales de cualquier especie.

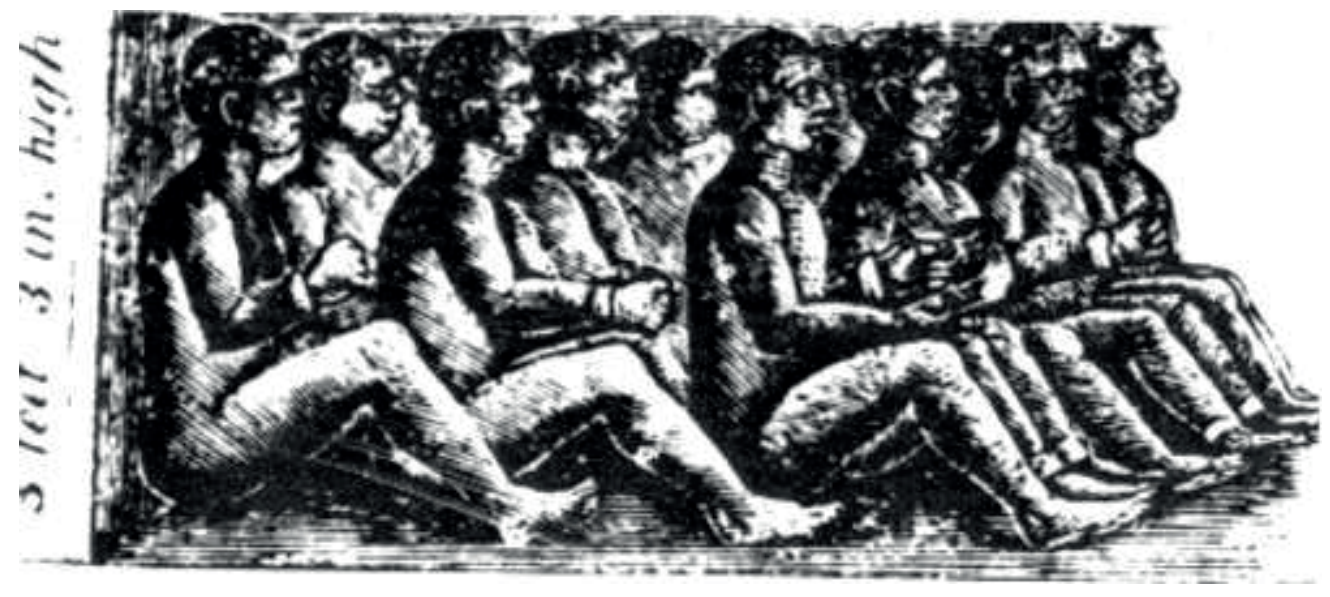

Figura 63a. Piezas de ébano II. Esclavos arrumados en un barco negrero. Ilustración probablemente del Siglo XVII, de artista desconocido. Slave Ship. African Presence 1492-1992 Schomburg Exhibit. 


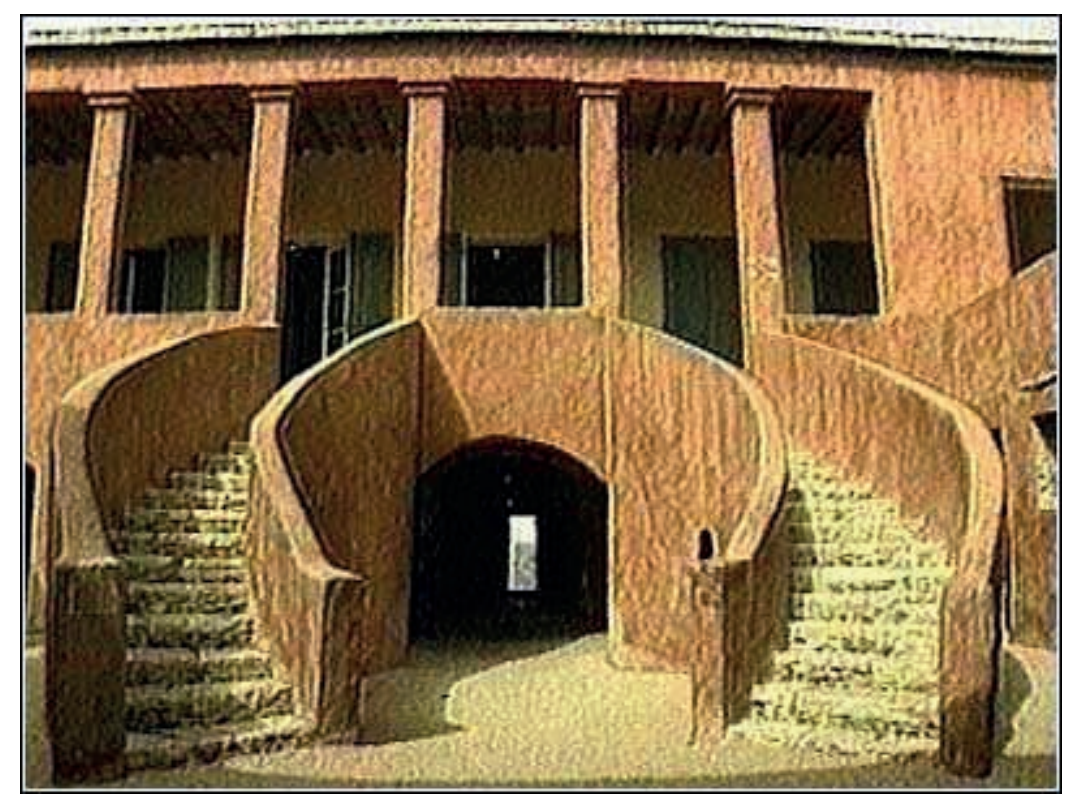

Figura 63b. Un cierto lugar llamado Goree. En esta isla, en realidad un islote de 900 metros de largo por 300 de ancho, ubicada frente a la costa de Senegal. Los franceses, sus últimos propietarios, aprovecharon la infraestructura dejada por portugueses, holandeses y daneses, que la ocuparon desde el siglo XV y la convirtieron en la factoría negrera más temida de África. Francia construyó en la isla varias "Casas de esclavos" a lo largo de sus costas y los tratantes continuaron llegando a ella hasta muy entrado el siglo XIX. En todo este tiempo, no se puede calcular la enorme escala humana que alcanzó este comercio infame en el mismísimo continente negro. Algunos investigadores calculan en veinte millones, tal vez más, los hombres, mujeres y niños que fueron literalmente arrebatados de sus aldeas, trasladados a la fuerza a esta u otras islas negreras, para ser vendidos a los traficantes.

En la época de mayor auge de la esclavitud, los tratantes establecieron en Goree sus propias "oficinas". Las "casas de esclavos" no eran otra cosa que lóbregas prisiones o calabozos donde los desdichados eran encerrados, encadenados y colocados unos contra otros, en espera de que algún "cliente" se fije en ellos antes de que el hambre, el cansancio, los maltratos y las enfermedades acaben con ellos. Ocurrida una "transacción" comercial, los esclavos eran sacados de su encierro por un pasaje, como 
aquel de la única "casa de esclavos" que aún está en pie, donde un letrero todavía reza: y se abre el camino sin retorno a la puerta del infinito dolor. Hoy la isla y sus viejas construcciones forman parte del Patrimonio Cultural por la UNESCO.

Foto del patio y las mazmorras de la mencionada "casa", hoy santuario a la memoria del sufrimiento africano.

Foto del portal La Senda de los Esclavos. La Isla de Goree.

(Nota 21) Los oficios a los que se dedicaban los esclavos negros no sólo se limitaron a dirigir a una tropa, también se dedicaron a limpiar armas y a la manufactura; con el tiempo sus habilidades se diversificaron a tal punto que los había desde peluqueros y "dentistas" -"blanqueo" dental y otros - hasta sastres, artesanos y fundidores; también brindaban servicios como braceros en las grandes haciendas de la costa peruana y como peones, albañiles, cargadores, arrieros, etc.

(Nota 22) Sobre la denominación negro. Una versión recogida por Jaime Pretell señala que en el nombre del río Níger no estaría el origen de la palabra "negro" aplicada a los esclavos africanos sacados de su tierra y llevados a las Indias. Según este autor, tal acepción tuvo su origen en el nombre que recibían estas personas: nigritae y no porque éstos fueran transportados por este río, que en ese entonces se llamaba Nigris, voz derivada de una corrupción del término berebere Gher-n-gher, que significaba río de ríos. A esto cabe añadir que por aquella época (S. XVI y ss.) los locales cuyas tierras eran bañadas por el Níger creían que este río era el más grande del mundo, por lo que la gente que vivía en sus márgenes era señalada como la gente del río o nigritae. El paso de los años se encargó de cambiar las cosas: el color oscuro del río y la piel azabache de los nigritae hizo que la denominación que recibían se volviera sinónimo de oscuro, y terminó convertido en lo que ahora conocemos: negro. Con el tiempo -dice Pretell - remplazó a la palabra romana ater para 
significar el color que ahora llamamos negro. En otras palabras, negro viene de un término étnico, no de una descripción de color. Más bien el color fue nombrado por la etnia.

Fuente: Origen del término "negro". Otra versión. Foro Afroperuano.

http://www.concytec.gob.pe/foroafroperuano/index1.htm

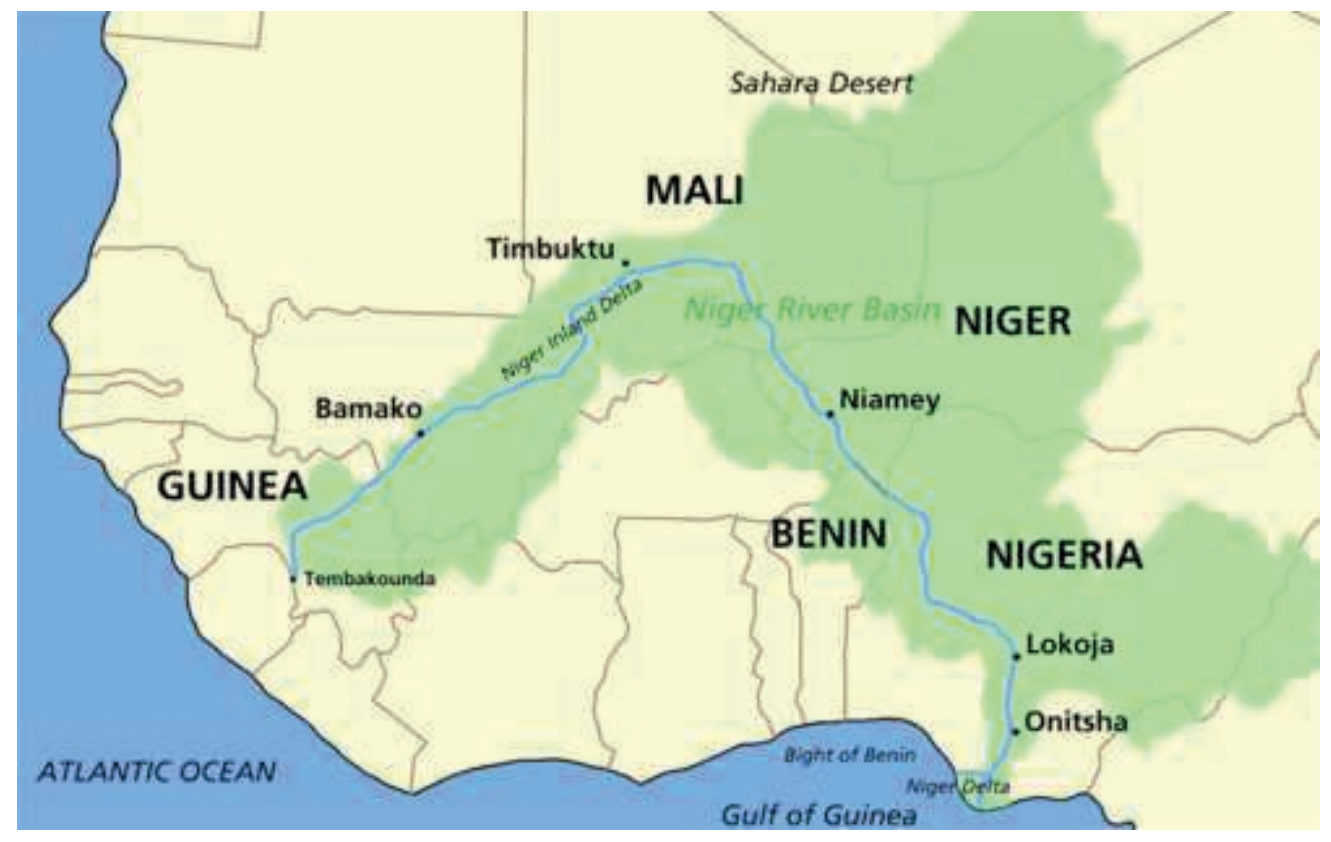

Figura 64a. El río de los nigritae, un gigante que besa el océano. Nace en Guinea Occidental, muy cerca del mar, y desemboca en la costa de Nigeria, recorriendo más de 4.000 kilómetros de tierras de todos los colores; el Níger es uno de los ríos más largos y caudalosos de África, y en sus márgenes se han desarrollado milenarias civilizaciones y ricas culturas. Esta región fue una de las más castigadas por la esclavitud que prácticamente despobló comarcas enteras, aunque sus pueblos nativos todavía conservan sus nombres originales. En el mapa, el color verde implica tierras fértiles, el amarillo, el desierto.

Ilustración de Astrokey44 publicada en Vikipedia, The free encyckioedia. 


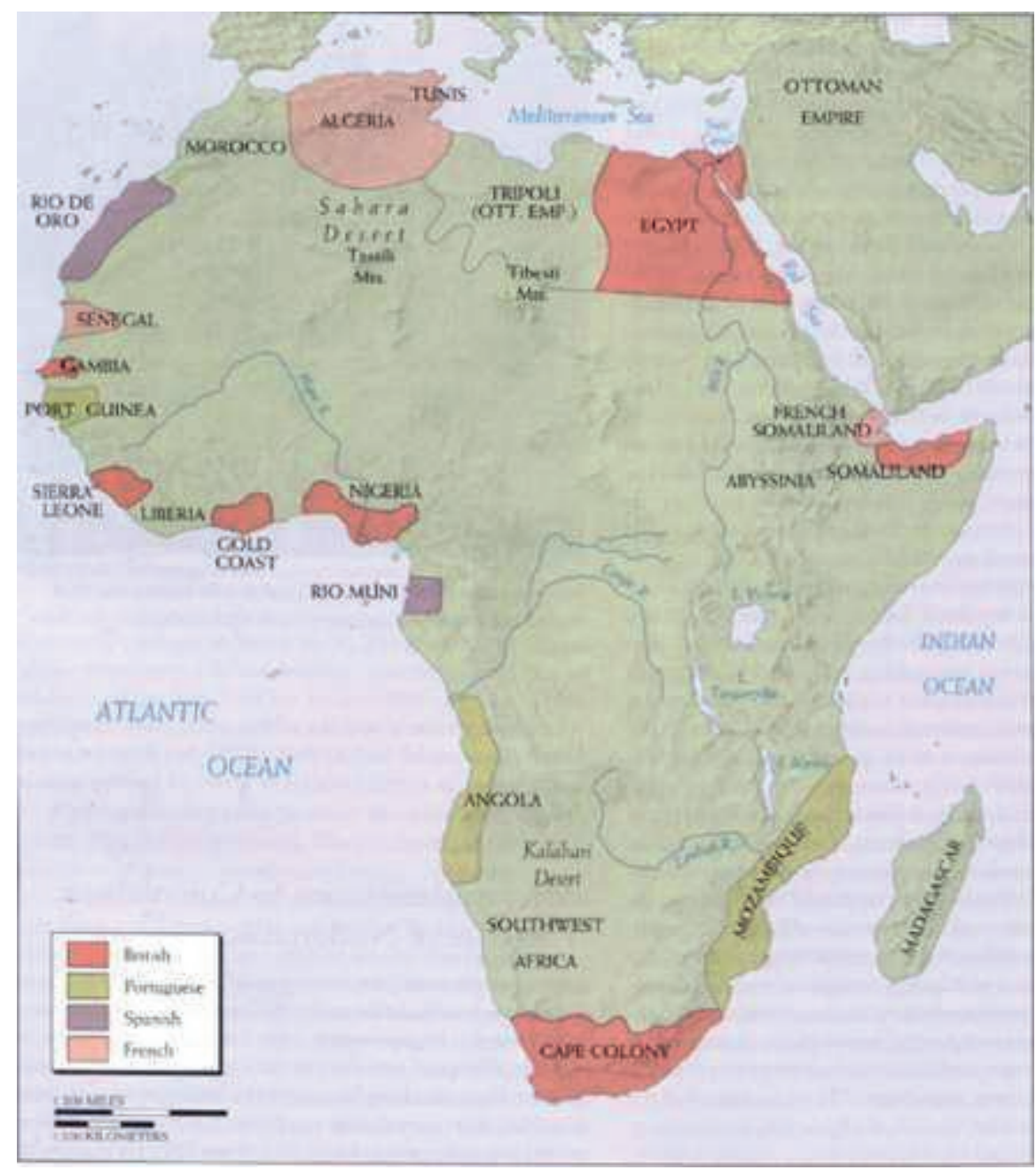

Figura 64b. Madre África. Expansiones imperiales europeas en África hacia 1880, con las áreas geográficas desde donde millones de africanos fueron llevados como esclavos a América y otras latitudes. Nótese resaltados los territorios que en su tiempo fueron emporios de la trata, tales como Gabón, Costa de Oro, Gambia, Senegal, Nigeria, Angola, Sierra Leona, Guinea, etc.

Introduction to World History. Gallery Images for Lecture. Part VI. andrew.cm

(Nota 23) Los negros que arribaban con sus amos muchas veces llegaban al país trayendo consigo a sus familias y se integraban a una gran población marginal que, sin embargo, a la larga terminaría por enriquecer la cultura del territorio donde se establecieron. 
(Nota 24) Según la Vikipedia, las reducciones de indios conformaban un sistema basado en la exclusión y la explotación del hombre por el hombre: (...) Ya desde los inicios de la presencia española en América, la Corona se había preocupado por la constitución de pueblos indígenas. La evolución de esta preocupación se ve plasmada en los diferentes documentos que la Corona va emitiendo: Instrucciones a Ovando (1501); las Leyes de Burgos (1512) y las Leyes Nuevas (1542). En las instrucciones a Nicolás Ovando, la Corona ordenaba que los indígenas vivieran en los pueblos de los españoles (favoreciendo así una asimilación total de la población indígena). Las Leyes de Burgos, primer código de los españoles en las Indias, encargaban a los encomenderos el adoctrinamiento de los indios que tuvieran encomendados, y a los indios les ordenaba vivir cerca de los poblados de los españoles, porque con la conversación continua que con ellos tendrán, como con ir a la iglesia los días de fiesta a oír misa y los oficios divinos, y ver cómo los españoles lo hacen, más pronto lo aprenderán.

Sin embargo, los abusos de los encomenderos y, sobre todo, el carácter "evangelizador" del estado castellano, que fundaba sus derechos sobre las tierras y personas de las Indias en el encargo papal de evangelizar a los indígenas, le hizo organizar los esfuerzos necesarios para facilitar el trabajo de los misioneros, para lo que era imprescindible la concentración de los indígenas en pueblos y ciudades al estilo castellano, si bien separados de los españoles. Al mismo tiempo, para que la Corona pudiese ofrecer a los indios protección y servicios, era necesario que la recaudación de los impuestos fuese eficaz, lo que no se podría realizar si la población vivía dispersa. De esta forma, puede deducirse que el sistema de reducciones, no sólo tenía propósitos misioneros y evangelizadores sino que también tuvo unos fines de carácter demográfico, económico y político. 
La organización efectiva de las reducciones data de 1531, según las instrucciones comunicadas a la segunda Audiencia de Nueva España. En cada reducción de indios debía haber una iglesia, atendida por un cura doctrinero (para adoctrinar a los indios en la religión católica; he aquí el propósito evangelizador). El sostenimiento del sacerdote corría a cuenta de los tributos que los indios estaban obligados a pagar (y aquí el propósito político y tributario). El régimen de vida en las reducciones era comunitario y los bienes de las reducciones (incluidas las tierras) pertenecían a la reducción, sin que pudiesen ser enajenados.

La mayoría de las reducciones fueron incorporadas a la corona española, aunque también se dieron a particulares en concepto de encomiendas. El conjunto de reducciones incorporadas a la corona recibió el nombre de corregimiento a cuyo mando estaba un corregidor. Sin embargo, esto trajo consigo el aumento de la corrupción, puesto que el cargo de corregidor era comprado y no conllevaba sueldo, lo que provocó todo tipo de extorsiones.

Fuente: Reducciones de Indios. Vikipedia, la enciclopedia libre.

http://es.wikipedia.org/wiki/Reducciones_de_indios

(Nota 25) Referencia: Historia de la Inquisición en el Perú. Congreso de la República.

http://www.congreso.gob.pe/museo/right03-1b.htm

(Nota 26)

Figura 65. Padrón de los Indios de Lima - 1613 
Grupos

$\begin{array}{llll}\text { Poblacionales } & \text { Varones } & \text { Mujeres } & \% \\ \text { Españoles } & 5.271 & 4.359 & 38,9 \\ \text { Religiosos } & 894 & 826 & 6,9 \\ \text { Negros } & 4.529 & 5.857 & 41,9 \\ \text { Mulatos } & 326 & 418 & 3 \\ \text { Indios } & 1.116 & 862 & 7,9 \\ \text { Mestizos } & 97 & 95 & 0,8\end{array}$

Fuente: Etnicidad y Discriminación Racial en la Historia del Perú. Varios autores. Instituto Riva Agüero (Pontificia Universidad Católica del Perú) y Banco Mundial. Lima, mayo 2002.

(Nota 27) Valen por mil palabras. En sus inigualables ilustraciones, el autor retrata la situación de la que fue testigo... y sufrió en carne propia. Se trata de un soberbio alegato contra los malos evangelizadores, los malos españoles, y el maltrato que sufrían tanto indígenas como negros en estos reynos del Perú. El Primer Nueva Corónica y Buen Gobierno (1615-1616) contiene unas 1117 páginas donde las ilustraciones ocupan un tercio de la obra. Se puede consultar en Internet la versión facsimilar completa de la primera edición original de esta obra, compilada por John Charles y Rolena Adorno:

http://www.kb.dk/elib/mss/poma/index-en.htm 


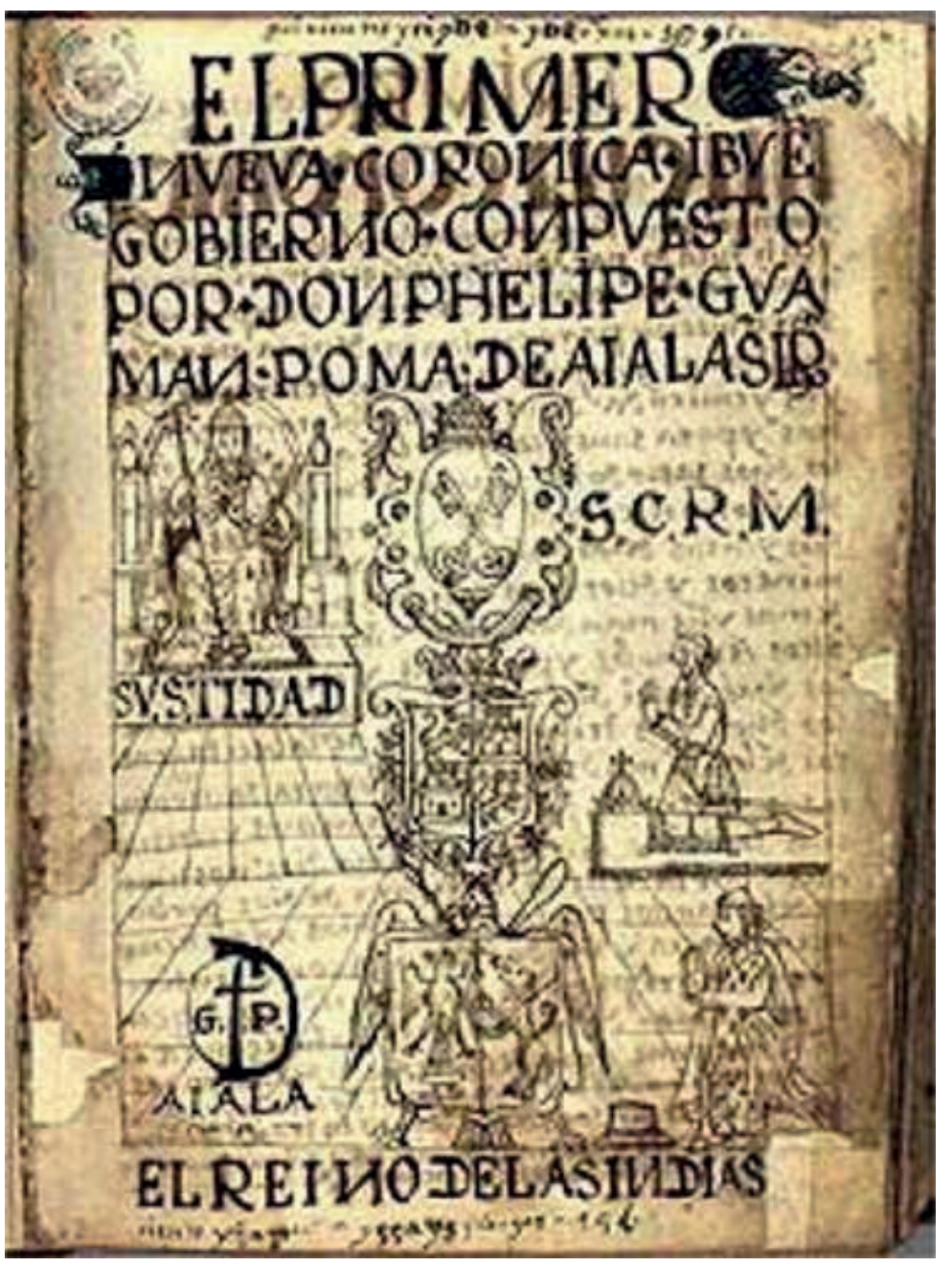

Figura 66. Portada de El Primer Nueva Corónica y Buen Gobierno (1615-16).

Ilustración tomada de la versión facsimilar de John Charles y Rolena Adorno.

(Nota 28) Esta cifra nos permite inferir que, a mediados del siglo XVII, la población limeña de origen africano había alcanzado su ápice, una presencia demográfica nunca antes registrada. En este mar humano, los angolas constituían uno de los grupos étnicos más importantes. No es casual por ello que, entre 1635 y 1638, los jesuitas contemplaran la posibilidad de aprender la lengua angola con fines de evangelización. Esta preocupación jesuita queda corroborada por los datos demográficos que proporciona Tardieu, quien señala que, entre 1640 y 1680, la 
población negra procedente de Angola era el grupo mayoritario en la Parroquia de San Marcelo: ascendía al 17,31\% de un total de 936 personas.

(Nota 29) El mismo autor indica también, al hablar de los barcos de la trata, que... Los costos de la operación negrera resultaban elevados (licencias, registros, mercancía de trueque). Existía la obligación de armar el barco debido a la piratería para revender ilegalmente esclavos tomados como presa. Un patache de 30 toneladas debía llevar ocho mosquetes y dos arcabuces, tres arrobas de pólvora y dos de plomo. Si el barco es de 100 toneladas son obligatorias cuatro piezas de artillería, 150 balas, 15 mosquetes, 12 picas, un quintal de plomo y pólvora.

Fuente: Duras condiciones del transporte (s.XVII).

Historia / Canarias / Navegación.

http://www.mgar.net/var/trata.htm

(Nota 30) De la "inferioridad" del negro africano. García también señala que: La idea de un "negro bárbaro" es una creación europea que continuó ejerciendo sus efectos sobre Europa hasta los inicios del siglo veinte (Leo Frobenius). En 1704, en una enciclopedia, la última palabra de la ciencia, decía: "Los africanos suelen ser negros y se les llama negritos o moros. Son viciosos, salvajes, crueles y muy fuertes, y cada año, se venden gran cantidad de ellos como esclavos a los europeos".

Fuente: Historia / Canarias / Navegación de Manuel García.

http://www.mgar.net/var/por_escl.htm

(Nota 31) El estudio Etnicidad y Discriminación Racial en la Historia del Perú advierte la dificultad existente en dar una explicación acerca de la definición de cofradía. "No existe una respuesta unánime" de los investigadores. Las distintas definiciones variarán según los contextos sociales y geográficos estudiados. De 
acuerdo con las personas que la integraban, el entorno en el que se desarrollaban y su propia evolución histórica, la cofradía fue ampliando o creando nuevas funciones. Beatriz Garland (1994-2001) manifiesta que una cofradía en nuestra ciudad fue una institución de seguro y crédito cuya actividad iba de la mano con el culto a un santo patrono y la promoción de una serie de manifestaciones socioculturales y espirituales. Entre ellas tenemos, por ejemplo, procesiones, fiestas, entierros, limosnas y dotes por sorteo para las hijas de los miembros. Además, no se puede concebir las actividades de crédito y seguro sin una advocación religiosa y sin las manifestaciones indicadas. Según Anthony de la Cruz, en Lima había dos tipos de cofradías, religiosas y étnicas, ya que el papel benéfico era desempeñado por las hermandades.

Fuente: Varios Autores. Publicación del Instituto Riva Agüero (Pontificia Universidad Católica del Perú) y el Banco Mundial. Lima, 2002 - Versión en formato PDF:

http://www.aprodeh.org.pe/desc/documentos_racial/EtniciTomo1.pdf\#search= $\% 2$ 2Etnicidad\%20y\%20Discriminaci\%C3\%B3n\%20Racial\%20en\%20la \%20Historia\%20de $1 \% 20 \mathrm{Per} \% \mathrm{C} 3 \% \mathrm{BA} \% 20 \% 22$ 


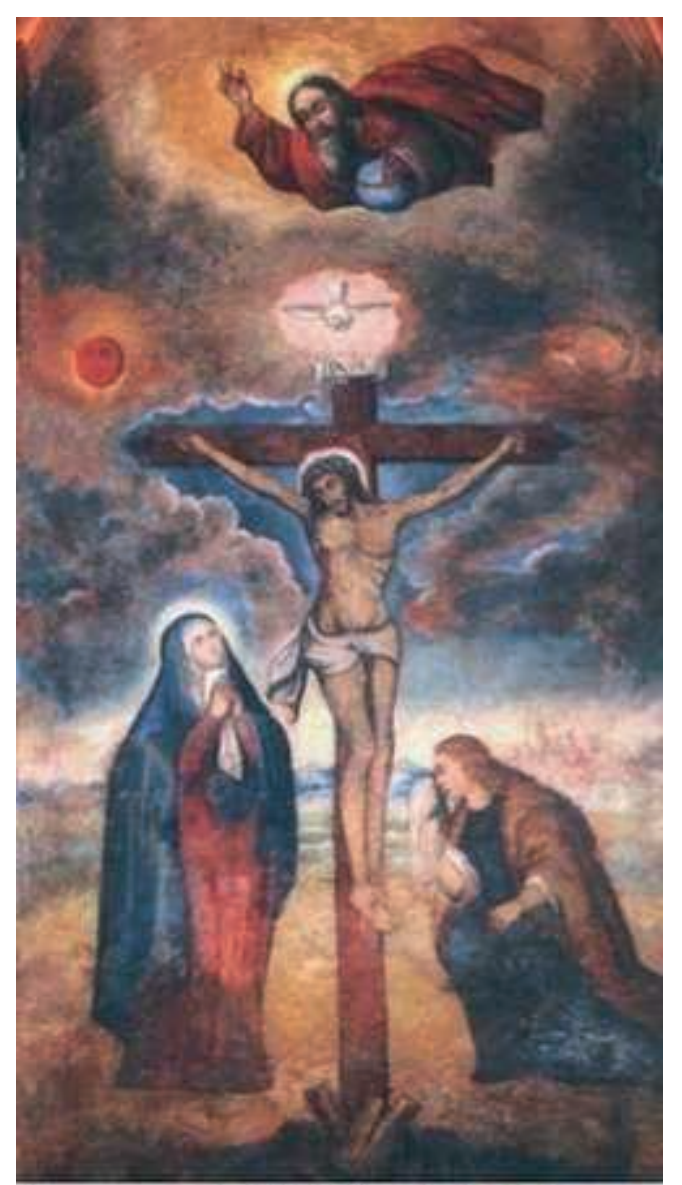

Imagen original del Sen̈or de los Milagros, la cual se encuentra en el AltarMayor de la Iglesia de las Nazarenas en Lima, Perú.

Figura 67. El muro del milagro. Imagen original pintada por el anónimo negro angoleño del barrio de Pachacamilla, en lo que hoy es el Jirón Huancavelica (Lima). Ahora se encuentra al interior del santuario de las Nazarenas. Lienzo al temple sobre pared. Circa 1650. Ilustración del portal Historia del Señor de los Milagros.

(Nota 32) El mismo autor agrega igualmente que: Los esclavos, por ejemplo, vivieron en galpones espaciosos con sus bases blanqueadas con cal para evitar la humedad. De igual manera, la dieta que se dio a los esclavos consistió en frijoles, sango, yucas, manteca, charqui o carne de vacuno los domingos, y cuando había trabajo en exceso, además de todo ello, se les agregaba aguardiente. Cantidades enormes de maíz se compran para la preparación del sango. También, cuando los esclavos realizaban 
faenas duras como la limpia de las acequias, se compraban toros en cantidades que, aunque parezca exagerado, era lo que acontecía: 10 toros para la limpia. Mucho fríjol se compra en Chincha, maíz de Asia, carneros a Juan Quiroz de Lunaguana, toros a Domingo Basombrío, todo ello para mantener contentos y a gusto a los esclavos. Por lo menos en el siglo XVIII la alimentación fue adecuada para los negros esclavos de las haciendas.

También los padres de la Buena Muerte cuidaron a sus esclavos edificando una enfermería bastante bien surtida en la hacienda de Casablanca, donde se dio atención a los esclavos y esclavas que padecían alguna enfermedad o se accidentaban y, cuando el mal o accidente era de cuidado, eran trasladados a Lima. Se podrá argüir que tener una enfermería redundaba en beneficio de la Orden, pues conservaba a los esclavos y por tanto se protegía la inversión en ellos, pero a lo que nos referimos es al trato que se daba a los esclavos que llegaban a la enfermería, por ejemplo, a las negras paridas se les daba una dieta adicional de gallinas por espacio de uno a dos meses.

Sin embargo, de una aceptable alimentación acompañada de tabaco, carne, aguardiente e incluso propinas en dinero, el deseo de ser libres en los esclavos de Casablanca y La Quebrada, y que se hace extensivo a todos los esclavos, fue más fuerte y como una epidemia, los esclavos frecuentemente fugaban de las haciendas no obstante que se reconstruyeron los galpones y se le dio mayor seguridad. El cimarronaje de las haciendas de la Orden es permanente y los esclavos huyen en forma individual o también en grupo. A los esclavos fugados se los encontraba en Chincha, Lunaguana, Castrovirreyna significando un egreso adicional para la hacienda, pues se tenía que pagar a indios o mestizos que capturaban a los negros huidos. 
Cuando los negros huidos eran atrapados y devueltos a la hacienda se les castigaba. No podía estar al margen de las relaciones amo/esclavo el azote, el cepo, la cárcel, todo ello es parte de la vida de los esclavos en las haciendas de Casablanca y La Quebrada. El paternalismo, como política de relación con sus esclavos desarrollada por los padres de la Buena Muerte, no significó que se dejara de lado el uso de la violencia cuando se hizo necesario, especialmente, contra aquellos esclavos que huían, robaban o trabajaban a desgana

Esta política, de mayor endurecimiento en las relaciones de los administradores de las haciendas con sus esclavos, comenzó a hacer crisis a principios del siglo XIX. Para estos años, los mayordomos fueron particulares, adoptaron un mayor rigor y exigencia en el trabajo que realizaban los esclavos, descuidando, en gran medida, la dieta que se les daba.

Esta política de aumentar los azotes y disminuir la dieta alimenticia hizo crisis en La Quebrada en 1809, provocando un alzamiento de esclavos y esclavas que tuvo repercusiones en Lima.

Fuente: Investigaciones Sociales - Universidad Nacional Mayor de San Marcos. (UNMSM)

http:/ / sisbib.unmsm.edu.pe/BibVirtual/Publicaciones/inv_sociales/N03_1999/ esclavitud.htm\#ESCLAVOS

(Nota 33) En septiembre del año 1713, a las afueras de la ciudad de los Reyes de Lima, en los montes de Huachipa, las tropas del Rey destruyeron uno de los Palenques más importantes del valle. La batalla que duró desde la mañana hasta las tres o cuatro de la tarde acabó cuando el general de los cimarrones cayó herido, su nombre: Francisco Congo, alias Chavelilla. 
Los cimarrones capturados fueron trasladados a la ciudad y se les abrió el proceso judicial titulado Instrucción abierta contra esclavos, Cimarrones, Ladrones y Resistencia a la Autoridad. Año de 1713. Gracias a este documento sabemos, por las propias declaraciones de Francisco Congo, que él había sido esclavo de una hacienda en Pisco, de la cual se había fugado hacia dos años atrás, viniendo a la ciudad de Lima "solo con Dios". El alias de Chavelilla se debió a que en Pisco se llevó a una negra de nombre Chavella, que fue recapturada por el corregidor. Tenía seis meses al mando del palenque y treinta años cuando fue capturado.

No tenemos más datos sobre su vida personal. Fue juzgado como criminal por liderar a los cimarrones que buscaban vivir en libertad y, por lo tanto, el proceso judicial estaba dirigido a sentenciarlo y castigarlo ejemplarmente. No sabemos cuál era su nombre original cuando nació libre, sólo el término Congo nos revela parte de su identidad africana debido a que, por regla general, a los esclavos se les ponía un nombre español, al cual se le agregaba el lugar de su procedencia. Sin embargo, este dato no nos dice nada del pueblo o grupo étnico al cual pertenecía Francisco Congo; pudo haber nacido en algún pueblo perteneciente al antiguo reino de Mwani Congo, cuya capital era Bonza Congo o Mbila, que en la actualidad se encuentra en la zona limítrofe con Zaire y la República del Congo, zona en donde se inicia el colonialismo portugués en 1490 .

De lo que no hay ninguna duda es que Francisco Congo fue cimarrón, palabra que utilizaban los españoles en América tanto para nombrar al esclavo que se fugaba de su centro de trabajo y trataba de vivir en libertad, como al animal doméstico que huía y habitaba en el monte y al fruto o planta silvestre para diferenciarlo de su variedad cultivada. Nuestro personaje era el líder de un palenque, nombre con el que se denominaba a la aldea cimarrona y al cerco de troncos que la protegía, aunque 
también con esta palabra se designaba a la cueva, choza o matorral que servia de refugio a uno o dos fugitivos.

Huachipa, "a legua y media de la ciudad de Lima", en tiempos de la fundación del palenque, era una zona propicia para refugiarse, los puquios y pantanos facilitaban la agricultura y cría de animales, los cañaverales, aparte de servir de protección, proporcionaban la materia prima para la confección de cestas por parte de las mujeres. Es muy probable que hacia fines de 1711 los cimarrones de origen terranovo levantaran el palenque en una zona que sería descrita luego como "paraxe muntuoso".

La población en un inicio estaba conformada por lucumis, araras, minas, criollos y principalmente terranovos, quienes tenían el control y estaban al mando de Martín. No admitían a cimarrones congos, probablemente por rivalidades étnicas o religiosas; sin embargo, a fines de 1712, aceptan a Nicolás Congo, seguramente porque tenía cerca de cincuenta años y, teniendo en cuenta las expectativas de vida y el desgaste físico de un esclavo agrario para los terranovos, su presencia no significaría amenaza alguna.

La organización interna del palenque estaba distribuida según actividades y cargos, había un general que era el líder y jefe militar, civil y administraba justicia; un capitán y un "capitanillo" o cabo que se encargaban de asistir al general en las batallas y expediciones y un alcalde que se encargaba de hacer cumplir las disposiciones del general así como administrar la aldea. Al momento de alguna acción militar todos los hombres pasaban a ser soldados; las labores agrícolas, domésticas y artesanales eran realizadas por las mujeres; dentro de estas últimas actividades se confeccionaba cestas de totora, "canastitas de junquillo y sombreros y petaquillas", las cuales eran vendidas en la ciudad a través de un "negro viejo" y las 
compras de algunos productos se realizaban a los negros que llegaban al monte a cortar leña y quienes también les llevaban noticias de la ciudad, según testimonio de uno de los cimarrones, en Lima también había un alcalde reclutador que se encargaban de mandar a cimarrones a Huachipa.

Francisco Congo ingresa al palenque entre los meses de enero y febrero del año 1713, autorizado por Martín Terranovo, dicho permiso, pese a las disposiciones de no aceptar negros congos en la aldea, se debió a que los terranovos se sentían seguros de su poder al ser mayoría y porque Francisco Congo debió demostrar cualidades muy especiales, y esto lo confirma su nombramiento como capitán y alcalde al mismo tiempo por su reconocido valor. Las rivalidades entre Congos y Terranovos se agravan cuando en marzo ingresa Joseph Congo y semanas después Lorenzo Congo. Este incremento de Congos dentro de la aldea se debió al afianzamiento de su liderazgo, mejora y engrandecimiento del palenque, con la construcción de otra aldea más arriba del poblado, que ocupaban y la habilitación de terrenos de cultivo.

El palenque ahora estaba dividido en dos sectores, el primero era el fuerte y se encontraba ubicado en los montes de Huachipa, dentro de los terrenos de la chacra Los Ancones, que eran propiedad del tesorero Juan Rodríguez Pedreros, estaba ubicada dentro de tupidos cañaverales y ciénagas sembradas con estacas de caña brava, cuyas puntas estaban endurecidas al fuego, de esta forma sólo se podía llegar hasta el fuerte a través de un único caminito que debía ser secreto. El fuerte estaba protegido por un cerco de troncos que tenía una puerta de ingreso pequeña por la cual podía ingresar únicamente un hombre a la vez y en cuclillas. Dentro del fuerte un árbol de sauce servía de mirador, el agua era obtenida de un puquio.

El segundo sector del palenque era la aldea en el Guaico o Guarco, que se encontraba en una "quebrada que está en las cabezadas de la sierra de la provincia de Guarochirí", que son las cabeceras de la ciudad prehispánica de Cajamarquilla. 
Estaba conformada por una plaza alrededor de la cual había treinta casas distribuidas según el sexo; la particularidad del clima de esta zona la hicieron propicia para tener silos subterráneos acondicionados con pellejos de vacas, en donde almacenaban principalmente maíz. Los campos aledaños habían sido habilitados para el cultivo de zapallo, maíz y tunas.

Esta organización del palenque generó rivalidades por el liderazgo. Una noche los terranovos atacaron a Francisco Congo en el fuerte con la intención de asesinarlo, en la lucha, sin embargo, murieron tres de los agresores; las rivalidades llegaron a su punto culminante dos días después cuando Martín Terranovo y Francisco Congo se enfrentaron en duelo para definir quién sería el líder, Martín Terranovo pagó con la vida su derrota, pero la lucha no terminó ahí, pues tuvo que hacer frente también al bozal Salvador Terranovo, a quien luego de vencerlo perdonó la vida; los terranovos sobrevivientes abandonaron el palenque, era abril de 1713.

Francisco Congo pasó a ser general, y con el poder que este cargo le daba, nombró a Manuel Lucumí como alcalde, a Miguel La Torre como capitán y a Nicolás Congo como "capitanillo". Estas victorias confirman a Francisco Congo como el auténtico líder de los cimarrones y fortalecía la creencia de que tenía poderes sobrenaturales; él mismo decía presentir las cosas "que su cuerpo le avisaba" y que estaba bajo la protección de Dios y la Virgen María. Salvador Terranovo a quien venció y perdonó la vida, permitiéndole seguir viviendo en el Palenque por ser "bozal que no sabía nada y no estaba bautizado ni lavado de la cabeza", diría en el proceso judicial que su líder "es brujo y que no morirá con hierro porque aunque le dio con el chuso, que le pasó la cara y lo dejó por muerto, no quiso morir y se levantó y luego se le cerró la herida".

Francisco Congo también es un líder religioso, y sería el chaman del palenque, es decir, la persona que podía comunicarse con los orishas o dioses africanos que se 
encontraban a miles de kilómetros al otro lado del océano, manteniendo de esta manera parte de sus tradiciones ancestrales, porque también tenían un tambor y este instrumento era el medio para "hablar" con los dioses y para usarlo requería de toda una ceremonia para consagrarlo, por eso que su uso estaba prohibido y perseguido en el virreinato.

Con los congos como líderes indiscutibles del palenque de Huachipa, su población crece rápidamente, las labores agrícolas eran combinadas con la comercialización de productos y el robo de ganado a los haciendas y nunca a los indígenas. Sin embargo, parte del ganado robado era compartido con los esclavos de las haciendas y con los que llegaban a la zona de dominio del palenque, de esta forma todos se beneficiaban con su existencia, menos los hacendados.

Una mañana de septiembre de 1713 las tropas del rey al mando del corregidor de Huarochirí, general Martín Zamudio, y con la ayuda de García Mogollón hacendado del valle, iniciaron el ataque al palenque. Luego de varios intentos para ponerlo al descubierto, como quemar la maleza, se optó por bloquear las salidas, para finalmente tomar por asalto el palenque con las milicias de indios reclutados por los hacendados.

Al momento del ataque el número aproximado de habitantes del palenque era de 38 personas, de los cuales 22 eran hombres y 17 mujeres. Los capturados al final de la batalla fueron 29, siendo 8 congos, 6 lucumi, 3 terranovos, 5 minas, 2 carabalí, 2 criollos, 1 arara y 1 popo, el resto probablemente huyó. La edad de los apresados estaba entre los 20 y 50 años, siendo mayor el número de cimarrones cuyas edades estaban entre los 25 y 30 treinta años. 
Tomado el palenque, se ordenó a las cuadrillas de indígenas que desforestaran totalmente el monte, el puquio que abastecía de agua al fuerte fue desaguado hacia el río por una enorme zanja, y la aldea junto con los terrenos de cultivo fueron arrasados y quemados.

27 de los cimarrones juzgados fueron indultados por el Virrey Diego Ladrón de Guevara con la condición de que fueran vendidos lejos de la ciudad de Lima y a una distancia no menor de cuarenta leguas, utilizando el dinero producido por la venta para cubrir las recompensas y gastos de la captura.

El tribunal encontró a Francisco Congo y Manuel Lucumí, culpables de "sedición y tumulto, robos y homicidios" y fueron condenados a la horca y descuartizamiento. Juana Cavesas, ama de Manuel, declaró "que no tenía ni podía defenderle y que si tenía delito fuese castigado", por su parte Isabel Fragoso, ama de Francisco Congo, dijo que "no tenía con que costear su defensa".

La sentencia se aplicó.

(Ver: ¿Qué era un palenque? - Nota 34)

Obtenido de: Los Afroperuanos. Historia y situación actual. Centro de Desarrollo Étnico. (CEDET)

http:/ / afrolatino.org/ forum/viewtopic.php?p=5611\&sid=47960a9f6b68d22df2d4b6e b57c44bb5

(Nota 34) Los palenques o pueblos de cimarrones no llegaron a constituirse en estados, ni tuvieron la magnitud poblacional que alcanzó en otras latitudes, sin embargo, fueron numerosos. Los medios de vida y formas de producción en los 
palenques estaban definidos por: 1.- Cultivos agrícolas en campos propios habilitados para este fin en los montes. 2.- Artesanías, especialmente cestas y sombreros que se vendían en los mercados de las ciudades. 3.- Ayuda recibida de los esclavos de fuera consistente en carnes, productos agrícolas, instrumentos de labranza y otros. 4.- Botín de los asaltos.

En Lima tenemos el palenque de Cieneguilla, establecido hacia 1631; en 1632 fue destruido uno entre Mala y Calango; el de Carabayllo y Zambrano en 1761; Vicentelo en 1796. Sin embargo, pese a que todos estos palenques fueron una amenaza significativa y requirieron para su destrucción la movilización de un contingente considerable, no tenemos mayores datos sobre su organización interna o líderes, simplemente fueron destruidos. El último cimarrón del que se tiene noticia fue "Zambillo" y fue muerto en la hacienda Quiroz en 1808 ante la negativa de rendirse.

(...) el término palenque para referirse a estos poblados no era de uso común en las colonias americanas, en otros lugares del continente se utilizaban nombres como quilombo, cumbe, ladeira, mocambo o mambisas. Su tiempo de duración también varia de un lugar a otro al igual que el número de sus integrantes; en algunos casos duraron apenas meses o algunos años, en otros, se convirtieron en reynos y estados con miles de miembros como el de Yanga en México, Bayano en Panamá, Miguel en Venezuela o Domingo Bioho en Colombia que sobrevivieron por generaciones.

Lo que sí es común a todos los poblados cimarrones es el anhelo de vivir de manera independiente, auto sostenible y afirmarse como grupo a partir de la práctica de sus tradiciones ancestrales; para lograr esto debían vivir en lugares poco accesibles o de difícil ubicación. 
Fuente: Los Afroperuanos. Historia y situación actual. Centro de Desarrollo Étnico. (CEDET)

http:/ / afrolatino.org/forum/viewtopic.php? $\mathrm{p}=5588 \&$ sid $=79685$ cc75786a0321853c28 b721a0261

(Nota 35) En junio de 1742 estalló este movimiento libertario cuyo primer objetivo era liberar los poblados de Matranza, Quispango, Pichana y Nijandaris. Juan Santos Atahualpa se enfrentó y venció a las tropas de José Antonio Manso de Velasco, Conde de Superunda, vigésimo cuarto virrey del Perú (1745 - 1761), un veterano de la guerra contra los naturales en Chile. Ante esto, Lima envió más refuerzos bajo la comandancia del prestigioso general José de Llamas, quien, en 1746, llegó al Chanchamayo con 850 hombres que fueron derrotados en una cruenta batalla. Los españoles hicieron una nueva intentona, pero fueron otra vez vencidos en la zona de Monobamba (1750). La estrategia de las emboscadas le estaba dando resultados al caudillo indígena, gran conocedor de la zona. Finalmente los españoles cambiaron de estrategia y convirtieron a Jauja y Tarma en bastiones militares con el fin de evitar que Juan Santos alcanzara la sierra, pues se temía que su movimiento terminara comprometiendo el abastecimiento de alimentos a Lima; de igual manera se quería evitar que el fenómeno provocara un levantamiento en toda la región andina. Entonces, se dispuso utilizar cinco compañías de infantería y caballería, apoyadas por milicias locales y patrullas de la región. Y el virrey encargó la campaña a militares de prestigio y a corregidores de la zona. Sin embargo, las fuerzas españolas y rebeldes nunca se volverían a enfrentar. Finalmente, Santos Atahualpa desapareció de la escena de luchas y su movimiento terminó diluyéndose. Se sabe poco o nada sobre esta "desaparición". Algunos autores refieren que desde 1756 ya no se sabía nada de su paradero. Otra versión dice que hubo una sublevación entre ellos mismos y que Santos Atahualpa ordenó la muerte de Antonio Gatica, su lugarteniente y otros 
hombres por posible traición. Se comenta también que fue envenenado, pero lo más probable es que haya muerto de vejez.

(Nota 36) Cuadro: 1. Población negra en América a fines del siglo XVIII. http://www.arbil.org/(42)irab.htm

(Nota 37)

Figura 68

Modelos Raciales según la clasificación de los cuadros que el virrey Manuel Amat mandó pintar (1770)

De negro y negra: negro

De negra y español: mulato

De mulata y mulato: mulato

De mulata y español: cuarterón de mulato

De cuarterona de mulato y español: quinterón de mulato

De quinterona de mulato y español: requinterón de mulato

De requinterona de mulato y español: blanco

Otros:

De negro con mulata: zambo

De negro con india: zambo de indio

De mulato e india: chino

De español y china: cuarterón de español 
El negro según su procedencia era: Bozal (africano) o Ladino (aculturado) y a partir de 1663 se les comenzó a denominar genéricamente como "morenos" y a los mulatos como "pardos" y en cuanto a los títulos que se daban entre sí, entre el siglo XVI y XVII predominó el de "reyes" para los nacidos en África, los criollos prefirieron otorgarse títulos militares en el siglo XVII como Capitanes y Coroneles.

Fuente: Los Afroperuanos. Historia y situación actual. Centro de Desarrollo Étnico. (CEDET)

(Nota 38) Todo empezó en 1776, cuando la Audiencia de Lima rechazó una petitorio suyo que pretendía liberar a los indios del trabajo en las minas y decidió tomar medidas más drásticas contra éstos. En noviembre de 1780, José Gabriel Condorcanqui lidera una insurrección cuya primera acción es detener y hacer ejecutar al corrupto y cruel corregidor Arriaga, en un acto de justicia que irritaría a las autoridades españolas. Imbuida de ideas independistas, la sublevación se extendió por gran parte de la sierra sur del Perú. Aunque el objetivo era luchar contra el mal gobierno y los excesos de la administración colonial, Tupac Amaru no pudo evitar que su gesta se convierta en una lucha de reivindicación racial. Al frente de 1.200 hombres, derrotó a un ejército español en la batalla de Sangarara, pero no quiso atacar el Cusco con la idea de iniciar negociaciones de paz.

El repliegue de Tupac Amaru II a Tinta fue aprovechado por los españoles para organizar la resistencia y vencer a los rebeldes el 8 de enero de 1781, por las tropas enviadas por el virrey Agustín de Jáuregui (1780-1784). Después, entre el 5 y el 6 de abril, las fuerzas rebeldes sufrieron una estrepitosa derrota en el valle de Tinta, por las tropas del mariscal Del Valle. Perseguido por el general Ventura Landa por Tamanico, Tupac Amaru II es finalmente detenido junto a sus colaboradores. El cacique fue juzgado y condenado a muerte por el visitador Areche, quien lo hizo ajusticiar el 18 de mayo de 1781 en la plaza de Armas del Cusco. Amarrado a cuatro 
caballos, su cuerpo fue descuartizado. Antes de su muerte, fue testigo de la ejecución de su esposa, Micaela Bastidas, y el asesinato de sus hijos. Pero a pesar de ello, la rebelión continuó, acaudillada por su medio hermano, Diego Cristóbal Tupac Amaro, quien finalmente depuso las armas en 1782, bajo la promesa de las autoridades coloniales de indultar a los rebeldes y mejorar las condiciones de vida de los indios, cosa que no cumplieron. Aún así, esta gran insurrección tendría una gran influencia en los movimientos independistas sudamericanos de la centuria siguiente (S. XIX).

(Nota 39) El mismo autor agrega también que... Cien azotes, amputaciones para evitar huidas, presentar la cabeza del negro para recibir recompensas, embadurnar miel a un esclavo amordazado para que miles de moscas pulularan enfermizamente por su rostro y cuerpo en plena calle, portar una calza de hierro de cinco kilos durante dos meses sin dejar de trabajar, o la pena de muerte. Entonces, cuerpos colgaban de sogas amarradas a maderos y a decenas de cadáveres les era echada la cal en la fosa común.

Desde que Francisco Pizarro obtuviera del emperador Carlos V la venia para introducir al Perú cincuenta esclavos, se dio inicio a trescientos años de tráfico de cautivos en esta parte del continente, y con ello, una legislación para la esclavitud llena de tormentos y cruentas sanciones.

A las colonias españolas de América fueron trasladados casi un millón seiscientos mil humanos, en un lapso de tiempo entre 1528 y 1870, siendo este número el resultado de un contingente humano mayor, pero fallecido en viajes marítimos eternos e insalubres. El trabajo de cientos de cautivos durante los primeros años de la conquista tuvo como fin el trabajo servil en casa de los conquistadores, como subalternos en los ejércitos o como peones de rudas maniobras de la construcción. 
Según el cronista Bernabé Cobo (1582-1657), Lima tenía una población de aproximadamente treinta mil negros, cuya mayoría podía encontrarse en las costas y en los valles agrícolas.

La trata humana se otorgó por contrato a comerciantes extranjeros. Recién, en 1784, se permitió a los barcos españoles el ingreso de esclavos previo pago de 150 monedas por persona. En 1804 se prorrogó por doce años más este permiso. Durante el gobierno de 1806, del virrey José Fernando de Abascal (1743-1821), llegó al Perú el último grupo de esclavos, cotizándose un varón adulto en 600 pesos. Los que llegaron al Perú pertenecían a diversas castas. Un artículo publicado por el Mercurio Peruano, en 1791, menciona a los mandingas, los misangas, los lucumés, los congos, los cambundas, los cangaes, los carabalíes, los chalas, los huarochiríes y los terranovas. A ellos debe añadirse a los angola, una de las etnias más conocidas y numerosas que había entonces en la capital.

Fuente: Revista Identidades. Edición \# 89. Diario El Peruano, Lima, 18 de julio de 2005.

http://www.elperuano.com.pe/identidades/89/precisiones.asp

(Nota 40) Para complementar lo señalado en la explicación referencial de la nota 29.

¿Cómo llegaban al Perú? Mientras unos eran llevados por los traficantes portugueses a los enclaves del comercio negrero de Veracruz, Cartagena y Buenos Aires -este último puerto era la meca del contrabando negrero -; los que iban al Perú viajaban hacinados en los barcos de la trata hasta Panamá, donde los bautizaban. En la época del monopolio comercial español, como toda mercadería, los esclavos tenían que entrar al Perú por el puerto del Callao. Aquí los revisaban y los hacían marchar a pie hasta Lima, cual ganado, atados con sogas, grilletes y cadenas, uncidos, como se dice, 
por la collera -un collar de hierro que los mantenía unidos al grupo de desventurados que iban a ser vendidos en el mercado de esclavos-. La procesión continuaba por las calles de la ciudad y atravesaban el río Rímac por el llamado Puente de Palo y los alojaban en unos corralones ubicados en el barrio de Malambo un sector que aún existe, incluso una de sus callejas todavía se llama Terranovos - en espera de ser llevados hasta el mercado negrero.

La historia cuenta que el tráfico de esclavos al Perú tuvo tres etapas bien definidas: la primera, a comienzos del siglo XVI, cuando la Corona española tenía el monopolio del otorgamiento de licencias para el tráfico negrero; la segunda, la llamada "trata a largo plazo", que se desarrollaba merced a un contrato entre la Corona española y un agente mercantil, que podía ser una compañía particular o un traficante de esclavos. La tercera, a partir del último tercio del siglo XVIII, cuando las reformas borbónicas del rey Carlos III liberan el comercio entre las Indias y terceros; entonces, a partir de 1778, comenzaron a llegar al Perú esclavos procedentes Cuba, Puerto Rico, Nueva Granada, Venezuela y otros.

Figura 69. Origen étnico de los bozales peruanos

Senagambia

Guinea-Bissau

Bram

Biafra

Berbesi

Jolofo

Mandinga

Nalu

Bañol
Otras zonas de

África Occidental

Terranovo

Zape

Cocoli

Arara/Arda

Caravali

Mina*

Lucumí
África Central

y Meridional

Congo

Mozambique

Anchico

Angola

Malamba/Malemba 


\section{Casanga}

Fula

Bioho

Guinea (sin especificar)

Folupo

Soso

Balanza

*Había grupos minoritarios de esclavos llegados en otros embarques negreros al Perú, como es el caso de los Ashantis, Ewes o Yorubas, que eran denominados Minas por el fuerte El Mina, en Ghana. En 1791, el Mercurio Peruano señalaba que... "las castas principales de los negros que nos sirven son diez: la de los Terranovos, Lucumés, Mandingas, Cambundas, Carabalíes, Cangaes, Chalas, Huarochiríes, Congos y Mucangas". No cabe duda que son datos del mismo origen.

Fuentes: Etnicidad y Discriminación Racial en la Historia del Perú. Varios Autores. Instituto Riva Agüero (Pontificia Universidad Católica del Perú) y Banco Mundial.

(Nota 41) Los Afroperuanos. Historia y situación actual. Centro de Desarrollo Étnico. (CEDET)

http:/ / afrolatino.org/forum/viewtopic.php?

$\mathrm{p}=5588 \& \operatorname{sid}=79685 \mathrm{cc} 75786 \mathrm{a} 0321853 \mathrm{c} 28 \mathrm{~b} 721 \mathrm{a} 0261$

(Nota 42)

Figura 70

Cuadro tentativo de la evolución de la población afroperuana (1570-1940) 


$\begin{array}{llll}\text { Año } & \text { Blancos } & \text { Indios } & \text { Negros } \\ 1570 & 25.000 & 8.000 .000 & \mathrm{n} / \mathrm{d} \\ 1650 & 70.000 & 600.000 & 90.000^{*} \\ 1791 & 380.000 & 764.894 & 59.462 \\ 1876 & 1.040 .652 & 1.504,678 & 40.664 \\ 1940 & 3.283 .360 & 2.874 .196 & 29.054\end{array}$

*30.000 eran mulatos.

Nota de Redacción: Si el amable lector se fija en este cuadro, podrá constatar a grandes rasgos un fenómeno que afectó a toda la zona andina durante la época colonial, es decir, el brusco descenso de la tasa demográfica de la población indígena entre 1570 y 1650, y una ligera recuperación de la misma a partir 1791; por otro lado, la población negra, experimentó un brusco aumento en las primeras décadas del virreinato (S. XVI) para luego descender ligeramente hasta estabilizarse en un promedio de entre 40 y 50 mil habitantes. La cifra de 1940 es relativa en cuanto a la gente de raza negra. Por su parte, la población blanca presenta una tasa de crecimiento relativamente baja entre los años citados.

Fuente: Los Afroperuanos. Historia y situación actual. Centro de Desarrollo Étnico. (CEDET)

(Nota 43)

Figura 71a. Libertos y esclavos Perú 1792

Libertos (a) 41.398

Esclavos (a) 40.337

Total 81.735 
Fuente: CDIP. Tomo XXI. Documentación Española. V. 1ㅜ, p.30

Figura 71b. Arequipa

Año 1785 1847

Población Total

9.059

$15.176^{*}$

Negros libertos

Hombres 148 57

Mujeres 232 46

Totales 380 103

Fuente - ALRE. ASG-2. Cap. 137 y El Republicano 22-05-1847, Arequipa № 36 p.3.

* El funcionario que realizó el censo manifestó que hubo reticencia por parte de los pobladores de censarse, por lo que él consideró que la población de Arequipa debió de ascender a 20.000 almas.

Fuente: Libertos en el Perú 1750-1854, Alejandro Reyes Flores. Revista Historia y Cultura del Museo Nacional de Arqueología, Antropología e Historia del Perú. Lima, $2001 ;(24): 41-54$.

(Nota 44) Referencia: Cronología: Esclavitud y trata del negro en América. Antología del Ensayo Hispánico - Emilio Castelar.

http://www.ensayistas.org/antologia/XIXE/castelar/esclavitud/c-esclavitud.htm

(Nota 45) Referencia: Cronología: Esclavitud y trata del negro en América. Antología del Ensayo Hispánico - Emilio Castelar.

http://www.ensayistas.org/antologia/XIXE/castelar/esclavitud/c-esclavitud.htm 
(Nota 46) Referencia: Cronología: Esclavitud y trata del negro en América. Antología del Ensayo Hispánico - Emilio Castelar.

http://www.ensayistas.org/antologia/XIXE/castelar/esclavitud/c-esclavitud.htm

(Nota 47) Referencia: Cronología: Esclavitud y trata del negro en América. Antología del Ensayo Hispánico - Emilio Castelar.

http://www.ensayistas.org/antologia/XIXE/castelar/esclavitud/c-esclavitud.htm

(Nota 48) Fuente: Manuel García, Historia / Canarias / Navegación.

http://www.mgar.net/var/trata.htm

(Nota 49) Francisco Quiroz Chueca, en su trabajo histórico "Un palenque llamado Lima" escribe al respecto que... Según se aprecia, la ciudad de Lima albergó esclavos en proporciones considerables. Especialmente, en tiempos coloniales tempranos. En un principio se observa una casi coincidencia, entre población negra y mulata, por un lado, y población cautiva, por otro. La liberación de esclavos fue un fenómeno paulatino y tardío. Recién a partir del siglo XVII, se hizo significativa la presencia de los libertos, llamados horros (de ahí provino "ahorro" como recurso liberado). Entre gente libre y horra se desenvolvió la esclavitud en el Perú.

Fuente: Un palenque llamado Lima.

Revista Alma Mater - Fondo Editorial. Universidad Nacional Mayor de San Marcos (UNMSM), Lima, 1997; (13 - 14) : 5 - 15. 
http://sisbib.unmsm.edu.pe/bibvirtual/publicaciones/Alma_Mater/1997_n1314/palenque.htm

(Nota 50) En Lima, el libertador San Martín reúne un Cabildo Abierto con la presencia de Don Manuel Pérez de Tudela, más tarde Ministro de Relaciones Exteriores, y se redacta públicamente el Acta de la Independencia, que fue suscrita por las personas notables de la ciudad: "En la ciudad de Los Reyes, el quince de Julio de mil ochocientos veintiuno. Reunidos en este Excmo. Ayuntamiento los señores que lo componen, con el Excmo. e Ilmo. Señor Arzobispo de esta santa Iglesia Metropolitana, prelados de los conventos religiosos, títulos de Castilla y varios vecinos de esta Capital, con el objeto de dar cumplimiento a lo prevenido en el oficio del Excmo. Señor General en jefe del ejercito Libertador del Perú, Don José de San Martín, el día de ayer, cuyo tenor se ha leído, he impuesto de su contenido reducido a que las personas de conocida probidad, luces y patriotismo que habitan en esta Capital, expresen si la opinión general se halla decidida por la Independencia, cuyo voto le sirviese de norte al expresado Sr. General para proceder a la jura de ella. Todos los Srs. concurrentes, por sí y satisfechos, de la opinión de los habitantes de la Capital, dijeron: Que la voluntad general está decidida por la Independencia del Perú de la dominación Española y de cualquiera otra extrajera y que, para que se proceda a la sanción por medio del correspondiente juramento, se conteste con copia certificada de esta acta al mismo Excmo. y firmaron los Srs.: El Conde de San Isidro, Bartolomé, Arzobispo de Lima, Francisco Javier de Zárate, El Conde de la Vega de Ren, El Conde de las Lagunas, Toribio Rodríguez, Javier de Luna Pizarro, José de la Riva Agüero, El marqués de Villa fuerte ..".Siguen más de un millar de rúbricas.

Fuente: Acta de la Independencia del Perú. 
(Nota de VA: El original de este documento se guarda actualmente en la Biblioteca de la Municipalidad de Lima Metropolitana)

Fuente imagen facsimilar:

Universidad Católica de Santa María, Arequipa.

http://www.ucsm.edu.pe/arequipa/peru2.htm

(Nota 51) Diez días después de la redacción y firma del Acta de Independencia, San Martín se reúne otra vez con el Cabildo Abierto, en la Plaza Mayor de Lima, para declarar junto con el pueblo la Independencia del Perú de la dominación española y de cualquier otra dominación extranjera. Ese 28 de julio, reunidos en sesión solemne del cabildo limeño, con la presencia de las autoridades civiles y religiosas, y ante la ciudadanía expectante, el general don José de San Martín procedió a proclamar la Independencia pronunciando las siguientes palabras:

"El Perú desde este momento es libre e independiente por la voluntad general de los pueblos y por la justicia de su causa que Dios defiende.

¡Viva la patria! ¡Viva la libertad! ¡Viva la Independencia!"

Según el historiador Jorge Basadre, estas palabras simbolizaban un cambio histórico, había surgido el principio de "la voluntad de los pueblos". Un testigo que estuvo presente aquel memorable día. Por su parte, cuenta: "...El 28 del mes anterior se juró en esta capital la Independencia del Perú. No he visto en América un concurso ni más lucido ni más numeroso. Las aclamaciones eran un eco continuado de todo el pueblo... Yo fui uno de los que pasearon ese día el estandarte del Perú independiente... Jamás podría premio alguno ser más lisonjero para mí, que ver enarbolado el estandarte de la libertad en el centro de la ciudad más importante de 
esta parte de América, cumpliendo el objeto de nuestros trabajos en la campaña ... ). En esa misma noche se dio refresco y baile en el cabildo. Ninguna tropa logró contener la aglomeración de gente y no pudo lucir el ambiguo que se preparó para los convidados (... ). En la noche siguiente se dio en el palacio del general un baile, al que asistieron todas las señoras, esto requeriría una descripción particular para lo que no tengo tiempo. La compostura con que se presentaron aquéllas era elegante... Yo bailé mi contradanza de etiqueta con una señora y me separé con mis amigos a analizar los efectos de la política del gobierno antiguo". (Carta de Tomás Guido amigo de San Martín - del 6 de agosto de 1821, a su esposa Pilar Spano).

Fuente: San Martín y la Independencia del Perú. Adonde.com. http://www.adonde.com/historia/1821_independencia.htm

(Nota 52) Humberto Rodríguez Pastor escribe al respecto: En este mismo año San Martín, con la intención de ganar a los esclavos y que se enrolaran a su ejército, publica en la Gaceta del Gobierno varios dispositivos legales: libertad a los esclavos que entren en combate contra los españoles ( 5 de septiembre), libertad anual a 25 esclavos por su apoyo en la defensa de la capital (26 de septiembre), abolición del azote (20 de octubre), sanciones a los amos que impidieran que sus esclavos se enrolaran en las huestes libertadoras (27 de octubre) y libertad a los esclavos cuyos amos españoles retornaran a la península Ibérica.

San Martín acertaba al reconocer la importancia social de la población negra, aunque su reconocimiento público fue un tanto despectivo, en alguna ocasión dijo: "la patria necesita a esos locos". Atraída por aquellos decretos, levados a la fuerza o partícipe consciente, es indudable que la población negro-esclava jugó un rol considerable en las luchas por la emancipación en el ejército de San Martín como en el de Bolívar. 
Es decir... las criaturas que de acuerdo al decreto de 1821 de San Martín nacían libres a partir de esta nueva ley eran siervos hasta que cumplieran los 50 años y sólo cuando llegaran a esta edad eran libres. El patrón debía darles desde ese momento alimento y otros auxilios en las enfermedades y en otras penurias de la vejez. En realidad hasta diciembre de 1854 los libertos continuaron bajo la dura servidumbre de los patrones.

Fuente: Esclavitud en el Peru -Parte 7 - Liberación de la Esclavitud: Reseñas y Cronología. AIPEUC-PS, Washington.

\section{http:/ / www.aipeuc-ps.org/index.php?name=News\&file=article\&sid $=247$}

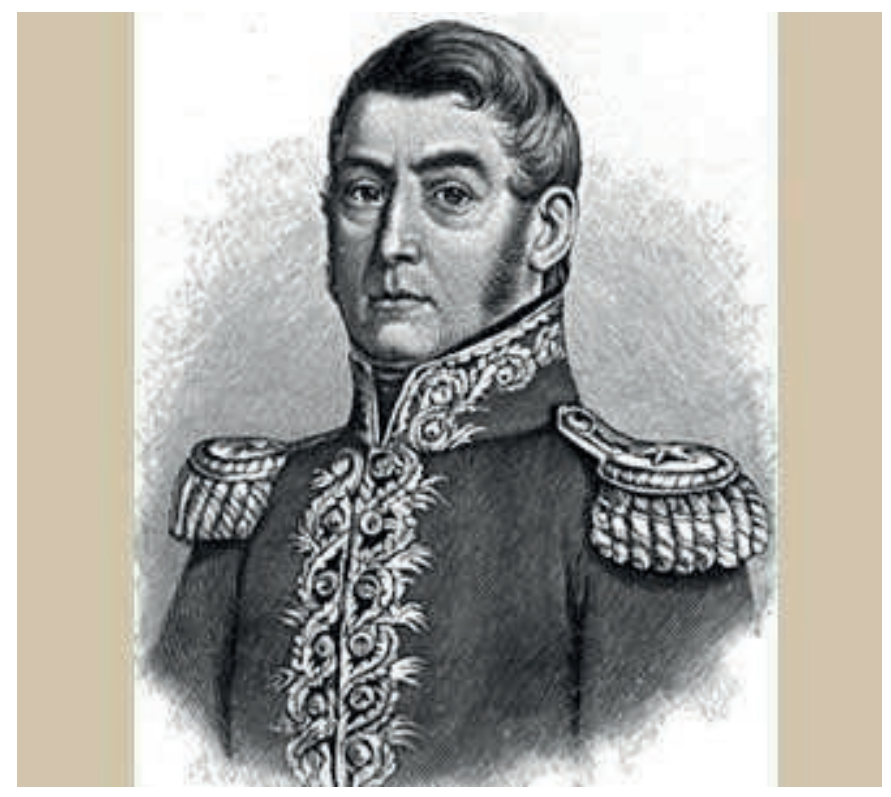

Figura 72. Don José de San Martín, el libertador de tres países, en acuarela de época. Aunque quiso liberar del todo a los esclavos, tuvo que contentarse con la libertad de vientre; aún así, quiso aprovechar la coyuntura política y una guerra de independencia para justificar que más esclavos negros queden libres si se enrolaban en su ejército. La Independencia del Perú. Educared.edu.pe. 
(Nota 53) Referencia: Cronología: Esclavitud y trata del negro en América. Antología del Ensayo Hispánico - Emilio Castelar.

http://www.ensayistas.org/antologia/XIXE/castelar/esclavitud/c-esclavitud.htm

\section{Origen de las ilustraciones}

(Advertencia al amable lector: Los hipervínculos que siguen a continuación estaban operativos en la fecha de cierre de este trabajo: 1 de octubre de 2006)

1. ¿Un negro en el Museo de Historia, Antropología e Historia del Perú, en Pueblo Libre, Lima?

http://www.andrew.cmu.edu/course/79-104/Readings/Gallery/3.html

2. Curioso "huaco chino".

http://victorian.fortunecity.com/klimt/83/arteperu/hframe3.html

3. El inca Tupac Yupanqui según una ilustración del cronista indígena Felipe Guaman Poma de Ayala.

http://de.wikipedia.org/wiki/Bild:Tupac_Yupanqui.jpg

4. Los 13 del Gallo (detalle). Óleo de Juan Dellepiani, pinacoteca del Museo de Arqueología, Antropología e Historia del Perú. Pueblo Libre, Lima.

http://www.educared.edu.pe/estudiantes/historia2/conquista_1.htm

5. Los viajes de Pizarro.

http://www.puc.cl/sw_educ/historia/conquista/parte2/html/index.htm 
6. Isola del Gallo. Foto de Pete Fagerlin.

http://www.petefagerlin.com/lapaz.htm

Volver al párrafo

Volver al principio de Origen de las ilustraciones

Volver al principio del artículo

Volver al principio

7. Ilustración del pintor holandés Theodore de Bry. Siglo XVI.

http:// www.andrew.cmu.edu/course/79-104/Readings/Gallery/3.html

8. El misionero dominico Bartolomé de las Casas. Óleo sobre lienzo del siglo XVI.

http://www.andrew.cmu.edu/course/79-104/Readings/Gallery/3.html

9. Viejo mapa del Virreinato del Perú en el S. XVI. Biblioteca Nacional de Chile.

http://www.puc.cl/sw_educ/historia/america/html/1_2_1_2.html

10a. Escena parecida. Trabajo esclavo indígena y negro en una mina colombiana.

http://www.puc.cl/sw_educ/historia/america/html/2_1_1.html

10b. La mina de Huancavelica, ilustración de Guamán Poma de Ayala en su obra El Primer Nueva Corónica y Buen Gobierno.

http://www.puc.cl/sw_educ/historia/america/html/2_1_1.html

11. Ilustración de Guamán Poma de Ayala. Versión digital de El Primer Nueva Corónica y Buen Gobierno.

http://base.kb.dk/manus_pub/cv/manus/ManusPage.xsql?nnoc=manus_pub\&p_ ManusId=253\&p_PageNo=939\&p_Lang=alt\&p_Mode=img

12. El concurrido Pueblo de Pisaq, en el Valle Sagrado de los Incas, cerca al Cusco. http://www.qosqo.com/qosqoes/pisaq.html 
13. Un obraje según una ilustración de Guamán Poma de Ayala en la primera edición de El Primer Nueva Corónica y Buen Gobierno.

http://base.kb.dk/manus_pub/cv/manus/ManusPage.xsql?nnoc=manus_pub\&p_ ManusId=253\&p_PageNo=578\&p_Lang=alt\&p_Mode=img

14. Le cortan la cabeza a Topa Amaro Ynga... Nueva Corónica y Buen Gobierno. http://www.kb.dk/elib/mss/poma/presentation/platesimg/lamina14.htm

15. Ilustración de Guamán Poma de Ayala. El Primer Nueva Corónica y Buen Gobierno.

http:/ / base.kb.dk/manus_pub/cv/manus/ManusPage.xsql?nnoc=manus_pub\&p_ ManusId=253\&p_PageNo=936\&p_Lang=alt\&p_Mode=img

16. Ilustración de Guamán Poma de Ayala. El Primer Nueva Corónica y Buen Gobierno.

http:/ / base.kb.dk/manus_pub/cv/manus/ManusPage.xsql?nnoc=manus_pub\&p_ ManusId=253\&p_PageNo=596\&p_Lang=alt\&p_Mode=img

17a. La América Española Colonial - El Trabajo. Ilustración sobre la esclavitud en Lima.

http://www.puc.cl/sw_educ/historia/america/html/2_1_4.html

17b. Plano de la ciudad de Lima en 1613.

http:/ / www.munlima.gob.pe/historia.htm

17c. Callao de Lima.

http://www.redperuana.com/fotos/antiguas/index.asp 
18.

a) La Babel Andina. Origen de la ilustración:

http://www.huancainos.com/literatura/babelandes.htm

b) Santiago, de Matamoros a Mataindios. Origen de la leyenda:

Revista La Aventura de la Historia \# 33.

http://www.el-mundo.es/ladh/numero33/santiago.html

19a. Razzia: cacería humana. Ilustración de la UNESCO.

http:// portal.unesco.org/culture/es/ev.php-URL_ID=19741\&URL_DO=DO_ TOPIC\&URL_SECTION=201.html

19b. Un barco negrero de mediados del Siglo XVII.

http://www.archivogeneral.gov.co/version2/htm/esclavitud/TESTIMONIOS1.htm

20. Posición de los esclavos en los barcos. Ilustración del S. XVII.

http://portal.unesco.org/culture/es/ev.php-URL_ID=19683\&URL_DO=DO_ TOPIC\&URL_SECTION=201.html

21. El virreinato del Perú hacía 1650.

http://www.historyteacher.net/EuroCiv/Weblinks/Weblinks-6AgeOfExploration.htm

22. Bandolero cimarrón según concepción artística de época (Florida). http://www.melfisher.org/henriettamarie/westindies.htm

23. Una negra, según acuarela del obispo Martínez Compañón (S. XVIII). 
http://www.educared.edu.pe/estudiantes/historia3/esclavos.htm

24. Un negro, según acuarela del obispo Martínez Compañón (S. XVIII).

http://www.educared.edu.pe/estudiantes/historia3/esclavos.htm

25a. Juan Santos Atahualpa.

http://www.educared.edu.pe/estudiantes/historia4/juan_santos_atahualpa.htm

25b. Plano de la ciudad de Lima amurallada en 1750.

http:// es.wikipedia.org/wiki/Lima

26. Cuadro: 1. Población negra en América a fines del siglo XVIII.

http://www.arbil.org/(42)irab.htm

27. "Español. Yndia Serrana o café(t)ada. Produce Mestizo".

http://www.educared.edu.pe/estudiantes/historia3/castas.htm

28. "Mestizo. con Yndia. Producen cholo".

http://www.educared.edu.pe/estudiantes/historia3/castas.htm

29. "Negro. con Mulata. Producen Sambo".

http://www.educared.edu.pe/estudiantes/historia3/castas.htm

30. Mapas de Historia Universal. Mapa LIX. América del Sur en el Siglo XVIII.

http://www.pais-global.com.ar/mapas/mapa59.htm

31. Muerte de Tupac Amaru II.

http://www.educared.edu.pe/estudiantes/historia4/tupac_amarue.htm 
32. Capoeira Angola Center of Mestre João Grande.

http://joaogrande.org/capoeira_angola.htm

33. El puerto del Callao en una acuarela del siglo XVIII.

http://www.gmcweb.net/todocallao/antiguas.htm

34. El virreinato del Perú en 1803. Educared. Perú.

http://www.educared.edu.pe/estudiantes/historia5/independencia.htm\#

35. El cacique y prócer indígena Mateo Pumacahua.

http://www.peru.com/otros_especiales/fiestas_patrias_2001/heroes/index.asp

36. La Plaza Mayor de Lima a mediados del Siglo XIX.

http://www.caretas.com.pe/1426/plaza/plaza.htm

37a. El fuerte portugués de El Mina.

http://www.upf.es/materials/fhuma/inth/tema6/mat6.htm\#uso

37b. Interior de una bodega de esclavos en un barco negrero...

http://www.upf.es/materials/fhuma/inth/tema6/mat6.htm\#uso

38a. Detalle del Acta de la Independencia del Perú.

http://www.ucsm.edu.pe/arequipa/peru2.htm

38b. San Martín proclama la Independencia del Perú.

http://museonacional.perucultural.org.pe/galeria4.shtml

39. Montonero negro peruano de la época de la Independencia. 
http://www.educared.edu.pe/estudiantes/historia5/independencia_2b.htm\#

(Figuras correlativas -40 a 57- en la segunda parte)

Siguen...

58. Fuente: Proyecto Ensayo Hispánico - Emilio Castelar.

http://www.ensayistas.org/antologia/XIXE/castelar/esclavitud/trata2.htm

59. Piezas de ébano I. Archivo General de Colombia.

http://www.archivogeneral.gov.co/version2/htm/esclavitud/TESTIMONIOS-

9.htm

60. Tapa de la primera edición de Brevísima relación de la destruición de las Indias, Sevilla, 1552.

http://www.spanisharts.com/books/literature/america.htm

61. Portada de las Leyes Nuevas de Indias. Barcelona, 1542. Portal Antehistoria.com. http://www.artehistoria.com/frames.htm?

http://www.artehistoria.com/historia/obras/10448.htm

62. Indio mitayo en labores agrícolas. América Española Colonial. El Virreinato del Perú. Trabajo.

http://www.puc.cl/sw_educ/historia/america/html/2_1_4.html

63a. Piezas de ébano II. Esclavos arrumados en un barco negrero.

http://www.si.umich.edu/CHICO/Schomburg/text/migration6big.html 
63b. La Isla de Goree.

http://www.rutatuareg.org/ruta_esclavos/goree_cast.htm

64a. El río de los nigritae.

http://en.wikipedia.org/wiki/Niger_River

64b. Madre África. Expansiones imperiales en África hacia 1880, con las áreas geográficas desde donde millones de africanos fueron llevados como esclavos a América y otras latitudes.

http://www.andrew.cmu.edu/course/79-104/Readings/Gallery/3.html

65. Padrón de los Indios de Lima - 1613.

http://www.aprodeh.org.pe/desc/documentos_racial/EtniciTomo1.pdf\#search=\%2 2Etnicidad\%20y \%20Discriminaci\%C3\%B3n\%20Racial\%20en\%20la\%20Historia\%20\%

66. Portada de El Primer Nueva Corónica y Buen Gobierno (1615-16).

http://www.kb.dk/elib/mss/poma/index-en.htm

67. El muro del milagro. Imagen original pintada por el anónimo negro angoleño... http:// www.800guia.com/cgibin/articuloview.pl?listado=peru\&volumen=conozca $\% 20$ peru\&codigo=peru6

68. Cuadro Modelos Raciales según la clasificación de los cuadros que el virrey Manuel Amat mandó pintar (1770). CEDET.

http:/ / afrolatino.org/ forum/viewtopic.php? $p=5588 \& s i d=79685 c c 75786 a 0321853 c 28$ b721a0261 
69. Cuadro. Origen étnico de los bozales peruanos. CEDET.

http://www.aprodeh.org.pe/desc/documentos_racial/EtniciTomo1.pdf\#search=\%2 2Etnicidad\%20y\%20Discriminaci \% C3\%B3n\%20Racial\%20en \%20la\%20Historia \%22

70. Cuadro tentativo de la evolución de la población afroperuana (1570-1940). CEDET.

http:/ / afrolatino.org/forum/viewtopic.php?p=5588\&sid=79685cc75786a0321853c28 b721a0261

71a. Cuadro. Libertos y esclavos Perú 1792.

http:// sisbib.unmsm.edu.pe/bibvirtual/publicaciones/Histo_cultura/2001_n24/lib er_peru.htm\#LIBERTOS_POBLACIÓN

71b. Cuadro. Arequipa.

http:// sisbib.unmsm.edu.pe/bibvirtual/publicaciones/Histo_cultura/2001_n24/lib er_peru.htm\#LIBERTOS_POBLACIÓN 